
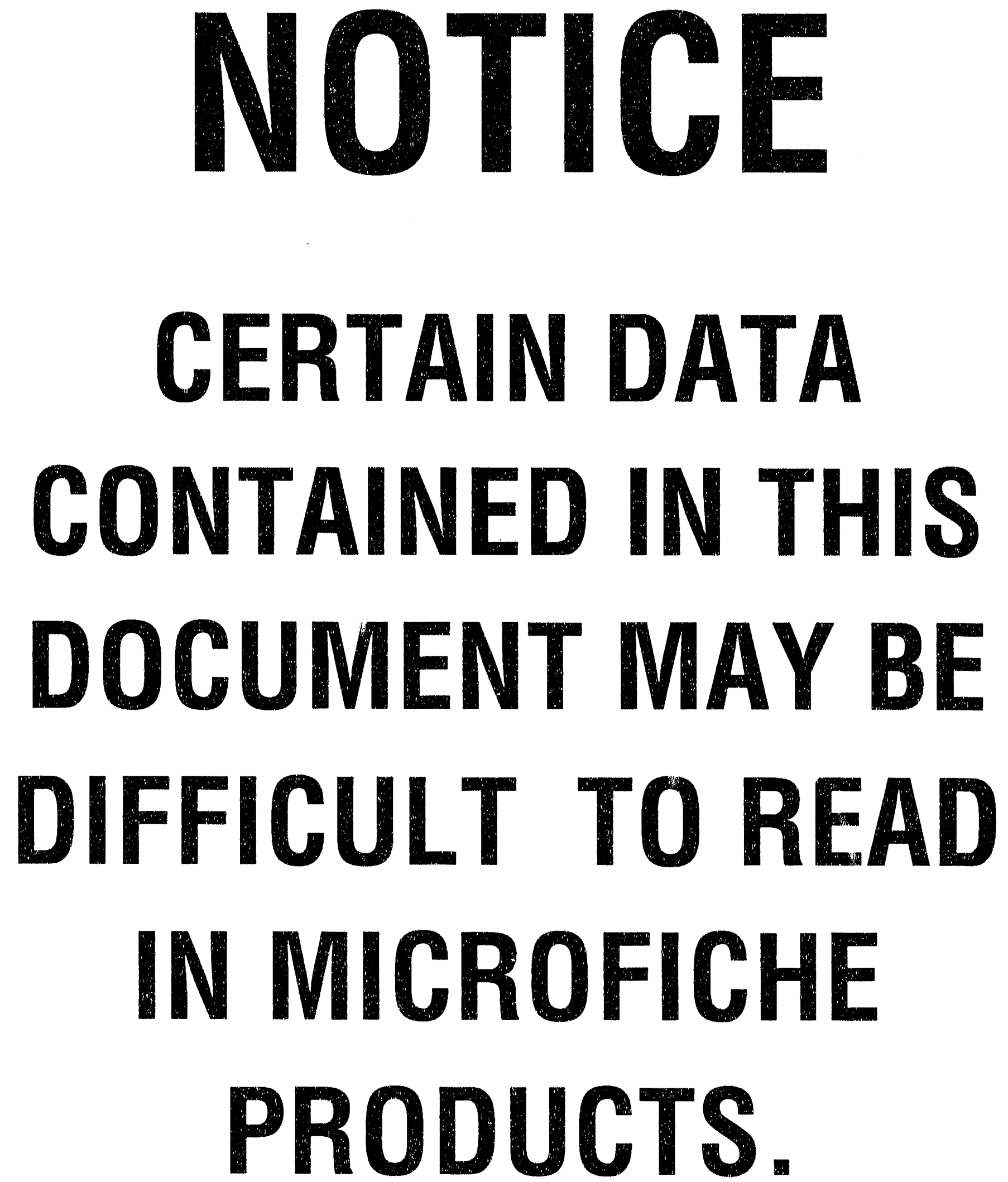
WSRC-TR- $-91-30$

DE92 016704

\title{
PEN BRANCH FAULT PROGRAM: INTERIM REPORT ON THE HIGH RESOLUTION, SHALLOW SEISMIC REFLECTION SURVEYS (U)
}

by

\author{
A. L. Stieve
}

Westinghouse Savannah River Company

Savannah River Laboratory

Aiken, South Carolina 29808

This is a technical report.

This report was prepared in connection with work done under Contract No. DE-ACO9-89SR 18035 with the U.S. Department of Energy. By acceptance of this paper, the publisher and/or recipient acknowledges the U.S. Government's right to retain a nonexclusive, royalty-free license in and to any copyright covering this paper, along with the right to reproduce and to authorize others to reproduce all or part of the copyrighted paper. 


\begin{abstract}
The Pen Branch fault was identified in the subsurface at the Savannah River Site in 1989 based upon interpretation of earlier seismic reflection surveys and other geologic investigations. A program was initiated at that time to further define the fault in terms of its capability to release seismic energy. The HighResolution, Shallow Seismic Reflection survey recently completed at SRS was initiated to determine the shallowest extent of the fault and to demonstrate the presence of flat-lying sediments in the top 300 feet of sediments. Conclusions at this time are based upon this shallow seismic survey and the Conoco deep seismic survey (1988-1989). Deformation related to the Pen Branch fault is at least 200 milliseconds beneath the surface in the Conoco data and at least 150 milliseconds in the shallow seismic reflection data. This corresponds to approximately 300 feet below the surface.

Sediments at that depth are lower Tertiary (Danian stage) or over 60 million years old. This indicates that the fault is not capable.
\end{abstract}




\section{TABLE OF CONTENTS}

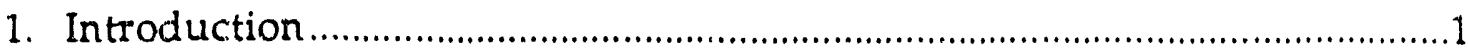

2. Geology at SRS

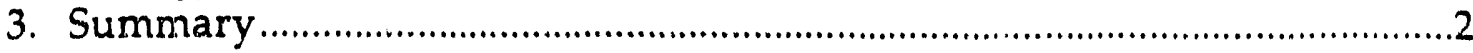

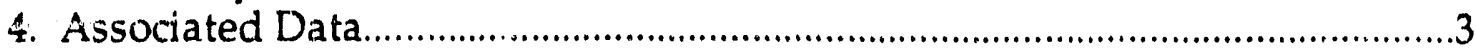

1.) Conoco Incorporated, 1987-1988 Survey..............................................3

2) D'Appolonia, Inc., 1978 Survey........................................................

3) Seismograph Service Corporation, 1969 Survey..................................4

5. Field Acquisition...............................................................................................4

5. A. Field Parameter Test. ..............................................................................4

5. B. Acquisition Parameters for the Production Lines...........................4

5. C. Vertical Seismic Profile Surveys.........................................................5

5. D. Data Acquisition Equipment..........................................................6

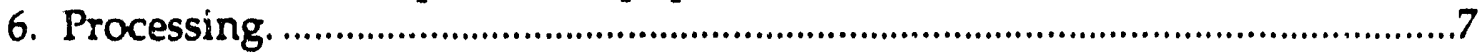

6. A. Proressing Procedure ...........................................................................

6. B. Amplitude Versus Offset (AVO) Analysis....................................

6. C. Synthetic Seismograms...................................................................8

6. D. Data Processing Equipment. ...............................................................8

7. Time Sections Versus Depth Sections................................................................8

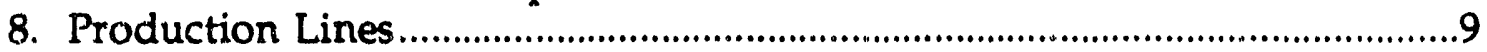

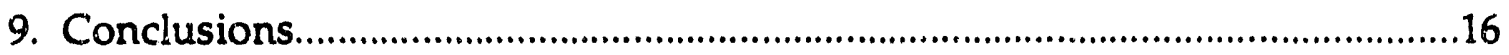

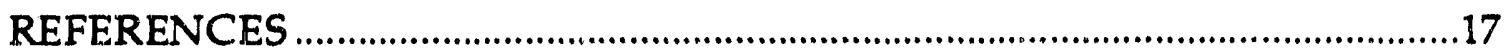

APPENDIX A

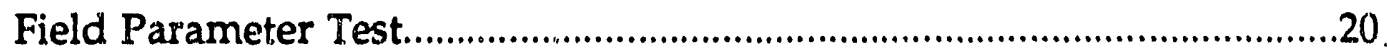

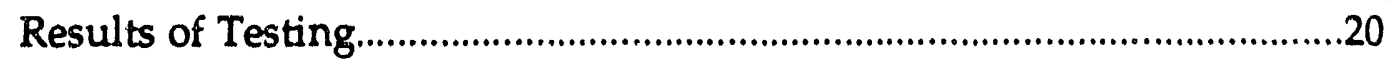

Vertical Seismic Profiles...................................................................................24

Amplitutde versus Offset Analysis Discussion............................................30

Geologic Factors...............................................................................................30

Data Acquisition Factnrs......................................................................................30

Data Processing Factors...........................................................................................31

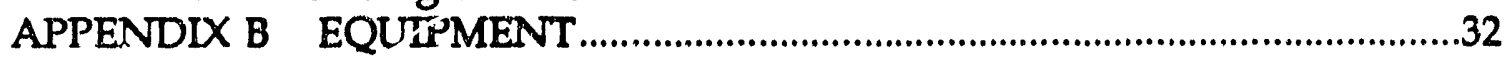

Data Acquisition..............................................................................................32

Vertical Seismic Profile Equipment..................................................................33

Safety Equipment...............................................................................................33

Data Processing.......................................................................................................34

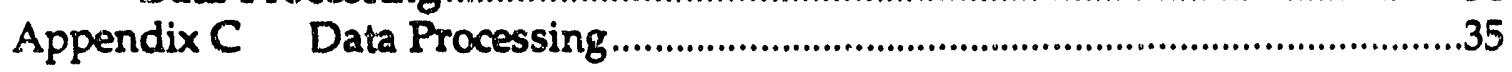




\section{INTRODUCTION}

The purpose of this project was to acquire, process, and interpret $28 \mathrm{~km}$ (17.4 miles) of high resolution seismic reflection data taken across the trace of the Pen Branch fault and other suspected, intersecting north-south trending faults (Figure 1). The survey was optimized for the upper $300 \mathrm{ft}$ of geologic strata in order to demonstrate the existence of very shallow, flat lying horizons, and to determine the depth to the fault or to sediments deformed by the fault. Field acquisition and processing parameters were selected to define small scale spatial variability and structural features in the vicinity of the Pen Branch fault leading to the definition and the location of the Pen Branch fault, the shallowest extent of the fault, and the quantification of the sense and magnitude of motion. Associated geophysical, borehole, and geologic data were incorporated into the investigation to assist in the determination of optimal parameters and aid in the interpretation.

The work covered by this report was conducted by Emerald Exploration Consultants, Inc. (EMEX) under subcontract number SA20207S with Westinghouse Savannah River Company during the period from August 14, 1990 to February 28, 1991. Subcontracted team members included ESI Geophysical, Inc. (ESI) for data acquisition, TLC Data Processing Center, Inc. (TLC) for data processing and interpretive support, and Energy Analysts, Inc. (EA) for quality assurance and computer assisted interpretation support. This report is derived from the subcontractor report (WSRC-TR-91-38).

\section{GEOLOGY AT SRS}

The SRS is located on the Atlantic Coastal Plain, which is a flat lying, undeformed pile of unconsolidated marine and fluvial sediments. The sediments are stratified sand, clay, limestone, and gravel that dip gently seaward and range in age from Late Cretaceous to Recent. The sedimentary sequence thickens from zero at the Fall Line to more than 4000 feet at the coast. There are about 600 to 1200 feet of Coastal Plain sediments at Savannah River Site. The section is divided into several groups based principally on age and lithology (Figure 2).

Beneath the Coastal Plain section is a pre-Cretaceous unconformity that developed on a basement consisting of two geologic terranes; 1 ) TriassicJurassic rift basin, the Dunbarton basin, filled with lithified terrigenous and lacustrine sediments with minor amounts of mafic volcanic and intrusive rock (Marine, 1974; Marine and Siple, 1974) and 2) crystalline terrane of metamorphosed sedimentary and igneous rock that may range in age from Precambrian to late Paleozoic. 
The Pen Branch fault is a recently discovered feature in the Coastal Plain and basement at SRS. A program has been underway since January 1989 to evaluate the ability of this fault to release seismic energy (earthquake energy).

\section{SUMMARY}

Evidence for the Pen Branch fault does not exist in the shallow seismic data. The Pen Branch fault can be interpreted to be at least, 300 feet below the surface. Sediments 300 feet below the surface are believed to be lower Tertiary in age (Danian stage) or older than $60 \mathrm{Ma}$.

The reprocessed Conoco data corroborate the shallow seismic data. The reprocessed Conoco data contains continuous reflectors to within 100 milliseconds of the surface. The Pen Branch fault is clearly seen in the reprocessed data at $\mathbf{4 0 0}$ milliseconds. However, all deformation from the fault attenuates between 300 and 200 milliseconds (Stephenson, personal communication, 1/91).

The reflectors in the shallow seismic data are interpreted to be predominantly sand/clay interfaces. Some of the reflectors are believed to be caused by carbonate material. Closely spaced shallow drilling done along one of the seismic lines could confirm the correlation of lithology to reflectors.

The seismic data show other geologic features not related to the Pen Branch fault but important to consider when making any interpretation about the section. Beds generally dip and thicken toward the southeast. This is consistant with the overall geometry of the Atlantic Coastal Plain. There are other, small-scale sedimentary features such as unconformities, and buried channels (marine and fluvial) that interrupt the normal stratigraphic sequence of well-behaved flat-lying strata. These features complicate the geology and make interpretations more difficult. Closely spaced shallow drilling along a specific seismic line would be needed to confirm the existence of the sedimentary features.

\section{ASSOCLATED DATA}

Three prior seismic reflection surveys were conducted at the Savannah River Site.

1.) Conoco Incorporated, 1987-1988 Survey. A vibroseis seismic reflection survey was conducted at the Savannah River Plant in 1987-88 by Conoco Inc. (Chapman and DiStefano, 1989) (Figures 3 \& 4). The survey lines covered approximately 130 line miles. Interpretation of this data indicates a southeast dipping basement surface with some minor highs and lows suggesting an erosional surface. Several basement 
faults were identified but, with the exception of one, none of them showed any signs of movement beyond the Cretaceous (more than 60 $\mathrm{Ma}$ ). The fault that showed continued movement beyond the Cretaceous paralleled the northwest boundary of the Dunbarton basin. This fault was named the Pen Branch fault (Figure 1). The dip on the fault is close to vertical. Slip direction in the crystalline basement was originally down to the southeast (normal movement). Movement during Cretaceous appears to have been reverse movement, that is, up to the southeast. There could also have been a component of strike-slip movement on this fault.

The objectives of the survey were to define basement structure and faulting. These data were acquired and processed for deeper target depths than was the high-resolution, shallow seismic done by EMEX. The Pen Branch fault was identified in this survey but the acquisition parameters were not focused for the shallow depths required to find its shallowest extent.

The Conoco survey utilized a sample rate of $2 \mathrm{~ms}$ and, except for one test line, the minimum shot to first trace offset was $100 \mathrm{ft}$. Trace spacing was $40 \mathrm{ft}$ but utilized a geophone array length of $60 \mathrm{ft}$. Vertical Seismic Profile (VSP) surveys were recorded but with large offsets of the seismic source from the well head which limited their usable data to $250 \mathrm{ft}$ and deeper. Chapman and DiStefano reported a significant difference in refraction velocities for the Paleozoic crystalline rocks $(18000,19000$, $18500,20600,18000$, and $18850 \mathrm{ft}$ per sec) and the Triassic Red Beds in the Dunbarton Basin (14200, 13600, and $15500 \mathrm{ft}$ per sec).

The throw on the Pen Branch Fault at the basement level in the Conoco data appears to be somewhat variable, and their reflection at 0.300 seconds appears to be folded, not faulted. The Conoco data is presently being reprocessed and previews of this reprocessing indicate all evidence for the fault and any deformation related to the fault attenuates between 300 and 200 milliseconds.

The Conoco seismic reflection data overlapped or intersected some of the high-resolution, shallow seismic reflection lines and was used in the interpretation. Locations for the high-resolution shallow seismic reflection lines are indicated in Figure 5.

2) D'Appolonia, Inc., 1978 Survey. Murdock (1982) presents the results of a high resolution minisosie reflection survey conducted in 1978 by D'Appolonia, Inc. in the AFR area (Figure 5). They utilized a 24 trace recording system, sample rate was $1 \mathrm{~ms}$, shot to first trace offset was 480 $\mathrm{ft}$, trace spacing was $40 \mathrm{ft}$, shot to far trace offset was $1400 \mathrm{ft}$. The large offset between the seismic source and the first trace precluded the recording of data between the surface and $250 \mathrm{ft}$. They used a sea level 
datum which gives the appearance of the data starting at zero time. The final processing filter was $25-40 / 90-110 \mathrm{~Hz}$. The indicated 6 fold was not attained until the same time as their basement reflection, as evidenced by the mute pattern utilized in data processing. All the reflectors are essentially flat lying and the Pen Branch Fault is not observed in these data.

3) Seismograph Service Corporation, 1969 Survey. The oldest survey on site was analog single fold data obtained by Seismograph Service Corporation in 1969. This survey gave the first indication of the basement faults underneath the Coastal Plain section at SRS (Figure 6).

\section{FIELD ACQUISITION}

\section{A. Field Parameter Test.}

A two phase test program was carried out at startup. This testing consisted of Geophone and Source Parameter Tests, and Energy Source Parameter Tests to determine the optimum parameters for the seismic survey. In the test program various source and receiver configurations were tested and noise records obtained to identify and eliminate, in so far as possible, the noise waves and investigate the optimum shot-receiver offset. More details and specific results are in Appendix A.

\section{B. Acquisition Parameters for the Production Lines.}

For the production program the acquisition layout was an asymmetric split-spread with parameters as listed below. Reversed refraction shots were taken at both ends of each line. Filter and charge size tests were repeated periodically.

\begin{tabular}{|c|c|}
\hline \multicolumn{2}{|c|}{ Acquisition Parameters } \\
\hline $\begin{array}{l}\text { Recording System } \\
\text { Sample Rate } \\
\text { Record Length } \\
\text { Shot Location } \\
\text { Shot Interval } \\
\text { Trace Interval } \\
\text { Subsurface Trace Spacing } \\
\text { Fold } \\
\text { Geophone Array }\end{array}$ & $\begin{array}{l}24 \text { channel EGG } 2401 \\
0.2 \mathrm{~ms} \\
0.400 \text { second } \\
\text { Trace } 4 \text { or } 4.5 \\
10 \mathrm{ft} \\
20 \mathrm{ft} \\
5 \mathrm{ft} \\
12 \quad 6 \quad \text { - spaced over } 1.5 \mathrm{ft} \text { parallel to the } \\
\quad \text { line }\end{array}$ \\
\hline $\begin{array}{l}\text { Ener } \\
\text { Reco }\end{array}$ & $\begin{array}{l}40 \mathrm{~Hz}, 3 \text { inch spike } \\
\text { Buffalo Gun }-12-\text { Gauge }- \text { light load } \\
50-1000 \mathrm{~Hz} \text {, with } 60 \mathrm{~Hz} \text { notch }\end{array}$ \\
\hline
\end{tabular}


When shot locations had to be skipped due to bridges, railroads, etc., extra shots were taken on both sides of the shotpoint gap to minimize the loss of fold. These extra shots minimized the loss of "deep" fold due to the skipped shots, but did not provide the near trace information to maintain the "shallow" fold.

The initial lines had some variation in the position of the shot with the final determination of the shot location being chosen to record more data outside the noise wave where better data quality was observable, and to obtain data at larger incident angles for the amplitude versus offset analysis. Lines 1 , 2 , and 3 were recorded with the shot location at trace 12 or 12.5 , and line 5 was recorded with the shot location at trace 6 or 6.5 . A portion of line 1 was also acquired with 24 fold data (line 16) by shooting twice at each location into cables that utilized traces at $10 \mathrm{ft}$ intervals. Line 16 also utilized a sample rate of $0.5 \mathrm{~ms}$ and a record length of 1.000 second.

Consistent "time breaks" required for high resolution stacking of the data were obtained by triggering the instruments with an uphole geophone. Initial lines were recorded with a "hammer switch" provided by EG\&G Geometrics but testing and examination of initial processing results indicated that significant delays in the firing of the shotgun shell were encountered (light load shotgun shells use propellant rather than black powder), therefore the procedure was modified to trigger the seismograph from an uphole geophone placed over the shot location. This modification was implemented during the shooting of line 10 . The time delay caused by the acoustic wave traveling the $3 \mathrm{ft}$ from the shot location to the surface is minimal considering the distance involved and the fact that the travel time is less than the $1.5 \mathrm{~ms}$ one would calculate with $2,000 \mathrm{ft} / \mathrm{sec}$ propagation. Woods (1952) points out that propagation of energy near the charge is not at seismic propagation velocity but at some higher "shock" velocity. Examination of the data recorded at the shot location indicates that the delay was between 0.4 and $0.6 \mathrm{~ms}$. When line 16 was shot to record the near distance traces, trace 1 remained at the shotpoint to verify adequate instrument triggering. When line 16 was shot to record the far distance traces, trace 1 duplicates the location of trace 24 of the shot to record the near distance traces, to allow for consistent adjustment of the time breaks.

\section{C. Vertical Seismic Profle Surveys.}

The VSP response is useful in providing a direct velocity measurement to determine time to depth conversions and to correlate relectors to lithologic layers in well information rather than computed inferences obtained with synthetic seismograms. An added benefit is that information can be obtained from depths deeper than the depth of the well. VSP data also enhances the AVO analysis (discussed in a following section). Many papers have been written dealing with theory and case histories (Balch et. al., 1982; Hardage, 1981; Lewkowicz et. al., 1983; Wyatt, 1981: and others). 
VSP surveys were conducted at four wells (PBF-4, PBF-5, PBF-7 and PBF-8) to obtain data consistent with the zone of interest for the high resolution seismic survey.

The VSP surveys consisted of recording surface generated seismic energy at 5 or $10 \mathrm{ft}$ increments down each borehole coincident with the recording of a 12 trace surface geophone spread for each shot to ensure consistent shot coupling and uniform energy source characteristics. The energy source was at a stationary location for each well, the distance from the well to the shotpoint was $30^{\prime}$, as determined by initial testing. Time break adjustments were made to the data based upon the surface spread information. Record length for all VSP surveys was 0.800 seconds.

There are several factors that influence the quality of VSP results, two major factors are tube waves and well casing. The VSP surveys at PBF-7 and PBF-8 encountered both of these problems. The VSP surveys at PBF-4 and PBF-5 were recorded in freshly drilled, uncased holes and did not encounter these problems with the same severity. The VSP surveys at PBF4 and PBF-5 therefore allowed for higher quality processing since the amplitude of the tube wave was reduced and could be removed by filtering. The VSP surveys at the uncased holes also allowed for the determination of shear wave velocities.

The velocity information obtained from the surveys is presented in time versus depth plots (Figure 7, 8,9,10). The first arrival time is picked from the monitor records (and adjusted for time break variations). The slope of these plots relates to the average velocity of the various layers.

The velocity information obtained from the VSP surveys indicated that in the dry, aerated, weathered, near surface layer the compressional wave and shear wave velocities are virtually identical. In the underlying saturated layer the compressional wave velocity increased in water filled sediment, whereas the shear wave velocity did not increase in water filled sediment. Numerous interval velocity versus depth plots with various smoothing and blocking factors were utilized to focus on the velocity trends present in the data. There was a general trend of low $P$ wave interval velocity and high $S$ wave interval velocity in sand, and high $P$ wave interval velocity arad low $\mathbf{S}$ wave interval velocity in clay. This general trend is consistent, with the observation that strong reflections relate to clay layers, and explains the physical basis for the correspondence. Poisson's ratio in sand is generally lower than Poisson's ratio in clay. This is consistent with the rnineralogy involved, clays retain more water than sand in the interstitial pore spaces. A correlation and examination of the stratigraphic information and the sonic logs generally supports the above observations with regard to $P$ wave velocities, although instances of variations do occur.

More details about the VSPs are discussed in Appendix A. 


\section{D. Data acquisition equipment.}

This is discussed in Appendix B.

\section{PROCESSING.}

The processing and output display parameter selection were based upon numerous tests. The final displays on reproducible vellum utilized horizontal and vertical scales of 32.5 inches per second and 12 traces per inch (no vertical exaggeration).

\section{A. Processing Procedure.}

The final data processing included the following steps which are discussed in more detail in Appendix B.

1 Demultiplex and Reformat to SEG Y

2 Geometry and Trace Editing

3 Filter

4 Gain Recovery

5 Time Break Correction (where applicable)

6 Elevation Datum and Refraction Statics

7 Surface Consistent Deconvolution and Spectral Balancing

8 Surface Consistent Residual Statics

9 Velocity Analysis

10 Surface Consistent Residual Statics

11 Application of Normal Move Out (NMO) Correction

12 Offset/Fold Limiting - Muting

13 Stack

14 F-K Noise Filter

15 Final Filter

16 Final Scaling

17 Display

18 Migration

19 Display

Lines 1 and 10 had extremely thick weathering and accompanying high amplitude noise and were processed differently as described in the report.

\section{B. Amplitude Versus Offet (AVO) Analysis.}

The AVO response is influenced by the velocity, density, and Poisson's ratio contrast at an acoustic interface. It is also used to interpret the lithology of various reflectors.

The procedure established to interpret the AVO effect was to generate two sections from the final processed data; one section with incident angles less 
than 15 degrees, and one section with incident angles greater than 15 degrees. In addition output plots were made of CDP gathers at intervals of $200 \mathrm{ft}$ along the une to assist in the evaluation of these two sections.

The sections with incident angles less than 15 degrees and greater than 15 degrees provides very helpful interpretation information. A very shallow, somewhat intermittent, unnamed horizon is present immediately below the surface. This reflection is virtually single fold data and in some instances may relate to the top of the water table or base of the weathered zone. Also, reflection horizon appears stronger on the AVO section with less than 15 degrees incident angle because the deeper high amplitude reflections are reduced in amplitude. This is due to the effect of the scaling used in the final display.

In addition the sedimentary features are significantly less pronounced in the AVO section with less than 15 degrees incident angle when compared to the AVO section with more than 15 degrees incident angle. However this phenomenon assists in establishing the relatively gentle dip.

For further discussion about the application of the AVO analysis at SRS please refer to Appendix A.

\section{C. Synthetic Seismograms.}

Synthetic seismograms were constructed by converting sonic and density information from geophysical logs which register in depth to a function of seismic reflectivity versus time. This function was then convolved with various shot pulses appropriate for the Buffalo Gun energy source.

Wuenshel (1960) describes the construction of synthetic seismograms in detail. Time based logs and synthetic seismograms were computed at the 8 PBF wells at a time scale common to the processed data(Figure 1).

The tentative identification or correlation of reflectors was accomplished by analysis of the synthetic seismograms, VSP surveys, and a review of the structural and stratigraphic geologic information, and the utilization of the results of prior work performed in the area. Figures 11 thru 18 portray the individual well sonic log information, the synthetic seismogram for a 70 100/250-300 filter, and the corresponding VSP corridor stack. Note that the mismatch in correlation between the synthetic seismogram and the VSP corridor stack is related to the unlogged weathered zone which was corrected with $5000 \mathrm{ft} / \mathrm{sec}$ velocity, rather than the correct but unknown thickness of approximately $2000 \mathrm{ft} / \mathrm{sec}$. During interpretation corrections were made, as deemed appropriate, at any given correlation point.

6. D. Data processing equipment. See Appendix B.

7. TMME SECTIONS VERSUS DEPTH SECTIONS. 
To obtain absolute ac, aracy ir depth on a seismic section, the sersmic data must be calibrated $t_{\text {. }}$ well log information. In this survey only PBF-6 was directly tied with the seismic data. However, for correlations within the upper $300 \mathrm{ft}$ of geolngic strata, the measurement of the near surface velocity with the VSP surveys and the continual refraction analysis along each seismic line provide a calibration of time with depth. In discussing relative and absolute accuracy a general concern is the theoretical one cycle resolution, i.e. $1000 \mathrm{~Hz}$ data $\sim 2.5 \mathrm{ft}, 200 \mathrm{~Hz}$ data $-12.5 \mathrm{ft}$, etc. Lateral consistency of data on traces spaced at $5 \mathrm{ft}$ subsurface intervals and displayed at an adequate scale (horizontal and vertical scales of 32.5 inches per second and 12 traces per inch) can yield resolution to less than a cycle. With these data a 2 millisecond offset would be observable, relating to accuracy of 5 to $7 \mathrm{ft}$.

The stacking and interval velocities generally indicate a velocity framework which matches the overall time configuration with excursions possibly related to the variable lithology. For ach production line, stacking and interval velocity diagrams were constructed to provide velocity information specific to that line and to assist in the interpretation of the seismic data. It is important in seismic interpretation to understand that variations in time on the seismic section may be caused by variations in velocity.

\section{PRODUCTIONLINTAS}

The location of all the shallow seismic lines are indicated in Figure 5. Full size seismic sections for all the lines that cross the Pen Branch fault are included with this document. Please note, as indicated in the information panel on each line, that the vertical time scale needs to be multiplied by 200 to convert to two way travel time in milliseconds.

\section{Line 1}

Data interpretation for Line 1 is not completed at this time.

\section{Line $2 \mathbf{a}$}

Line $2 a$ is the southwestern-most line done for this project and it is located on one of the lower river terraces of the Savannah River. Data quality is generally good to fair degrading somewhat with depth. The refraction analysis shows the thickness of the weathered layer as generally $20 \mathrm{ft}$ or less, occasionally as thick as $40 \mathrm{ft}$. Data quality is generally better in the areas of thin weathering. Correlation of the synthetic seismograms from PBF-4 and PBF-5 to the seismic data at shotpoint 150, line 2A established the geologic layering. Local variations exist in the reflection character along this line.

The data show no faulting. All layers are undeformed. The reflectors highlighted on the seismic section are intended to demonstrate examples of continuous flat lying reflectors are various depths. The upper reflector at 
shotpoint 240 is at 100 milliseconds two way travel time. At this portion of the section that reflection is at approximately 200 feet. The lower reflector is located at 24.0 milliseconds, two-way travel time or approximately $480 \mathrm{ft}$.

The location of the Pen Branch Fault is interpreted to be between shotpoint 245 and 260 at greater depths than the data can resolve.

Figure 19 portrays the stacking velocities. Figure 20 portrays the interval velocities derived from the stacking velocities. The interval velocity framework matches the overall time configuration with excursions possibly related to the variable lithology.

\section{Line 3}

This line is not discussed in this report because it does not cross the Pen Branch fault.

\section{Line 4}

This line is not discussed in this report because it does not cross the Pen Branch fault.

\section{Line 5}

This line is not discussed in this report because it does not cross the Pen Branch fault.

\section{Line 6}

Line 6 is located along the northeast end of the fault. Data quality is generally good. The refraction analysis shows the thickness of the weathered layer is generally $20 \mathrm{ft}$ with variations between 10 and $30 \mathrm{ft}$. Data quality is generally better in the areas of thin weathering. Correlation of the synthetic seismograms from PBF-7 and PBF-8 to the seismic data at shotpoint 380, and correlation to lines 7, 8, and 9 established the geologic layering. Local variations exist in the reflection character along this line.

The data show no evidence for faulting. All layers are flat lying.

The reflectors highlighted on the seismic section are intended to demonstrate examples of continuous flat lying reflectors at various depths. The upper reflector at shotpoint 310 is at 140 milliseconds two way travel time. At this portion of the section that reflection is at approximately 280 feet. The next reflector is located at 230 milliseconds, two-way travel time or approximately $460 \mathrm{ft}$. The lowest reflector is located at 260 milliseconds twoway travel time or approximately 520 feet.

Line 6 is located close to line 28 from the Conoco survey. A portion of line 28 is provided for comparison with line 6 (Figure 21). Figure 22 portrays the 
shallow seismic data from line 6 decimated to 1 out of 11 traces.

Comparison of Figure 21 and Figure 22, with the correlation of a time of $0.000 \mathrm{sec}$ on the high resolution data to a time of $0.070 \mathrm{sec}$ on the Conoco data appears reasonable to account for the difference in correctional velocity and to produce a satisfactory character correlation between the two data sets.

Figure 23 portrays the stacking velocities. Figure 24 portrays the interval velocities derived from the stacking velocities. The interval velocity framework indicated in these figures and the migration velocity overlay indicate a general match to the overall time configuration, with random variations. These random variations may relate to the changes in lithology of the various stratigraphic units indicated by local variations in the clay content.

\section{Line 7}

Line 7 is also located in the northeast part of the site. Data quality is generally good. The refraction analysis shows the thickness of the weathered layer is generally less than $20 \mathrm{ft}$. Correlation of the synthetic seismogram from PBF-2 to the seismic data at shotpoint 165, correlation to line 6, and ties to lines 8 and 9 established the geologic layering. No direct evidence for the fault is present in the high resolution data. All layers are flat lying.

The reflectors highlighted on the seismic section are intended to demonstrate examples of continuous flat lying reflectors at various depths. The upper reflector at shotpoint 160 is at 90 milliseconds two way travel time. At this portion of the section that reflection is at approximately 180 feet. The next reflector is located at 190 milliseconds, two-way travel time or approximately $380 \mathrm{ft}$. The lowest reflector is located at 254 milliseconds twoway travel time or approximately 508 feet.

Figure 25 portrays the stacking velocities. Figure 26 portrays the interval velocities derived from the stacking velocities. 
Line 8

This line is not discussed in this report because it does not cross the Pen Branch fault.

\section{Line 9}

This line is not discussed in this report because it does not cross the Pen Branch fault.

\section{Line 10}

Data quality is too poor to interpret. The poor data quality is attributed to an abnormally thick low velocity layer near surface layer.

\section{Line 11}

Line 11 is located in the central portion of Savannah River Site. Data quality is generally good to fair, degrading somewhat with depth. The refraction analysis shows the thickness of the weathered layer as variable between 10 and $50 \mathrm{ft}$. Data quality is generally better in the areas of thin weathering. The loss of fold in the area of shotpoint 605 was due to a railroad crossing. Correlation of the synthetic seismograms from PBF-7 and PBF-8 to the seismic data at shotpoint 590, and correlation to lines 12 and 13 established the geologic layering. Local variations in the reflection character along this line appear relatively smooth, rather than abrupt, as seen on most of the other lines.

The high resolution data show no evidence for faulting. The presence of the Pen Branch fault is inferred at about shot point 150 based upon a projection from a nearby Conoco seismic line (Line 3).

The reflectors highlighted on the seismic section are intended to demonstrate examples of continuous flat lying reflectors at various depths. The upper reflector at shotpoint 140 is at 90 milliseconds two way travel time. At this portion of the section that reflection is at approximately 180 feet. The next reflector is located at 156 milliseconds, two-way travel time or approximately $312 \mathrm{ft}$. The lowest reflector is located at 316 milliseconds twoway travel time or approximately 632 feet.

Figure 27 portrays the stacking velocities. Figure 28 portrays the interval velocities derived from the stacking velocities. The interval velocity framework is complicated by a few atypical determinations but appears to be a general dipping and increasing in thickness of velocity interfaces to the north. This dip and thickening to the north is the inverse of the overall time configuration. As a result a general increase of velocity to the south is inferred, which relates to a general increase in clay content to the south. 
The fact that local variations in the reflection character along this line appear relatively smooth rather than abrupt is consistent with this inference.

\section{Line 12}

Line 12 is located in the central portion of the plant, approximately 0.3 of a mile away from line 11. Data quality is generally fair to good depending on the amount of high frequency noise. A loss of fold in the area of shotpoint 295 was due to a railroad crossing. Correlation of the synthetic seismogram from PBF-2 to the seismic data at shotpoint 330, and correlation to line 13 established the geologic layering. Local variations exist in the reflection character along this line.

The Conoco data (Line 3) ties this line. Figure 29 portrays the high resolution data decimated to 1 trace out of every 11 , played out to a common datum, and with a common time scale. Comparison of Figure 29 and Figure 30 , with the correlation of a time of $0.000 \mathrm{sec}$ on the high resolution data to a time of $0.070 \mathrm{sec}$ on the Conoco data appears reasonable to account for the difference in correctional velocity and to produce a satisfactory character correlation between the two data sets. The Conoco data located the fault at depths greater than this data records at shot point 160 on line 12

The reflectors highlighted on the seismic section are intended to demonstrate examples of continuous flat lying reflectors at various depths. The upper reflector at shotpoint 180 is at 130 milliseconds two way travel time. At this portion of the section that reflection is at approximately 260 feet. The next reflector is located at 286 milliseconds, two-way travel time or approximately $572 \mathrm{ft}$. The lowest reflector is located at 330 milliseconds twoway travel time or approximately 660 feet.

Figure 31 portrays the stacking velocities. Figure 32 portrays the interval velocities derived from the stacking velocities. The stacking velocities at shotpoints $137.5,337.5,362.5$, and 412.5 clearly distort the velocity framework of relatively smooth interval velocity zones undulating and thickening to the south, which would match the overall time configuration. These anomalous stacking velocities are attributed to near surface irregularities and problems inherent in interpreting stacking velocities on a geologic basis.

\section{Line 13}

Line 13 is located just south of R-Reactor Area. Data quality is generally good but degrades somewhat to the south. The refraction analysis shows the thickness of the weathered layer ranges 10 to $40 \mathrm{ft}$ being thickest and most erratic in the center of the line. Correlation of the synthetic seismogram from PBF-2 to the seismic data at shotpoint 170 established the 
geologic layering. Although local variations exist the reflection character is very consistent along this line. Conoco Line 4 almost ties the north end of this line, although the lines are at a significant angle to each other (Figure 33). Figure 34 portrays the high resolution data decimated to 1 trace out of every 11, played out. Again a correlation of $0.000 \mathrm{sec}$ on the high resolution data to a time of $0.070 \mathrm{sec}$ on the Conoco data appears reasonable to produce a satisfactory character correlation between the two data sets. Based on the Conoco data we would expect to see the fault at the southwestern and of this line.

There is no evidence for a fault in these seismic data. All the identified layers are undeformed.

The reflectors highlighted on the seismic section are intended to demonstrate examples of continuous flat lying reflectors at various depths. The upper reflector at shotpoint 120 is at 44 milliseconds two way travel time. At this portion of the section that reflection is at approximately 88 feet. The next reflector is located at 54 milliseconds, two-way travel time or approximately $108 \mathrm{ft}$. The next reflector is located at 104 milliseconds twoway travel time or approximately 208 feet. The lowest reflector is located at 244 milliseconds two-way travel time or approximately 499 feet.

Figure 35 portrays the stacking velocities. Figure 36 portrays the interval velocities derived from the stacking velocities.

\section{Line 14}

Line 14 is located just southwest of K-Reactor. Data quality is highly variable and generally degrades with depth. The loss of fold in the areas of shotpoints 285, 240, and 195 was due to the Indian Grave Branch Creek and cultural features associated with it. Correlation of the synthetic seismograms from PBF-4 and PBF-5 to the seismic data at shotpoint 120, and correlation to lines 3 and 5 established the geologic layering. Local variations exist in the reflection character along this line.

Line 14 virtually overlays Conoco Line 8 (Figure 37 ). Figure 38 portrays the high resolution data decimated to 1 trace out of every 11, played out. Again a correlation of $0.000 \mathrm{sec}$ on the high resolution data to a time of $0.070 \mathrm{sec}$ on the Conoco data appears reasonable to produce a satisfactory character correlation between the two data sets.

The Pen Branch Fault may be present in the vicinity of shot point 160 . This is close to where the Conoco deep seismic reflection positioned the fault. From the shallow seismic data the Pen Branch fault appears to be located below shotpoint 145 where a probable basement reflector abruptly terminates. 
The reflectors highlighted on the seismic section are intended to demonstrate examples of continuous flat lying reflectors at various depths. The upper reflector at shotpoint 130 is at 40 milliseconds two way travel time. At this portion of the section that reflection is at approximately 80 feet. The next reflector is located at 120 milliseconds, two-way travel time or approximately $240 \mathrm{ft}$. The next reflector is located at 240 milliseconds twoway travel time or approximately 480 feet. The lowest reflector is located at 350 milliseconds two-way travel time or approximately 700 feet.

Figure 39 portrays the stacking velocities. Figure 40 portrays the interval velocities derived from the stacking velocities. The interval velocity framework indicated in these figures and the migration velocity overlay does not match the overall time configuration. Velocities appear generally lower in the area between shotpoints 280 and 160. This may indicate variations in the lithology of the various stratigraphic units.

\section{Line 15}

Line 15 is located just southwest and subparrallel to HWY 125. There is no evidence for a fault in this seismic data.

The reflectors highlighted on the seismic section are intended to demonstrate examples of continuous flat lying reflectors at various depths. The upper reflector at shotpoint 140 is at 80 milliseconds two way travel time. At this portion of the section that reflection is at approximately 160 feet. The next reflector is located at 140 milliseconds, two-way travel time or approximately $280 \mathrm{ft}$. The next reflector is located at 200 milliseconds twoway travel time or approximately 400 feet. The lowest reflector is located at 294 milliseconds two-way travel time or approximately 588 feet. All the identified layers are undeformed.

Figure 41 portrays the stacking velocities. Figure 42 portrays the interval velocities derived from the stacking velocities.

\section{Line 16}

Data interpretation for this line is not yet completed.

\section{CONCLUSTONS}

The conclusions based upon the best available data on hand at this time are:

1) Evidence for the Pen Branch fault does not exist in the shallow seismic data. The Pen Branch fault can be interpreted to be at least 300 feet below the surface. Sediments 300 feet below the surface are believed to be lower Tertiary in age or older than $60 \mathrm{Ma}$. The acquisition parameters were 
designed to optimize data capture in the 0 to $300 \mathrm{ft}$ range; deeper than that depth the data degrade.

The reprocessed Conoco data corroborate this conclusion. The Pen Branch fault is clearly seen in the reprocessed data at 400 milliseconds. However, all deformation from the fault attenuates to nothing between 300 and 200 milliseconds (Stephenson, personal communication, 1/91). Please note that the time to depth conversion for the Conoco data is not the same as for the high resolution shallow seismic reflection.

2) The reflectors in the shallow seismic data are interpreted to be predominantly sand/clay interfaces. Some of the reflectors are believed to be caused by carbonate material. Closely spaced shallow drilling done along one of the seismic lines could confirm the correlation of lithology to reflectors.

3) The seismic data show other geologic features not related to the Pen Branch fault but important to consider when making any interpretation about the section.

a) Beds generally dip and thicken toward the southeast.

b) Numerous small-scale sedimentary features such as' possible unconformities, and channels (marine and fluvial) interrupt the normal stratigraphic sequence of well-behaved flat-lying strata. These features complicate the geology and make interpretations more difficult. Closely spaced shallow drilling along a specific seismic line would be needed to confirm their existence. 


\section{REFERENCES}

Aadland, R. K. and H. W. Bledsoe, 1990, Classification of hydrostratigraphic units at Savannah River Site, south Carclina, USDOE Report WSRC-RP-90-987, Savannah River Site, Aiken South Carolina.

Balch, A. H., Lee, M. W., Miller, J. J., and Ryder, R. T., 1982, The use of vertical seismic profiles in seismic investigations: Geophysics, v. 47, n. 6, p. 906-918, 17 figures.

Berkman, E., 1990, Proposal to provide services for the high resolution seismic survey of of the Pen Branch Fault: Prepared in response to Solicitation Number A55978A, Westinghouse Savannah River Company, Aiken, South Carolina.

Berkman, E., 1991, High Resolution Seismic survey, Pen Branch Faultl, Savannah River Site, South Carolina, WSRC-TR-91-38, Savannah Rivere Site, Aiken South Carolina.

Berteussen, A. K., and Ursin, B., 1983, Approximate computation of the acoustic impedance from seismic data: Geophysics, v. 48, n. 10, p. 1351-1358, 5 figures, 1 table.

Castagna, J. P., Batzle, M. L., and Eastwood, R. L., 1985, Relationships between compressional-wave and shear-wave velocities in clastic silicate rocks: Geophysics, v. 50, n. 4, p. 571-581, 25 figures, 2 tables.

Chacko, S., 1989, Porosity identification using amplitude versus offset: Geophysics, v. 54, n. 8, p. 942-951, 11 figures.

Chapman, W. L., and Di Stefano, M. P., 1989, Savannah River Plant Seismic Survey, 1987-88: Conoco Inc., Seismic Acquisition Section, Research Report 1809-005-006-1-89, $110 \mathrm{p}$.

Cunningham, A. B., 1974, Refraction data from single-ended refraction profiles: Geophysics, v. 39, n. 3, p. 292-301, 7 figures.

Dobrin, M. B., 1976, Introduction to Geophysical Prospecting: McGrawHill, New York.

Fry, R. C., and Orange, A. S., 1982, High Resolution Seismic: A Practical Approach to Coal Exploration: Fifth Symposium on the Geology of Rocky Mountain Coal Proceedings, Claus Kurgel, Editor.

Hardage, B. A., 1987, Tectonics of the southern and central Appalachian internides: Ann. Rev. Earth Planet. Sci, p. 337-362, 4 figures. 
Lavergne, M., and Willm, C., 1977, Inversion of seismograms and pseudo velocity logs: Geophysical Prospecting, v. 25, p. 231-250.

Lewkowicz, J. F., Reischman, R., and Walsh, J. J., 1983, Results from open hole and cased hole vertical seismic profiles: SPWLA Twenty Fourth Annual Logging Symposium, June 27-30, 1983.

Lindseth, R. O., 1979, Synthetic sonic logs - A process for stratigraphic interpretation: Geophysics, v. 44, n. 1, p. 3-26, 22 figures.

Marine, I. W., 1974, Geohydrology of a Buried Triassic Basin at Savannah River Plant, South Carolina: AAPG Bull. v. 58 p. 1825-1837.

Marine, I. W. , 1976, Structural and sedimentational model of the buried Dunbarton Triassic basin, South Carolina and Georgia, DP-MS-74-39, Savannah River Site, Aiken, South Carolina.

Marine, I. W., and Siple, G. E., 1974, Buried Triassic Basin in the Central Savannah River Area, South Carolina and Georgia: GSA Bull. v. 85 p. 311320

Miller, R. D., Pullan, S. E., Waldner, J. S., and Haeni,F. P., 1986, Field comparison of shallow seismic sources: Geophysics, v. 51, n. 11 p. 2067 - 2092, 30 figures, 1 table.

Murdock, J. S., 1982, Preliminary Safety Analysis Defense Waste Processing Facility: E. I. du Pont de Nemours \& Co., Savannah River Laboratory, DPST-82-675, 4 volumes, prepared for the D. O. E. under contract DE-AC09-76SR00001.

Musgrave, A. W. (Ed.), 1967, Seismic Refraction Prospecting: Society of Exploration Geophysicists, Tulsa, Oklahoma.

Pullan, S. E., and H. A. MacAulay, H. A., 1987, An in-hole shotgun source for engineering seismic surveys: Geophysics, v. 52, n. 7 p. $985-996,9$ figures.

Stephenson, D. E., 1991, personnal communication.

Stephenson, D. E., 1988, August 1988 Savannah River Plant Earthquake: E. I. du Pont de Nemours \& Co., Savannah River Laboratory, Aiken, South Carolina, DPST-88-841, p. 1-12, 6 figures.

Stephenson, D. E., Talwani, P., and Rawlins, J., 1985, Savannah River Plant Earthquake of June 1985: E. I. du Pont de Nemours \& Co., Savannah River Laboratory, Aiken, South Carolina, DPST-85-583, p. 131 , 13 figures, 2 tables. 
Taner, M. T., and Koehler, E., 1981, Surface-consistent corrections:

Geophysics, v. 46, p. 17-22.

Woods, J. P., 1952, Up-Hole Times: Geophysics, v. 17, n. 2, p. 229-235, 7 figures.

Wuenshel, P. C., 1960, Seismogram synthesis including multiples and transmission coefficients: Geophysics, v. 25, n. 1 p. 106-129, 11 figures.

Wyatt, K. D., 1981, Synthetic vertical seismic profile: Geophysics, v. 46, n. 6, p. 880-891, 17 figures, 2 tables.

Yu, G., 1985, Offset-amplitude variation and controlled amplitude processing: Geophysics, v. 50, n. 12, p. 2697-2708, 15 figures. 


\section{APPENDIX A}

\section{Field Parameter Test.}

At startup a two phase test program was carried out which consisted of Geophone and Source Parameter tests, and Energy Source Parameter tests to determine the optimum parameters for the seismic survey. In the test program various source and receiver configurations were tested and noise records obtained to identify and eliminate, in so far as possible, the noise waves and investigate the optimum shot-receiver offset.

The Geophone and Source Parameter tests determined the geophone parameters and ascertained their proper emplacement. These tests utilized several energy source and distance variations with a common line of traces for comparison of 12 traces of geophones spaced at $10 \mathrm{ft}$ intervals over $110 \mathrm{ft}$ of the test line.

The Energy Source Parameter tests determined the optimum parameters for the Buffalo Gun. The tests were conducted with various 12-gauge shotgun shells shot singly with a manual fire Buffalo Gun. The tests also included a modification utilizing an electrical detonation device attached to the 8-gauge shotgun shell encased in a small PVC container, without the Buffalo Gun, loaded in a 3-ft deep auger hole. Summation of multiple shots was not performed since the signal to noise ratio observed on the initial shots indicated that this operation was not required. These tests utilized traces consisting of 6 geophones "potted", as determined from the previous tests to select the total configuration that gave the best high frequency energy while minimizing accompanying adverse surface noise effects. The "potted" geophone arrangement was 6 geophones spaced equally over $1.5 \mathrm{ft}$ parallel to the line cable.

These tests verified, for the most part, the planned parameters for signal attenuation versus distance, optimum recording filters, optimum distance window for maximum information in the zone of interest, etc.

Table 1 lisits and describes the test program

\section{Results of Testing}

Optimum parameters were determined in the field based upon the project goals and geologic constraints of the area, which attempted to optimize reflections from the upper $300 \mathrm{ft}$ of geologic strata. Processing of the test program included playbacks of the raw data, cornputation of amplitude spectra, playbacks of filtered data, playbacks of filtered and deconvolved data, and comparisons plots of the various records 
Tamp - The initial shots (90 to 98) of the test program compared wet versus dry tamp. Wet tamp was a water and dirt mixture; dry tamp was dry surface dirt. In-field examination of the initial shots indicated that wet tamp was clearly superior, it reduced the noise wave amplitude and duration and gave a cleaner and stronger signal.

Playback Filter - In-field filter panels on shot 90 established a high pass playback filter of $70 \mathrm{~Hz}$ to sufficiently reduce the amplitude of the noise wave on the field monitor records.

Frequency Content - In-field filter panels on shot 93 established the frequency of signal to be up to $400 \mathrm{~Hz}$.

Geophone Configuration - Shots 94, 95, 96, 97, and 100 of the test program utilized 6 geophones spaced over $10 \mathrm{ft}$. This spacing degraded the data. A spacing of $20 \mathrm{ft}$ would have been required to partially cancel the noise wave, but that spacing would have clearly degraded the desired high resolution signal. Shots 101 to 107 directly compared single geophones at the surface and single geophones buried at the grass roots. No significant improvement was observed with the geophone burial, in fact it appeared as if the surface plant gave marginally better results. Shots 108 to 119 directly compared single geophones at the surface and 6 geophones potted. Significant improvement was observed with the 6 geophones potted, especially on the far traces.

Record Filters - Shots 103 to 107 of the test program compared various low cut recording filters and established a $50 \mathrm{~Hz}$ low cut filter to allow for adequate processing without elimination of desired signal. The coupling of the air blast to rocks having the same velocity adds to the amplitude of noise and requires filtering in $8 \mathrm{ral}$ passes for adequate removal. The $50 \mathrm{~Hz}$ low cut recording filter, fcilowed by the prefiltering in processing, and the data processing sequence was adequate for noise removal. A high cut anti. aliasing $1000-\mathrm{Hz}$ filter was used on all shots.

Charge Size - The Buffalo Gun was clearly the energy source choice for this project because the frequency content was high enough and the amplitude sufficient. The 8-Gauge electrical detonation devise was clearly overshooting. The 12-Gauge light load shotgun shell looked noticeably better than 12-Gauge Magnum shotgun shell. The various loads tested were:

8-Gauge - electric fire - industrial load - 300 grain black powder load.

12-Gauge - Winchester - Dove \& Quail - 2.75n - 3.25 Dr. Eq. Pwdr. - 90 grain black powder equivalent.

12-Gauge Magnum - Winchester Super Steel - 3" - Max. Load - 115 grain black powder equivalent. 
Cable Configuration. The test shots and the first shots on Line 1 indicated that good reflections were recorded on all traces including the trace at the shot location. The production cable configuration was therefore established with no gap at the shotpoint. For the production program the acquisition layout was an asymmetric split-spread with the shot location at trace 4 or 4.5. These field procedures were utilized in an attempt to record more data within the the upper $300 \mathrm{ft}$ of geologic strata.

The production procedure of taking additional shots at the start and end of each line was established to to build up or maintain the fold by utilizing all 24 channels even though some offset distances were repeated. The production sequence at the beginning and end of each line included reversed refraction shois (Musgrave, 1967) to obtain additional velocity control.

By quantifying the noise parameters these tests allowed determination of the various data acquisition parameters discussed above, for maximum information in the shallow zone of interest. 
TABLE 1

TEST PROGRAM

\begin{tabular}{|c|c|c|c|c|c|}
\hline Shot th & $\begin{array}{l}\text { Geophones at } \\
\text { Traces } 1.12\end{array}$ & $\begin{array}{l}\text { Geophones at } \\
\text { Traces 13-24 }\end{array}$ & Charge Size & $\begin{array}{l}\text { Tamp } \\
\text { Type }\end{array}$ & $\begin{array}{l}\text { Low Cut } \\
\text { Record } \\
\text { Filter }\end{array}$ \\
\hline 90 & 1 on Surface & 6 Potted & 12-Gauge & Dry & $35 \mathrm{~Hz}$ \\
\hline 91 & 1 on Surface & 6 Potted & 12-Gauge & Wet & $35 \mathrm{~Hz}$ \\
\hline 92 & 1 on Surface & 6 Potted & 12-Gauge Mag & Dry & $35 \mathrm{~Hz}$ \\
\hline 93 & 1 on Surface & 6Potted & 12-Gauge Mag & Wet & $35 \mathrm{~Hz}$ \\
\hline 94 & 1 Buried & 6 over $3 \mathrm{~m}$ & 12-Gauge & Dry & $35 \mathrm{~Hz}$ \\
\hline 96 & 1 Buried & 6 over $3 \mathrm{~m}$ & 12-Gauge & Wet & $35 \mathrm{~Hz}$ \\
\hline 96 & 1 Buried & 6 over $3 \mathrm{~m}$ & 12-Gauge Mag & Dry & $35 \mathrm{~Hz}$ \\
\hline 97 & 1 Buried & 6 over $3 \mathrm{~m}$ & 12-Gauge Mag & Wet & $35 \mathrm{~Hz}$ \\
\hline 98 & 1 on Surface & 6Potted & 8-Gauge & Dry & $35 \mathrm{~Hz}$ \\
\hline 99 & 1 on Surface & 6 Potted & 8-Gauge & Wet & $35 \mathrm{~Hz}$ \\
\hline 100 & 1 Buried & 6 over $3 \mathrm{~m}$ & 8-Gauge & Wet & $35 \mathrm{~Hz}$ \\
\hline 101 & 1 Buried & 1 on Surface & 12-Gauge Mag & Wet & $35 \mathrm{~Hz}$ \\
\hline 102 & 1 Buried & 1 on Surface & 12-Gauge & Wet & $35 \mathrm{~Hz}$ \\
\hline 103 & 1 Buried & 1 on Surface & 12-Gauge & Wet & out \\
\hline 104 & 1 Buried & I on Surface & 12-Gauge & Wet & $25 \mathrm{~Hz}$ \\
\hline 105 & 1 Buried & 1 on Surface & 12-Gauge & Wet & $50 \mathrm{~Hz}$ \\
\hline 106 & 1 Buried & I on Surface & 12-Gauge & Wet & $35 \mathrm{~Hz}$ \\
\hline 107 & 1 Buried & 1 on Surface & 12-Gauge & Wet & $70 \mathrm{~Hz}$ \\
\hline 108 & 6 Potted & 1 on Surface & 12-Gauge & Wet & $50 \mathrm{~Hz}$ \\
\hline 109 & 6 Potted & I on Surface & 12-Gauge Mag & Wet & $50 \mathrm{~Hz}$ \\
\hline 110 & 6 Potted & 1 on Surface & 8-Gauge & Wet & $50 \mathrm{~Hz}$ \\
\hline 111 & 6 Potted & 1 on Surface & 8-Gauge & Wet & $50 \mathrm{~Hz}$ \\
\hline$\overline{112}$ & 6 Potted & 1 on Surface & 12-Gauge Mag & Wet & $50 \mathrm{~Hz}$ \\
\hline 113 & 6 Potted & I on Surface & 12-Gauge & Wet & $50 \mathrm{~Hz}$ \\
\hline 114 & 6 Potted & I on Surface & 12-Gauge & Wet & $50 \mathrm{~Hz}$ \\
\hline 115 & 6 Potted & I on Surface & 12-Gauge Mag & Wet & $50 \mathrm{~Hz}$ \\
\hline 116 & 6 Potted & 1 on Surface & 8-Gauge & Wet & $50 \mathrm{~Hz}$ \\
\hline 117 & 6 Potted & 1 on Surface & 8-Gauge & Wet & $50 \mathrm{~Hz}$ \\
\hline 118 & 6 Potted & 1 un Surface & 12-Gauge Mag & Wet & $50 \mathrm{~Hz}$ \\
\hline 119 & 6 Potted & 1on: & 12-Gauge & Wet & $50 \mathrm{~Hz}$ \\
\hline
\end{tabular}




\section{Vertical Seismic Profiles}

Tables $2 a$ through $d$ include nummerical results of the VSPs.

The theoretical AVO effect of the data at PBF-4 is shown by the Zeopritz calculations portrayed in Figure 1. Note the extreme amplitude variations at the larger angles of incidence for sand/clay and clay/sand reflections. No carbonate zones are present in PBF-4; however, a sand/carbonate or carbonate/sand reflection would be anticipate to show less AVO effect. These reflections would be higher in amplitude than sand/clay and clay/sand reflections at low angles of incidence, and show no significant variation with increasing angles of incidence.

The Castagna (1985) model computation at PBF-3 in the first 200 feet is in the form of a simulated CDP gather (Figure 2). A theoretical synthetic seismogram computed at various angles of incidence is based on the values portrayed in Figure 2 (Figure 3 ). It is a wiggle variable area display of the traces versus time for the various offsets encountered in this survey, with appropriate muting causing the limited number of traces being displayed at the shallow reflection times. Note the amplitude variations at the larger angles of incidence generally match those indicated in Figure 1. Although the interval velocities do not fit the generalization discussed above the values for Poisson's ratio are consistent with the generalization. The variations are felt to relate to the fact that Castagna utilized consolidated sediments to generate his empirical relationships. The observation that Castagna model computation shows lower values of Poisson's ratio in sands and higher values of Poisson's ratio in clays is consistent with the mineralogy involved, as mentioned above. This change in Poisson's ratio is discussed in more detail below and relates to the AVO characteristics of the data.

The VSP data processing included the following steps:

1 Demultiplex and transcribe to SEG Y format.

2 For both compressional and shear waves, large scale outputs were made to allow for trace editing and picking of compressional and shear wave arrival times. The shear wave arrival time was based on selecting the horizontal trace that showed the minimal arrival time. This included the preparation of two-way time versus depth graphs and tabular listings at the same datum used for the seismic survey.

3 Datum adjustment/alignment corrections for shot geometry and time break variations. 
4 Filtering, deconvolution, amplitude, and spectral analysis at appropriate intervals.

5 Separation of downward traveling waves.

6 Separation of upward traveling waves using dip dependent filtering.

7 Corridor stack.

8 Application of various final filters to match those utilized for the synthetic seismograms. 
TABLE 2a

VSP PROGRAM

PBF-7

Cased to TD, August 20, 1990, water level at $100 \mathrm{ft}$. Figure 20a.

\begin{tabular}{|l|l|l|l|l|}
\hline Shot * & Depth (ft & $\begin{array}{l}\text { Distance } \\
\text { (ft) }\end{array}$ & $\begin{array}{l}\text { Compressional } \\
\text { Wave Time } \\
\text { (ms) }\end{array}$ & $\begin{array}{l}\text { Shot Point } \\
\text { Distance }\end{array}$ \\
\hline 155 & 10 & 31.6 & 18 & 30 \\
\hline 154 & 30 & 42.4 & 22 & 30 \\
\hline 152 & 50 & 58.3 & 24 & 30 \\
\hline 153 & 70 & 76.2 & 31 & 30 \\
\hline 151 & 80 & 85.4 & 32 & 30 \\
\hline 150 & 90 & 94.9 & 32 & 30 \\
\hline 149 & 90 & 94.9 & 32 & 30 \\
\hline 148 & 100 & 104.4 & 32 & 30 \\
\hline 147 & 110 & 114.0 & 31 & 30 \\
\hline 146 & 120 & 123.7 & 33 & 30 \\
\hline 145 & 130 & 133.4 & 36 & 30 \\
\hline 144 & 140 & 143.2 & 37 & 30 \\
\hline 143 & 150 & 153.0 & 38 & 30 \\
\hline 142 & 160 & 162.8 & 39 & 30 \\
\hline 141 & 170 & 172.6 & 42 & 30 \\
\hline 140 & 180 & 182.5 & 42 & 30 \\
\hline 139 & 190 & 192.4 & 44 & 30 \\
\hline 138 & 200 & 200.1 & - & 5 \\
\hline 137 & 300 & 202.2 & 46 & 30 \\
\hline 136 & 210 & 318.9 & 70 & 240 \\
\hline 135 & 210 & 210.1 & - & 5 \\
\hline 134 & 210 & 210.2 & 46 & 10 \\
\hline 133 & 210 & 211.0 & 46 & 20 \\
\hline 132 & 210 & 212.1 & 47 & 30 \\
\hline 131 & 210 & 213.8 & 47 & 40 \\
\hline 130 & 210 & 215.9 & 47 & 50 \\
\hline & & & & \\
\hline
\end{tabular}


TABLE 2b

PBF-8

Cased to TD, August 21, 1990, water level at $100 \mathrm{ft}$. Figure 20b.

\begin{tabular}{|l|l|l|l|l|}
\hline Shot * & Depth (ft) & $\begin{array}{l}\text { Distance } \\
\text { (ft) }\end{array}$ & $\begin{array}{l}\text { Compressional } \\
\text { Wave Time } \\
\text { (ms) }\end{array}$ & $\begin{array}{l}\text { Shot Point } \\
\text { Distance }\end{array}$ \\
\hline 179 & 10 & 31.6 & - & 30 \\
\hline 178 & 30 & 42.4 & - & 30 \\
\hline 177 & 50 & 58.3 & - & 30 \\
\hline 176 & 60 & 67.1 & 26 & 30 \\
\hline 175 & 70 & 76.2 & 26 & 30 \\
\hline 174 & 80 & 85.4 & 27 & 30 \\
\hline 173 & 90 & 94.9 & 28 & 30 \\
\hline 172 & 100 & 104.4 & 30 & 30 \\
\hline 171 & 110 & 114.0 & 32 & 30 \\
\hline 170 & 120 & 123.7 & 34 & 30 \\
\hline 169 & 130 & 133.4 & 36 & 30 \\
\hline 168 & 140 & 143.2 & 37 & 30 \\
\hline 167 & 150 & 153.0 & 40 & 30 \\
\hline 166 & 160 & 162.8 & 41 & 30 \\
\hline 165 & 170 & 172.6 & 42 & 30 \\
\hline 164 & 180 & 182.5 & 44 & 30 \\
\hline 163 & 190 & 192.4 & 45 & 30 \\
\hline 158 & 200 & 202.2 & 48 & 30 \\
\hline 160 & 200 & 200.2 & 47 & 10 \\
\hline 159 & 200 & 201.0 & 48 & 20 \\
\hline 157 & 200 & 204.0 & 49 & 40 \\
\hline 156 & 200 & 206.2 & 49 & 50 \\
\hline & & & & \\
\hline
\end{tabular}


TABLE 2c PBF-4

Not cased, $180 \mathrm{ft} \mathrm{TD}$, October 3, 1990, water level at surface, shotpoint at 30 $\mathrm{ft}$. Note that shots 21 thru 35 were not recovered from the hard disk and were not available for processing. Figure 20c.

\begin{tabular}{|l|l|l|l|l|l|l|}
\hline Shot & $\begin{array}{l}\text { Depth } \\
\text { (ft) }\end{array}$ & $\begin{array}{l}\text { Distance } \\
\text { (ft) }\end{array}$ & $\begin{array}{l}\text { PWave Tiqshear Wave } \\
\text { (ms) }\end{array}$ & $\begin{array}{l}\text { Trace * } \\
\text { (vertical } \\
\text { (ms) }\end{array}$ & $\begin{array}{l}\text { Time break } \\
\text { adjustment(phone) } \\
\text { s) }\end{array}$ \\
\hline 35 & 10 & 31.6 & - & - & - & 0.0000 \\
\hline 34 & 15 & 33.5 & - & - & - & 0.0000 \\
\hline 33 & 20 & 36.1 & - & - & - & 0.0000 \\
\hline 32 & 25 & 39.1 & - & 0.0260 & 15 & 0.0000 \\
\hline 31 & 30 & 42.4 & - & 0.0280 & 15 & 0.0000 \\
\hline 30 & 35 & 46.1 & 0.0180 & 0.0310 & 15 & -0.0010 \\
\hline 29 & 40 & 50.0 & 0.0185 & 0.0320 & 15 & -0.0010 \\
\hline 28 & 45 & 54.1 & 0.0185 & 0.0325 & 15 & 0.0000 \\
\hline 27 & 50 & 58.3 & 0.0190 & 0.0350 & 19 & 0.0000 \\
\hline 26 & 55 & 62.6 & 0.0195 & 0.0385 & 15 & 0.0000 \\
\hline 25 & 60 & 67.1 & 0.0200 & 0.0425 & 15 & 0.0000 \\
\hline 24 & 65 & 71.6 & 0.0205 & 0.0465 & 19 & 0.0000 \\
\hline 23 & 70 & 76.2 & 0.0220 & 0.0525 & 19 & -0.0010 \\
\hline 22 & 75 & 80.8 & 0.0225 & 0.0560 & 19 & -0.0010 \\
\hline 21 & 80 & 85.4 & 0.0235 & 0.0605 & 19 & -0.0015 \\
\hline 20 & 85 & 90.1 & 0.0250 & 0.0645 & 15 & -0.0020 \\
\hline 19 & 90 & 94.9 & 0.0250 & 0.0695 & 15 & -0.0005 \\
\hline 18 & 95 & 99.6 & 0.0265 & 0.0745 & 15 & -0.0010 \\
\hline 17 & 100 & 104.4 & 0.0275 & 0.0775 & 15 & -0.0015 \\
\hline 16 & 105 & 109.2 & 0.0280 & 0.0840 & 17 & -0.0010 \\
\hline 15 & 110 & 114.0 & 0.0290 & 0.0850 & 17 & -0.0005 \\
\hline 14 & 115 & 118.8 & 0.0305 & 0.0900 & 19 & -0.0005 \\
\hline 13 & 120 & 123.7 & 0.0305 & 0.0930 & 19 & 0.0005 \\
\hline 12 & 125 & 128.5 & 0.0315 & 0.0960 & 19 & 0.0000 \\
\hline 11 & 130 & 133.4 & 0.0320 & 0.0990 & 19 & 0.0005 \\
\hline 10 & 135 & 138.3 & 0.0330 & 0.1045 & 15 & 0.0000 \\
\hline 9 & 140 & 143.2 & 0.0335 & 0.1110 & 15 & 0.0005 \\
\hline 8 & 145 & 148.1 & 0.0345 & 0.1130 & 21 & 0.0000 \\
\hline 7 & 150 & 153.0 & 0.0355 & 0.1190 & 19 & 0.0000 \\
\hline 6 & 155 & 157.9 & 0.0355 & 0.1260 & 15 & 0.0010 \\
\hline 5 & 160 & 162.8 & 0.0365 & 0.1300 & 21 & 0.0005 \\
\hline 4 & 165 & 167.7 & 0.0370 & 0.1335 & 21 & 0.0005 \\
\hline 3 & 170 & 172.6 & 0.0380 & 0.1360 & 19 & 0.0005 \\
\hline 2 & 175 & 177.6 & 0.0395 & 0.1390 & 17 & -0.0005 \\
\hline 1 & 180 & 182.5 & 0.0395 & 0.1420 & 19 & 0.0000 \\
\hline & & & & & & \\
\hline
\end{tabular}


TABLE 2d PBF-5

Not cased, $95 \mathrm{ft} \mathrm{TD}$, October 9, 1990, water level at surface, shotpoint at $30 \mathrm{ft}$. Figure 20d.

\begin{tabular}{|c|c|c|c|c|c|c|}
\hline Shot \# & Depth & $\begin{array}{l}\text { (idistance } \\
\text { (ft) }\end{array}$ & \begin{tabular}{|l|} 
PWave \\
Time \\
(ms) \\
\end{tabular} & \begin{tabular}{|l} 
Shear Wave \\
Time \\
(ms)
\end{tabular} & $\begin{array}{l}\text { Trace \# } \\
\text { (vertical } \\
\text { geophone) }\end{array}$ & $\begin{array}{l}\text { Time break } \\
\text { adjustment(p } \\
\text { s) }\end{array}$ \\
\hline 18 & 10 & 31.6 & 0.0140 & - & - & 0.0000 \\
\hline 17 & 15 & 33.5 & 0.0150 & $E$ & E- & 0.0000 \\
\hline 16 & 20 & 36.1 & 0.0160 & E & 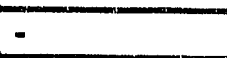 & 0.0000 \\
\hline 15 & 25 & 39.1 & 0.0165 & 0.0305 & 17 & 0.0000 \\
\hline 14 & 30 & 42.4 & 0.0175 & 0.0330 & 15 & -0.0005 \\
\hline$\overline{13}$ & 35 & 46.1 & 0.0180 & 0.0345 & 21 & 0.0000 \\
\hline 12 & 40 & 50.0 & 0.0215 & 0.0400 & 21 & -0.0010 \\
\hline 11 & 45 & 54.1 & 0.0250 & 0.0440 & 21 & 0.0000 \\
\hline 10 & 50 & 58.3 & 0.0280 & 0.0475 & 15 & -0.0010 \\
\hline 9 & 55 & 62.6 & 0.0300 & 0.0500 & 21 & -0.0005 \\
\hline 8 & 60 & 67.1 & 0.0330 & 0.0520 & 15 & 0.0000 \\
\hline 7 & 65 & 71.6 & 0.0355 & 0.0565 & 15 & -0.0010 \\
\hline 6 & 70 & 76.2 & 0.0355 & 0.0605 & 15 & 0.0000 \\
\hline 5 & 75 & 80.8 & 0.0355 & 0.0650 & 15 & 0.0005 \\
\hline 4 & 80 & 85.4 & 0.0370 & 0.0705 & 15 & -0.0005 \\
\hline 3 & 85 & 90.1 & 0.0370 & 0.0745 & 15 & 0.0000 \\
\hline 2 & 90 & 94.9 & 0.0375 & 0.0815 & 15 & 0.0005 \\
\hline 1 & 95 & 99.6 & 0.0390 & 0.0845 & 19 & 0.0000 \\
\hline
\end{tabular}




\section{Amplitude versus Offiset Analysis Discussion.}

Geologic factors. Geologic factors that affect the utility of AVO analysis are the theoretical ability tol discern the effect in the seismic data. There are a few basic questions thatt, are generally asked when an AVO is being analyzed:

Are there significantly large differences in the physical properties involved? The available shear wave information from SRS indicates that there are large differences in the physical properties involved.

Are there lateral variations in the stratigraphy which will complicate the results? The geologic information from SRS indicates that there are large lateral variations in the stratigraphy which will complicate the results.

Are the beds sufficiently thick to see reflections from both the top and bottom of the unit being investigated? Log information and evidence from outcrops and photographs taken of the burial ground at F and $\mathrm{H}$ area suggest that the beds are not generally sufficiently thick to see reflections from both the top and bottom of an individual stratigraphic unit, at le:ast in the upper $300 \mathrm{ft}$ of the geologic section.

The Biot-Gassman equations and the empirical relationships of Castagna were utilized to determine the expected Poisson's ratio from sonic log, core information, engineer data, along with reasonable values of the parameters for which no information was available. Offset-dependent reflection and transmission coefficients were calculated using the Zeopritz equations.

Data acquisition factors. Data acquisition factors that effect the utility of AVO analysis are the theoretical ability to discern the effect in the seismic data. A few basic questions generally asked are:

Are the original data sufficiently good quality to observe the AVO phenomena? Unfortunately the seismic data at SRS at small angles of incidence are highly contaminated with noise.

Are the angles of incidence at the zone of interest sufficiently large? Angles from 20 to 30 degrees (and greater) are desired (Chacko, 1989, figure 6). Unfortunately the seismic data in a high resolution seismic survey provide a limited amount of traces at large angles of incidence. 
Data processing factors. Data processing factors that effect the utility of AVO analysis are the practical ability to discern the effect in the seismic data. The basic question generally asked is:

Since various factors that effect the amplitudes are normally required to improve the visual data quality, is good quality true amplitude data available over the zone of incident angles required to observe the theoretical effects?

It should be noted that in this survey better quality data was recorded at the larger incidence angles of interest because of the noise contamination of the near traces. The problem is therefore one of comparison of better data to poorer data. 


\section{APPENDIX B EQUIPMENT}

\section{Data Acquisition}

\section{Seismograph}

The multichannel recording equipment consisted of an EG\&G Geometrics ES-2401 seismograph. This 24-channel system is one of the most advanced seismographs available. High resolution data was acquired with instantaneous floating point ( $24 \mathrm{~dB}$ single stage, automatic gain ranging) amplifiers and 15 bit analog to digital converters with a 32-bit memory. With this size memory and dynamic range (114 dB), manual gain controls are not required and field operation is simpler than with older seismographs. System noise is very low. Analog lowcut (out, 25, 35, 50, 70, $100,140,200,280$, and $400 \mathrm{~Hz}-18 \mathrm{~dB}$ per octave slope), notch (50 and $60 \mathrm{~Hz})$, and highcut (250,500, and $1000 \mathrm{~Hz}-18 \mathrm{~dB}$ per octave slope) filters with frequencies selectable from an interactive menu and keyboard, and the ability for internal summation are features of this system which allows sampling to as small as 50 microsecond intervals. The selectable sample intervals are 50,100,200,500, microseconds, 1 and 2 milliseconds. The system was operated on 200 microseconds ( 0.2 milliseconds). A backlit liquid crystal display (LCD) and a thermal graphics plotter (high resolution, $11 \mathrm{~cm}$ wide, 640 dot wide) allowed for immediate viewing of the field data. Paper records included automatic annotation of acquisition parameters. The recording media was a removeable hard disk and PCcompatible 5.25 inch floppy disks which were converted to 6250 bpi 9 track tape at the processing center.

\section{Geophones and Cables}

Geophones were Mark Products L-40A, 40-Hz geophones. The geophones, in strings of 6 , were equipped with 3 -inch spikes, molded water tight connectors, standard pins for picking up and laying out the geophone strings, and the necessary geophone testing equipment. Four Tesco cables with 12 molded water tight takeouts per cable; takeout spacing of $25 \mathrm{ft}$ were utilized. Light weight canvas bags for picking up and laying out the cable, cable protectors for road crossings, and the appropriate cable testing equipment were used. Although only 24 traces were recorded with an individual shot, sufficient geophones and cables to lay out 96 traces at a single time were available. A roll along box was utilized for trace selection which allowed for rapid field operations.

\section{Energy Source}

The energy source was a Buffalo Gun. Gun in this context is a misnomer as no rifle barrel is used. The Buffalo Gun is described by Pullan et. al. 
(1987). The authors describe how a Buffalo Gun is built from standard $3 \mathrm{ft}$ long 3/4-inch steel pipe and 3/4-inch pipe fittings and can utilize electrical or mechanical firing devices. The frequency content of this type source has been shown in the above referenced article, and numerous others, to be superior in producing high frequency energy. Miller et. al. (1986) is an excellent review and comparison of different possible high resolution seismic energy sources, 30 multi-component figures showing sample data and frequency spectra allow the reader to examine numerous energy sources in detail.

It should be noted that shotgun shells up to 8-Gauge industrial size, 500 grain maximum load, are classifiad as small arms ammunition and no permits or licenses are required to buy, transport, store, or use these shells in the United States. They may be shipped air, Federal Express preferred, clearly marked "small arms ammunition, ORM-D-AIR" in packages that do not exceed 65 pounds gross weight.

Small portable mechanical augers ("Little Beaver") were utilized from the truck tailgate for rapid drilling of the required auger holes) to locate the shotgun shell assembly approximately $3 \mathrm{ft}$ beneath the ground surface.

\section{Vertical Seismic Profile Equipment}

Vertical Seismic Profile surveys and velocity check shots were obtained at 5 or $10 \mathrm{ft}$ spacing in four area wells to depths of 200 feet by lowering a geophone assembly into the well and shooting on the surface. The borehole geophone assembly was a commercially available down-hole, high output, low noise, five geophone $(8 \mathrm{~Hz})$ assembly, with a wall locking mechanism. The five geophone assembly had one vertical geophone for recording compressional wave information, and 4 horizontal geophones oriented in increments of $\mathbf{4 5}$ degrees for recording shear wave information. Each of the five geophones had two outputs allowing for setting different gains or polarities to facilitate measuring the arrival times. As there was no facility to orient the geophone assembly, the shear wave arrival time was based on selecting the horizontal trace that showed the minimal arrival time. The wall locking mechanism was an inflatable inner tube taped to the geophone assembly. Wireline cable and hoist equipment were not required since the geophone cable contained a reinforcing member.

\section{Safety Equipment}

Safety equipment consisted of hard hats, safety glasses, ear plugs, leg covers, work gloves, work boots, fire extinguishers, shovels and spades, first aid kits, radio communication equipment, "Men Working" signs, etc. The Safety Plan was addressed in detail in the technical proposal (Berkman, 1990). 


\section{Data Processing}

\section{Hardware}

The computer equipment for data processing was supplied by TLC Data Processing Center, Inc. (TLC). TLC's computer hardware utilizes a standard tape density is $6250 \mathrm{BPI}$ and includes:

- One Convex C-120 computer system

- Two Perkin Elmer 3242's with 4 FPS array processors

- Two Lucky 386 (IBM compatible) systems.

\section{Software}

The specialized software for data processing was supplied by 'TLC. TLC's specialized software includes:

- land and marine, 2-D and 3-D processing

- prestack migration

- amplitude versus offset

- refraction analysis and statics with rigorous quality control

- powerful surface consistent statics

- surface consistent deconvolution and other variants

- DMO - comprehensive emergent angle approach

- F-X deconvolution

- random noise filtering

- phase analysis to achieve phase ties around loops

- full color attribute package

- an efficient velocity inversion package with accurate low frequency modelling

- FLEXFIL dispersive noise filtering

- a database mapping package 


\section{Appendix C Data Processing}

The following is a brief elaboration of the processing routines.

\section{Demultiplex and Transcribe to SEG Y Format}

In the demultiplexing step the "bookkseping" process of rearranging the time sequential data samples, with all traces multiplexed as recorded in the field, into a trace sequential format was accomplished. In the transcription step the "bookkeeping" process of changing from the SEG D format used in the recording to the SEG Y format used for the further processing was accomplished. The data were recorded in SEG D format at a sample rate of 0.2 millisecond.

2 Geometry and Trace Editing

In the geometry step the source-geophone pairs from the field format records that relate to a CDP point are indicated in the header information and stored in preparation for further processing. Trace editing is the removal of noisy or defective traces from each CDP set.

$3 \quad$ Filter

In this step a $50-100 / 500-600 \mathrm{~Hz}$ bandpass filter was applied to the data to enhance the reflections of interest by filtering out noise that is outside the frequency band which contains the majority of the reflection signal (Figure $24 \mathrm{~A}$ ). The earth itself acts as a filter, with lower frequencies penetrating farther with the result that more higher frequencies are present in the seismic data for shallow reflections than for deeper reflections. Since high resolution at all depths was the goal, it was desirable to utilize the highest frequencies possible at each depth. It should be noted that this filtering must be done prior to gain recovery (and the later processing) to maintain relative amplitudes.

\section{Gain Recovery}

There was a test loop on, and application of geometric spreading and inverse amplitude loss corrections. These trace scaling operations involve the comparison of adjacent traces and the adjustment of the amplitude of the trace to give $a$ uniform appearance to the final plot. This compensates primarily for the variations in energy contained in each shot resulting from changes in shot-to-rock coupling that occur. No relative changes in amplitude were imposed on the data. This is opposed to Automatic Gain Control (AGC) which was used on the field monitor records. With AGC, within a sliding "time window" of adjustable length, equalization is applied which has the effect of normalizing strong and weak signals. The 
disadvantage of AGC is that subtle natural variations in signal amplitude are removed in the process. There was a brute stack to test the previous processing.

5 Time Break Correction (where applicable)

The consistency of the time breaks for lines $1,2,3,5$, and 10 was assured by applying time break shifts as indicated by a careful examination of large scale playouts of the data and consideration of the geometry involved. The processing included the picking of time break shifts on these lines and also the picking of refraction breaks which also served as quality control on the time break shifts. It must be kept in mind that when performing the surface consistent static corrections the seismic data are further adjusted based upon statistical averages obtained from the data, the purpose of this application of time break shifts is to minimize the shifts allowable in the surface consistent static correction routine. Clearly the accuracy of the shifts required are far less than perfection.

When line 16 was shot to record the near distance traces, trace 1 remained at the shotpoint to verify adequate instrument triggering and no time break correction was required. When line 16 was shot to record the far distance traces a time break correction was required. Trace 1 duplicated the location of trace 24 of the shot to record the near distance traces and large scale playoutz of the data allowed for consistent adjustments of the time breaks.

A datum correction was applied to insure proper reflection arrival times, i.e. the geometric configuration of reflecting horizons $w$ re portrayed accurately to a flat datum of $350^{\prime}$ and was not influenced by surface elevation changes. The concept of datum is illustrated in Figure 2. In the

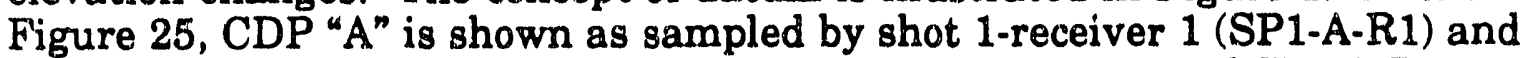
shot 2-receiver 2 (SP2-A-R2). The two raypaths, SP1-A-R1 and SP2-A-R2, need to be corrected for the difference in local elevation between SP1, SP2, $R 1$, and R2. The datum is chosen at an elevation which assures that no information is placed above zero time. Each trace is corrected or adjusted by a time equal to the difference in travel time resulting from the difference in shot and geoplione elevation below the datum. The "time = distance/velocity" formula is used to determine the correction, with the velocities chosen from a knowledge of the velocity of the near surface rocks or through empirical testing. This computation is refined with the velocities determined by analysis of the refraction information. Refraction statics (Cunningham, 1974) included near trace gathers, overburden velocity analysis, refractor velocity analysis, depth interpretation, and replacement static correction calculation and application. There was a brute stack to test the refraction statics. 
There was a test loop on, and application of surface consistent deconvolution and spectral balancing to determine and remove shot and receiver wavelets. This included spectral analysis and optimum parameter selection. Choice of deconvolution type and parameters was based upon tests made at minimum intervals of 200 shotpoints. It should be kept in mind that the Buffalo Gun is equivalent to a sharp acoustic energy "spike" propagating through the earth as described earlier. The filtering effect of the earth broadens the "spike" into a lengthy complex waveform. The deconvolution and spectral balancing process attempts to rec-eate the original sharp "spike" from each reflector by operating on the signal with the inverse of an assumed earth filter. An explanation past this is beyond the scope of this report; the interested reader is directed to the references, in particular Dobrin (1976), pages 177 and 178. In practice, the deconvolution operator is chusen on the basis of experience and upon tests performed on the data. Several "rules of thumb" which are in general use have been developed based upon theory and experience. They are: the operator length should be 2 to 3 times the natural period of the data (the natural period being trough-to-trough or peak-to-peak time); and the design length should be 8 to 10 times the operator length. For this project the operator length 40 $\mathrm{ms}$ and the design length was $280 \mathrm{~ms}$ (60 ms to $340 \mathrm{~ms}$ ). There was a brute stack to test the deconvolution and the previous processing.

It should be noted that the $0.2 \mathrm{~ms}$ sample rate allowed for an adequate number of samples to be utilized in the processing computations. The theoretical frequency limit of approximately $1200 \mathrm{~Hz}$ was not the objective of the $0.2 \mathrm{~ms}$ sample rate utilized. The Buffalo Gun energy source (or any other practical energy source for this project) does not generate frequencies in the ultra high range of 500 to $1200 \mathrm{~Hz}$. Figure 3 demonstrates the spectral balancing achieved by comparing the frequency spectra before and after processing between shotpoints 147.5 and 152.5 on line 11 . The before processing spectra is from the initial brute stack, the after processing spectra is from the final stacked data (after step 13 and prior to final filtering). The spectrum is clearly evenly balanced from $80 \mathrm{~Hz}$ to $260 \mathrm{~Hz}$, with signal present to $350 \mathrm{~Hz}$.

\section{Surface Consistent Residual Statics}

Surface consistent residual statics (Taner and Koehler, 1981) were applied to ensure that the reflections on all traces were properly aligned and would sum for maximum benefit. The determination of the correct static shift applied was based upon the cross-correlation of a pilot trace to each trace in the CDP set. The pilot trace was formed by summation of several uncorrected CDP's. The number of CDP's to be summed is determined to a large degree by the data quality. In deep seismic reflection work the practice is to use a large number of CDP's, but in high resolution seismic 
work the number of CDP's should be kept to a minimum. The expression "surface consistent" indicates that the same correction is used for all static corrections at a specific location, whether it is a trace or a shotpoint location. The cross-correlations are treated with a least squares optimization algorithm to determine the best correction at each specific location. For this project the pilot trace was formed by summation of 7 uncorrected CDP's and the maximum static shift allowed was $8 \mathrm{~ms}$, the correlation window was $60 \mathrm{~ms}$ to $340 \mathrm{~ms}$.

$9 \quad$ Velocity Analysis

There was a test loop on, and application of the normal move out (NMO) correction. NMO is termed a "dynamic "correction since it is viriable with time, as discussed below, as opposed to "static" corrections where the misalignment which occurs in the CDP set is assumed to be due to minor variations in the thickness and velocity of the near surface low velocity layer. To understand the dynamic NMO correction, reference to Figure 4 is required. In this figure a simple CDP set and the resulting data display are shown. Clearly, although energy from both shots is reflected from the same point on the reflector, the ray path length from SP1 to R1 is longer than the path length from SP2 to R2. This results in the time t1 (from shot to when the reflection is received) from shot 1 being greater than the time $t 2$ from shot 2 . If the reflections can be assumed as coming from the same point, then the difference in time can be measured and the difference in path length determined geometrically, the average velocity of the material between the surface and the reflector can be estimated using the "velocity $x$ time $=$ distancen relationship. The variation of velocity with time is determined through an analysis of this physical phenomena and the results utilized to correct the data as an adjustment to each component trace of the CDP set, such that identical reflections occur at identical times on each trace. Since the velocity varies laterally as well as vertically, the process is repeated along each line. Velocity analysis was at minimum intervals of 50 shotpoints. Note that the reference for velocity at this stage is the surface. Time in ms equals the value read in the header box times 200, while the velocity in $\mathrm{ft} / \mathrm{sec}$ equals the value read in the header box times 5 . This is due to the $0.2 \mathrm{~ms}$ sample increment and the programs accepting integer sample rates. The procedure was to indicate a $1 \mathrm{~ms}$ sample rate and then to convert the time (and other associated scales) by a factor of 5 or $1 / 5$ as appropriate.

10 Surface Consistent Residual Statics - see discussion under step 8.

11 Application of Normal Move Out (NMO) Correction - see discussion under step 9. 
There was a test loop on, analysis of, and application of offset/fold limiting (muting) prior to stacking. When a shot is fired, the first signals to reach each geophone are either ground roll (waves propagated along the surface like ripples on a pond) or refracted energy from shallow high velocity interfaces. These "noise" signals may mask reflections arriving at the same time on other traces. Since the component traces of the CDP set are going to be added (stacked), then it is undesirable to add this noise, if present, into the signal. Thus, the noisy initial fraction of a second of each trace was removed, or muted. Since the farther traces receive the noise at a time later than the near traces, the length of mute applied to each trace is a function of the source to receiver distance as well as the noise content of the signal. Field records with and without mute were reviewed to insure the proper design of the mute parameters. It should be noted that the early reflections were in many cases significantly stronger than the noise and the mute was therefore adjusted accordingly. In the final mute unwanted data are removed so that signals of interest will not be interfered with. The NMO correction was applied as an adjustment to each component trace of the CDP set, such that identical reflections occur at identical times on each trace. To accomplish this, reflection events are moved varying amounts in a manner which simulates stretching the seismic trace, with more correction applied on the far traces. This "stretch" which occurs as a result of the NMO stretch in the shallower portions of far traces was removed by muting for the same reasons as discussed above. When one considers the extreme NMO stretch that was undoubtedly encountered in the D'Appolonia data (with offset distances to $1400 \mathrm{ft}$ ), and how NMO stretch degrades the high frequency content of seismic data, it is surprising that the D'Appolonia data was as good as it appears.

The significance of the mute process is that although the final output is nominally 12 fold, maximum fold is not attained until all traces contain signal in both the time and distance domain. With regard to the time domain for this data only one trace has signal in the time range of 0 to $4 \mathrm{~ms}$, in the time range of 4 to $35 \mathrm{~ms}$ the number of traces containing signal increases linearly until 4 fold is reached, in the time range of 35 to $70 \mathrm{~ms}$ the number of traces containing signal increases linearly until 12 fold is reached. It should be realized that this mute pattern is variable dependent upon the depth of weathering as determined by the refraction statics. With regard to the distance domain, line end effects were alleviated to some extent by the procedure of taking additional shots at the start and end of each line to build up or maintain the fold. It should be realized that full fold of a CDP set does not occur until some finite distance down the line is reached, as the fold increases. 
13 Stack

Stacking is the step of adding together the traces that make up the CDP set, to make one composite trace. When constituent traces of the CDP set are added, or "stacked", the reflections which occur at the same time on each constituent trace will add constructively whereas noise and multiples, being random in nature, will cancel, if the static (datum) and dynamic (velocity) corrections have been applied correctly. Thus the stacking process, using properly aligned traces, can significantly enhance the seismic information. The "fold" refers to the number of individual traces which have been added to yield the composite trace. As discussed above, because of muting 12 fold was not attained until a reflection time of $70 \mathrm{~ms}$.

F-X Deconvolution

There was a test loop on and application of an F-X noise reduction deconvolution. In simple terms, in a $\mathrm{T}$ (time)- $\mathrm{X}$ (distance) deconvolution each time slice is considered a trace, i.e., instead of a vertical trace being utilized as discussed above a horizontal trace is manufactured from each equivalent sample from all traces. In more complicated terms, in the $F$ (frequency)-X (distance) deconvolution each trace is transformed to the frequency domain and each frequency interval is considered a trace for the deconvolution, then the deconvolved frequency domain information is transformed back to the time domain. The deconvolution operator is designed to remove the random noise. This noise reduction technique is quite strong and was utilized to reduce the effect of the random noise present in the data.

There was a test loop on and analysis of a post stack deconvolution. The results did not indicate improvement in the data.

In this step a final filter was applied to the data to enhance the reflections of interest. Filter control points were based upon tests made at minimum intervals of 200 shotpoints. Numerous filter studies led to the design of the final 70-100-340-360 filter. Figure 26 supports this filter design.

Final trace scaling with a $100 \mathrm{~ms}$ gate was applied prior to display.

17 Display

The display of the final stacked sections utilized horizontal and vertical scales of 32.5 inches per second and 12 traces per inch. Reproducible vellum output was normal polarity. 
There was a test loop on, analysis of, and application of migration. The actual location in space of any reflection event on a single trace is impossible to determine from that trace itself. The difference in the reflection times between traces which are adjacent is called "apparent dip". The actual position of the reflection surface is determined from the apparent dip and properties of wavefront and diffraction curves and are velocity dependent. Figure 5 illustrates the above concept. Migration is especially useful when stratigraphic layers are steeply dipping or faulted so that true positions of reflecting surfaces can be observed on the seismic section. In addition, a pseudo-mixing of adjacent traces occurs to further enhance the data.

Note that the reference for migration velocity is zero time. The replacement velocity was utilized from zero to the surface with the interval velocities as determined above being utilized from the surface down. Again time in ms equals the value read in the header box times 200 , while the velocity in $\mathrm{ft} / \mathrm{sec}$ equals the value read in the header box times 5 . A reproducible vellum output indicates these velocities as a contoured overlay to the migrated data.

19 Display

The display of the final migrated sections utilized horizontal and vertical scales of 32.5 inches per second and 14 traces per inch. Reproducible vellum output included normal and reversed polarity.

Lines 1 and 10 had extremely thick weathering that precluded adequate refraction static analysis. The accompanying high amplitude noise also precluded the application of surface consistent deconvolution and spectral balancing in the same sequence as all other lines. For these lines the application of surface consistent deconvolution and spectral balancing was delayed until after the second pass of surface consistent residual statics. Following application of surface consistent deconvolution and spectral balancing a final pass of surface consistent residual statics was applied. 


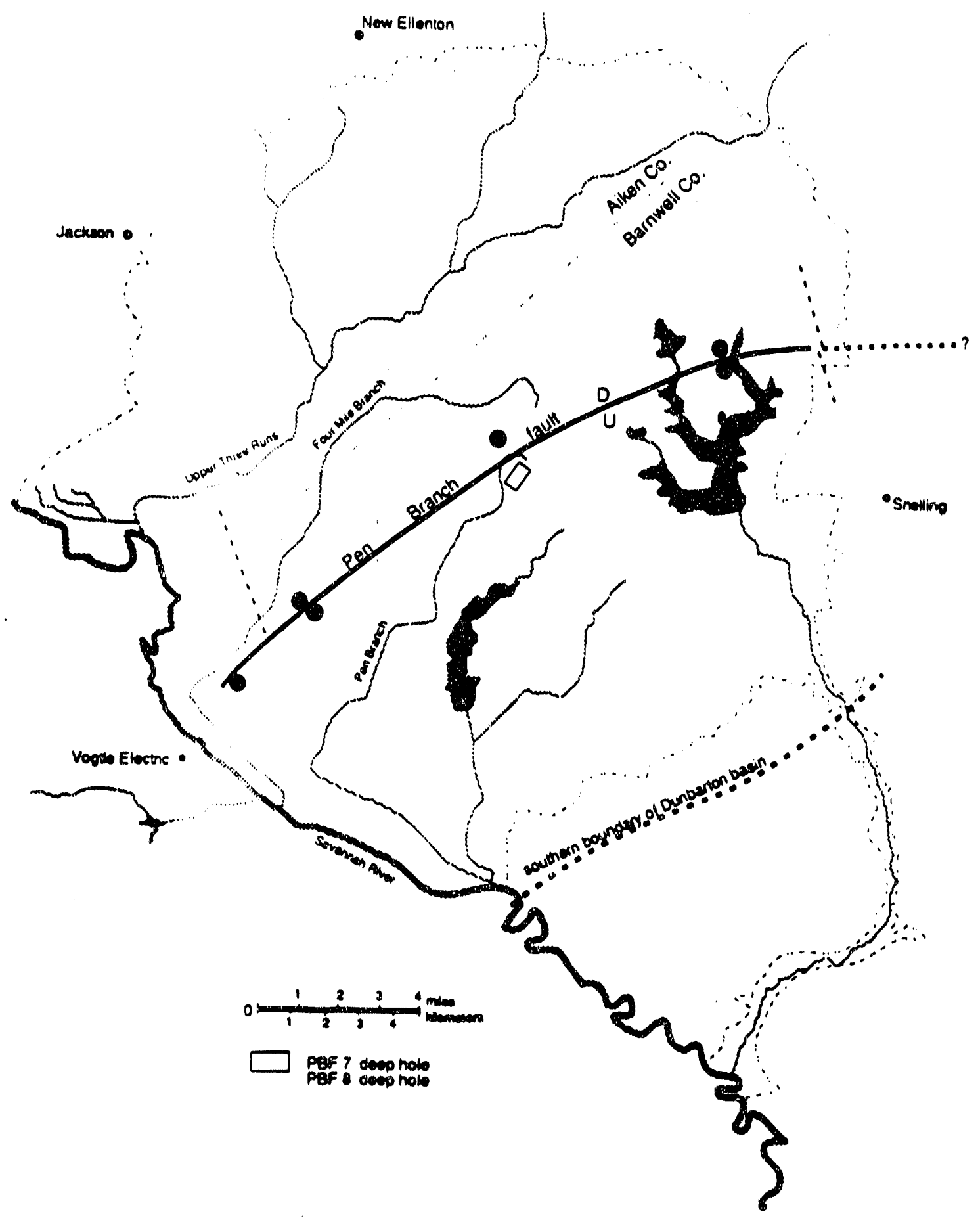

Figure 1. Location of Pen Branch fault at SRS with phase 1 shallow coring locations shown as large filled circles. Two other possible north-south trending faults were thought to intersect the Pen Branch fault. 


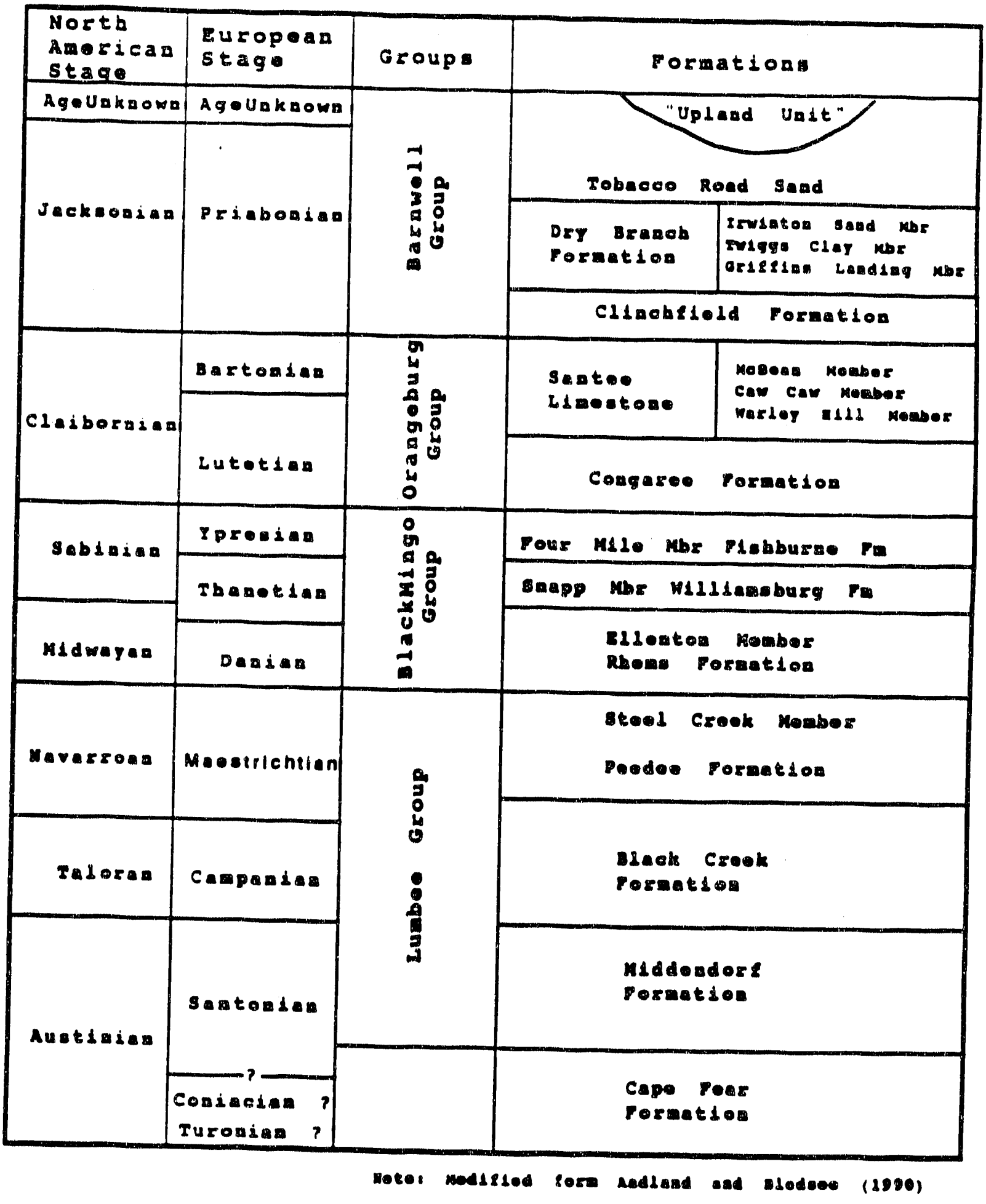

Figure 2. Stratigraphic column for SRS. 







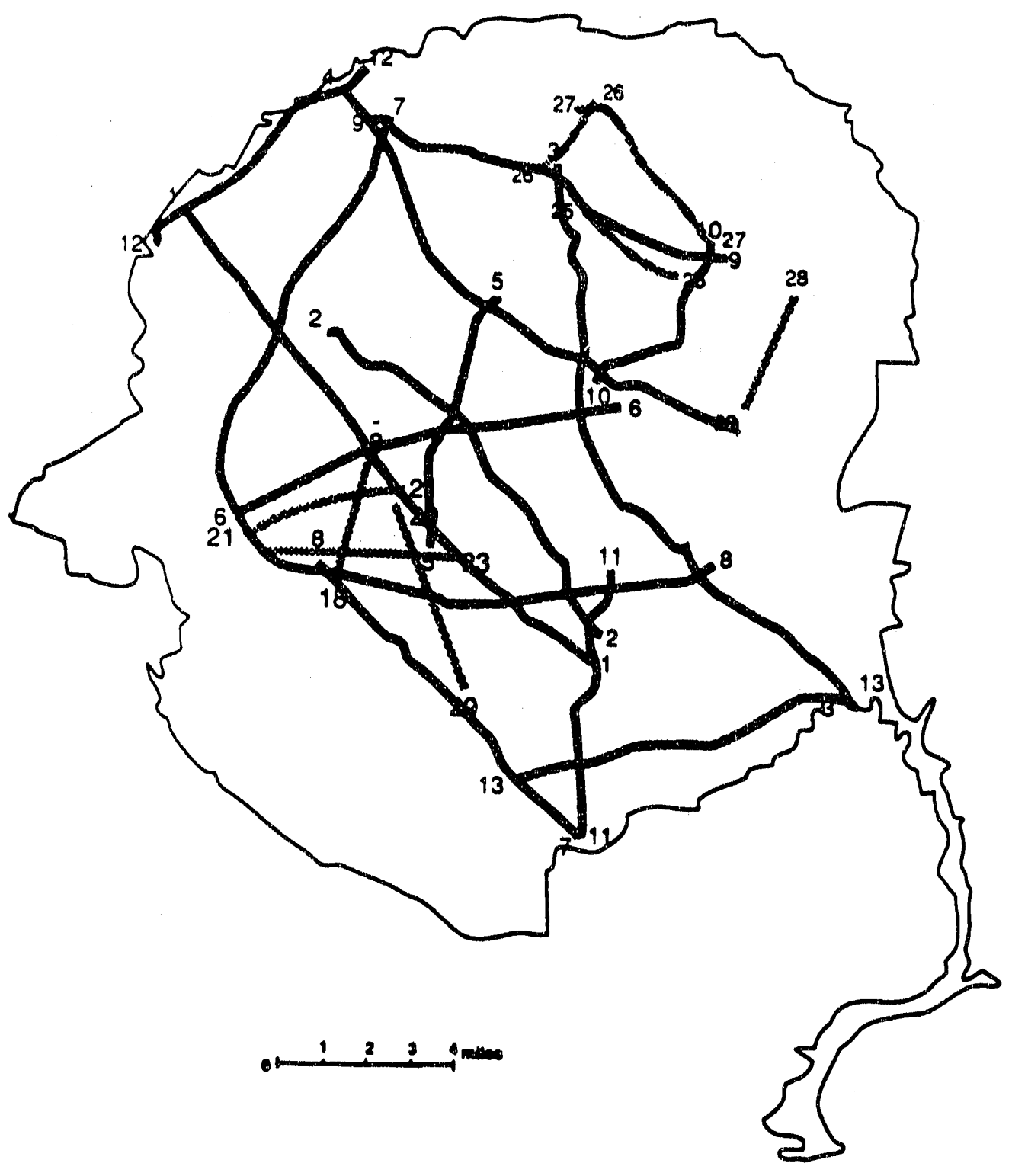

Figure 4. Location of deep seismic reflection lines done by Conoco, 1988-1989. 


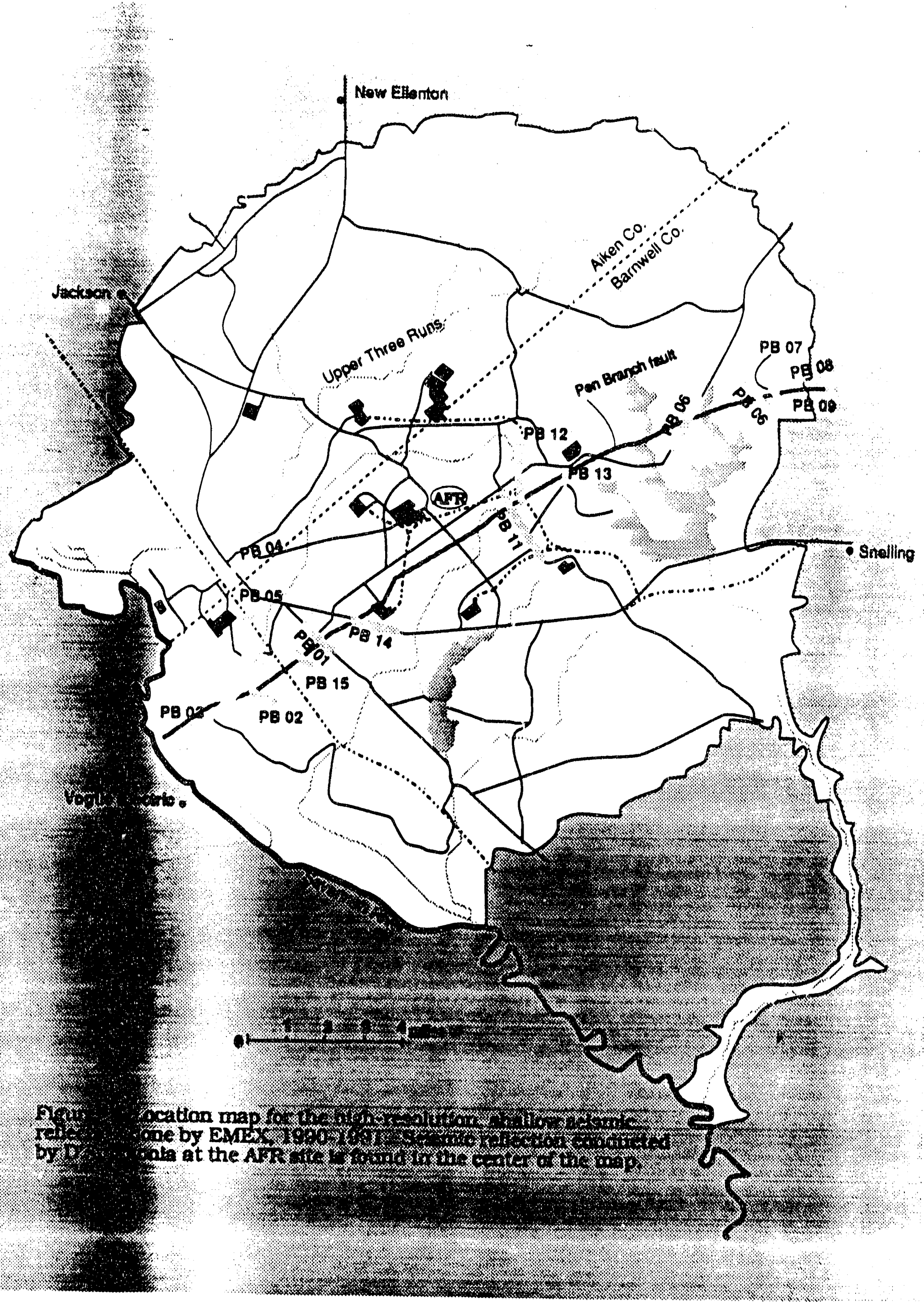






Figure 6. Location map for the 1969 Seismograph Service Corporation single fold seismic survey. Figure taken from Marine, 1976. 


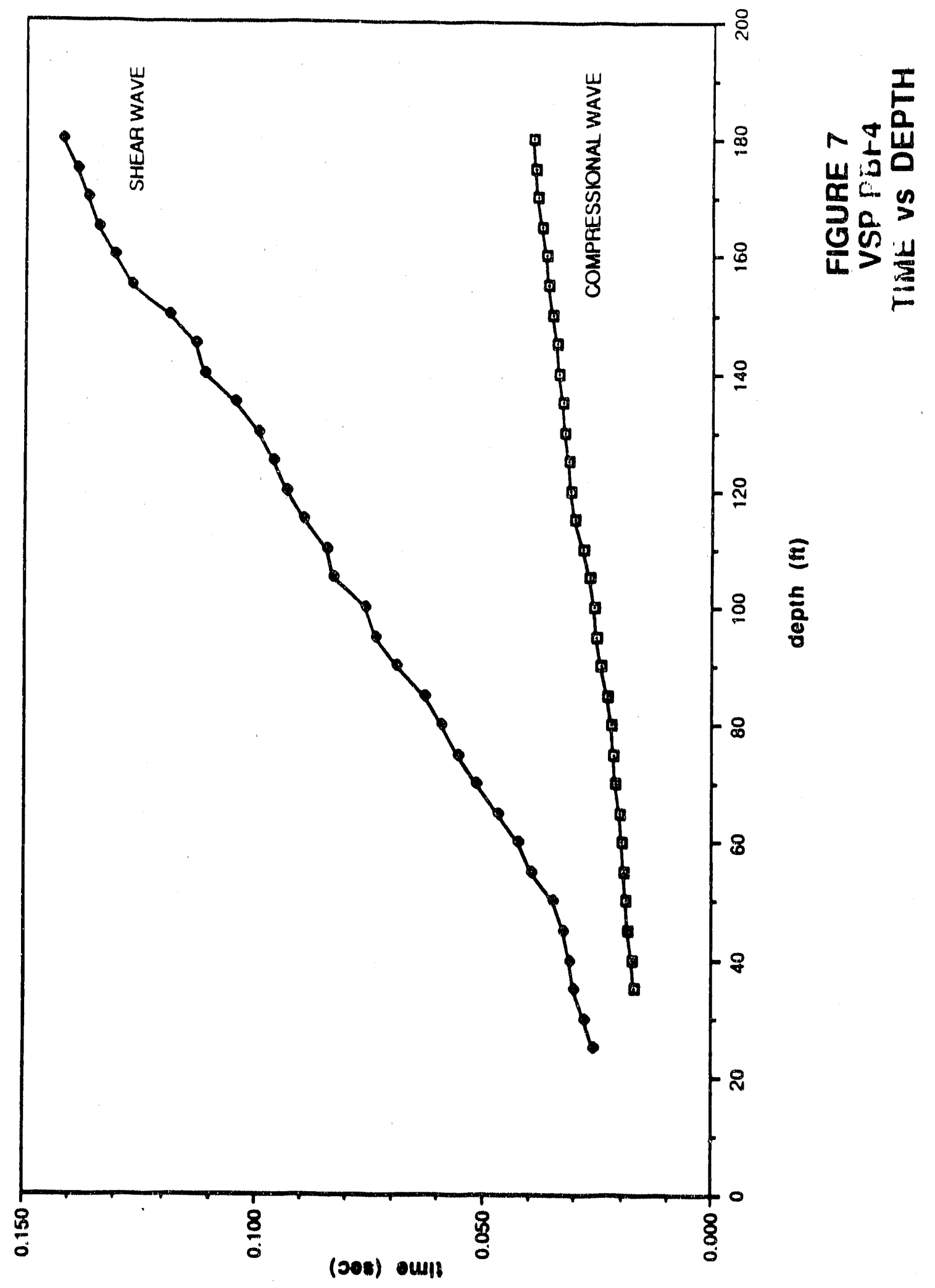




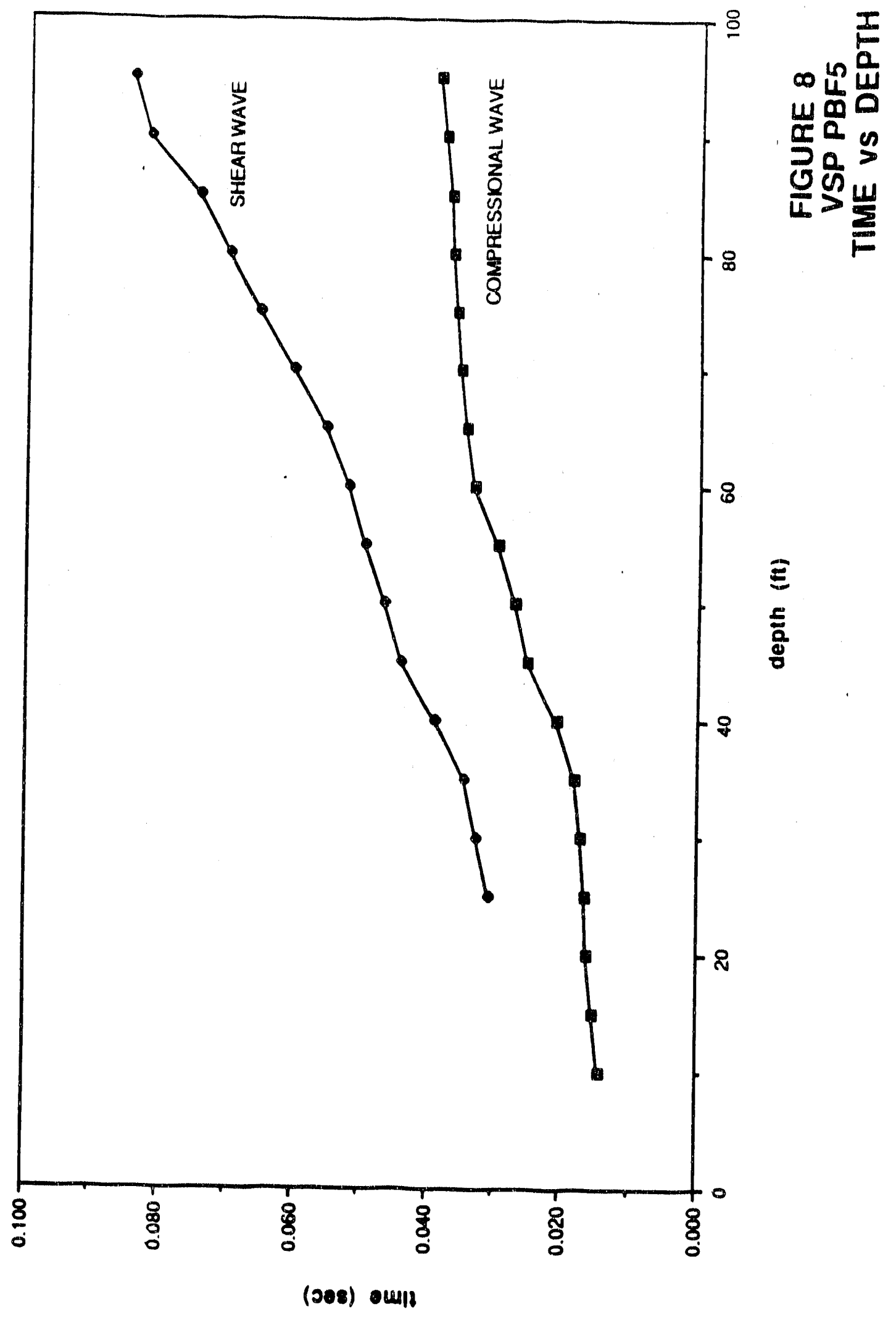




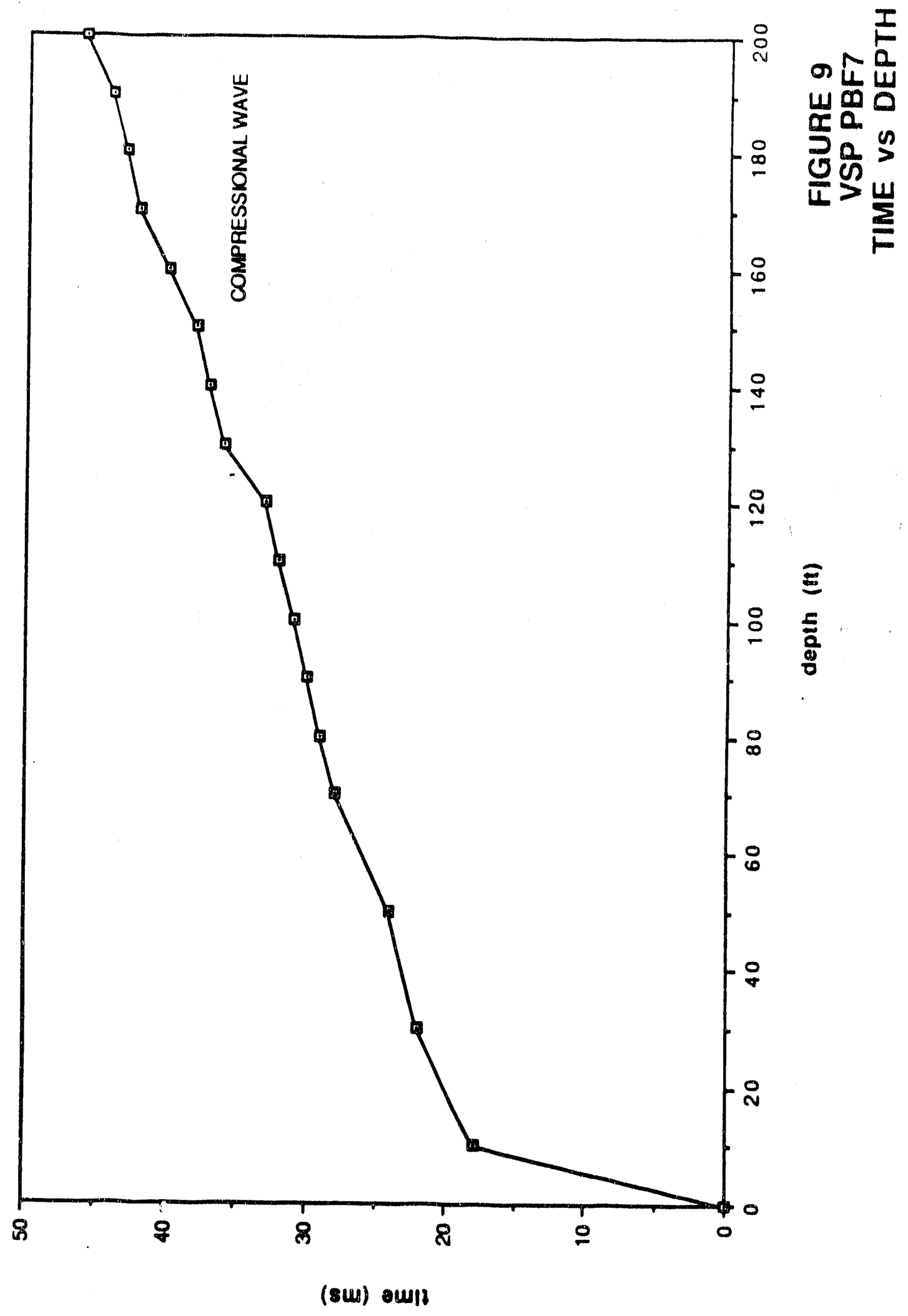




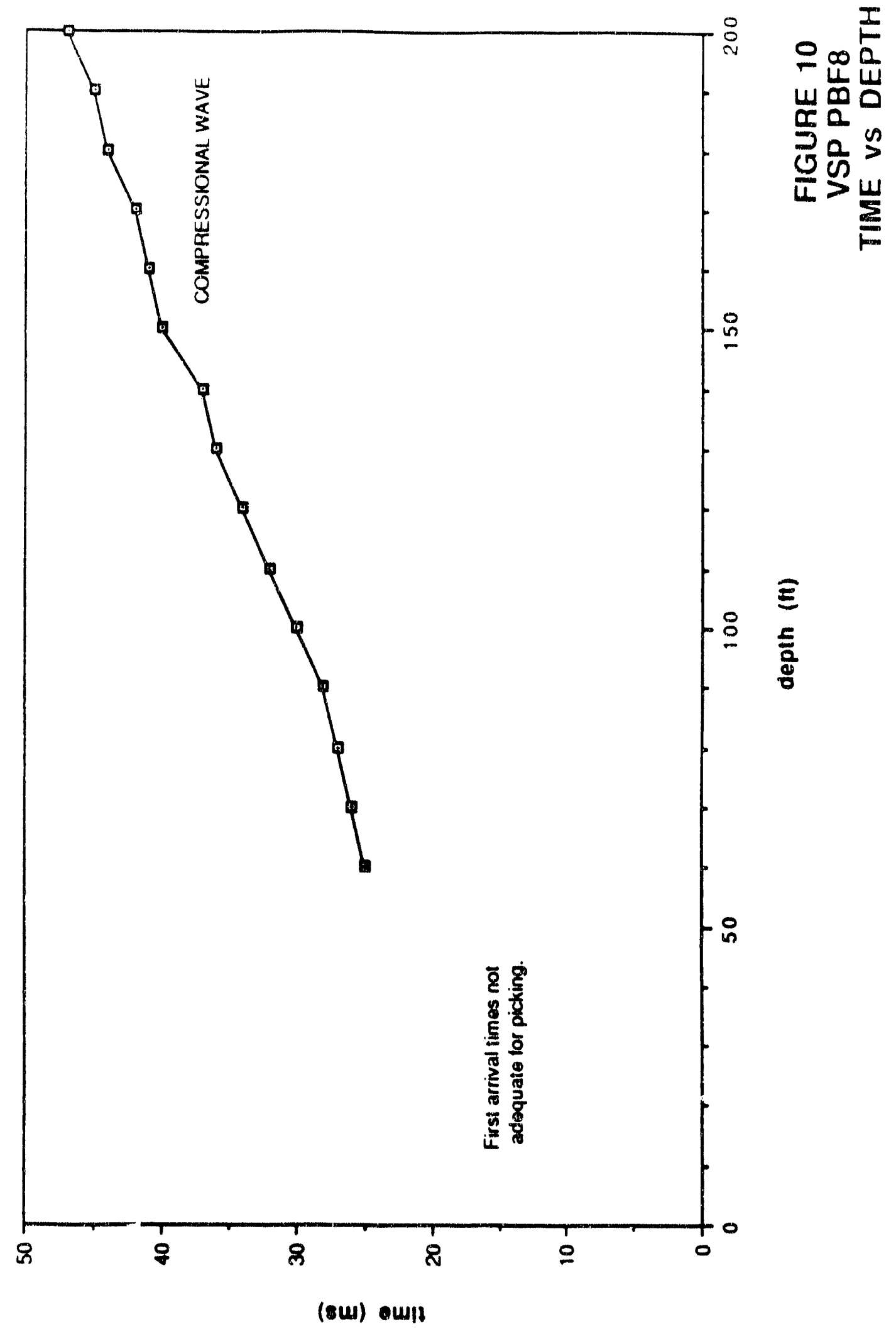




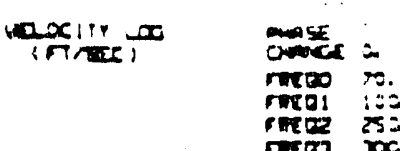

(con)

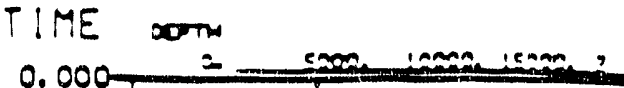


-ing

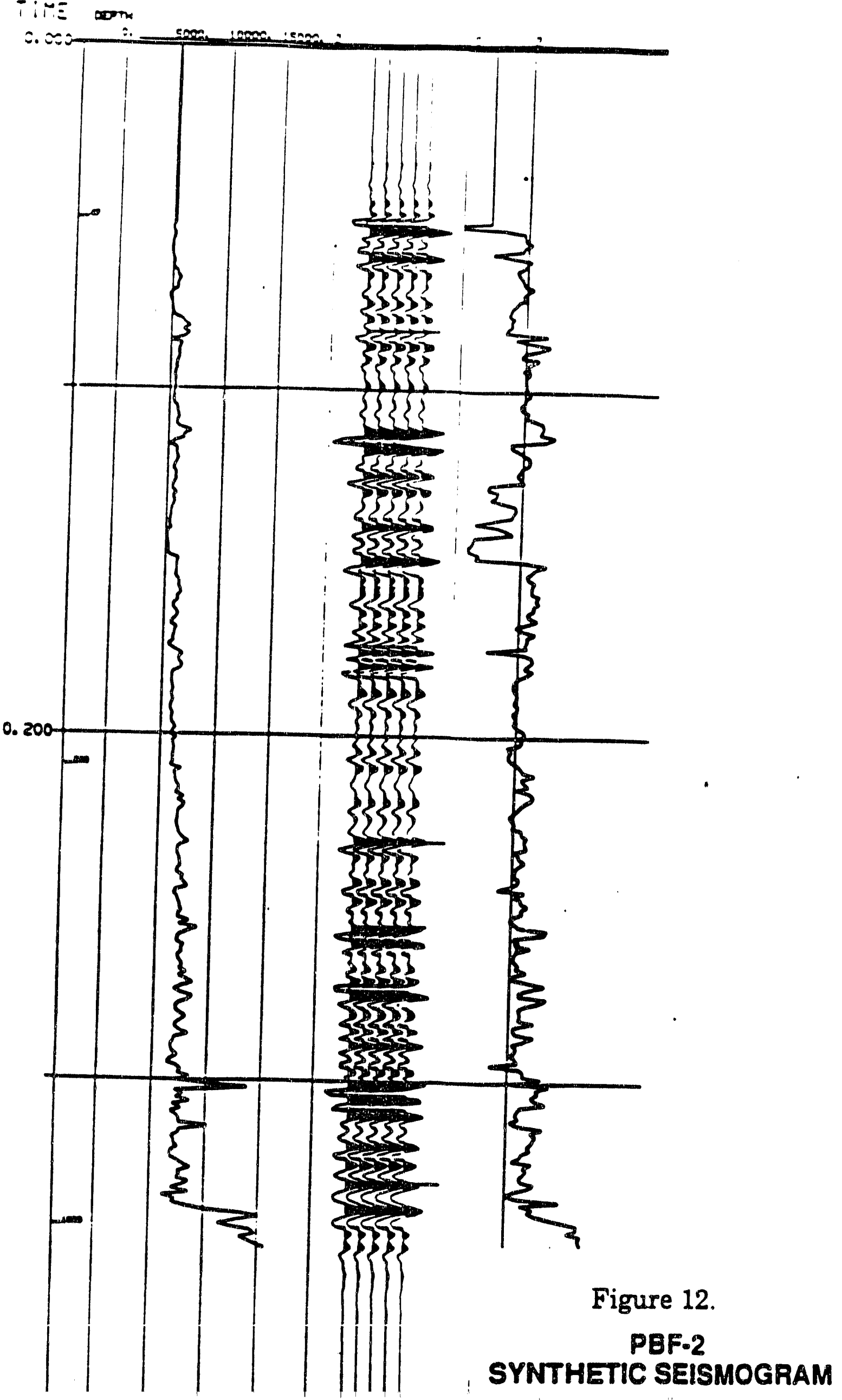




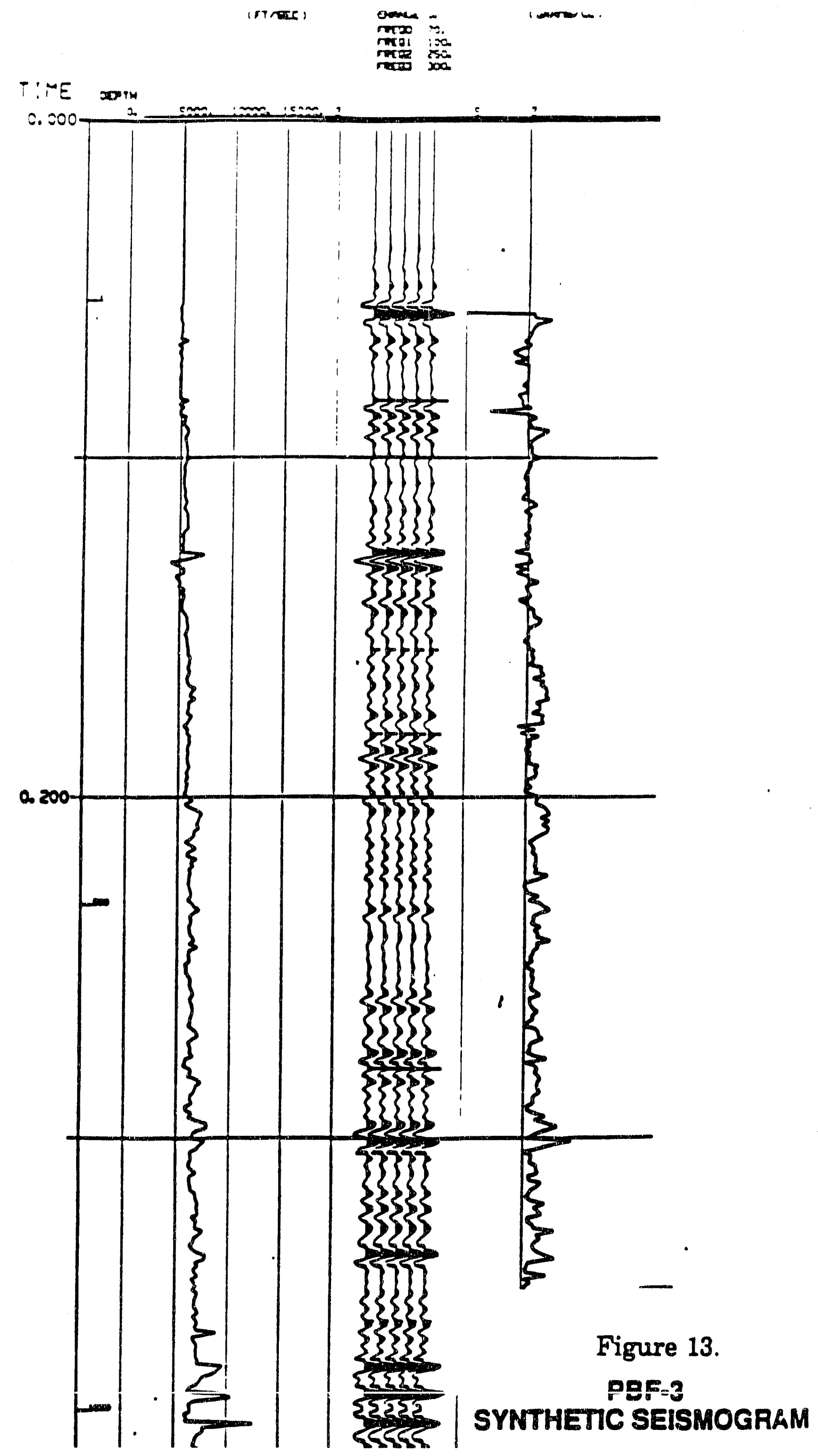




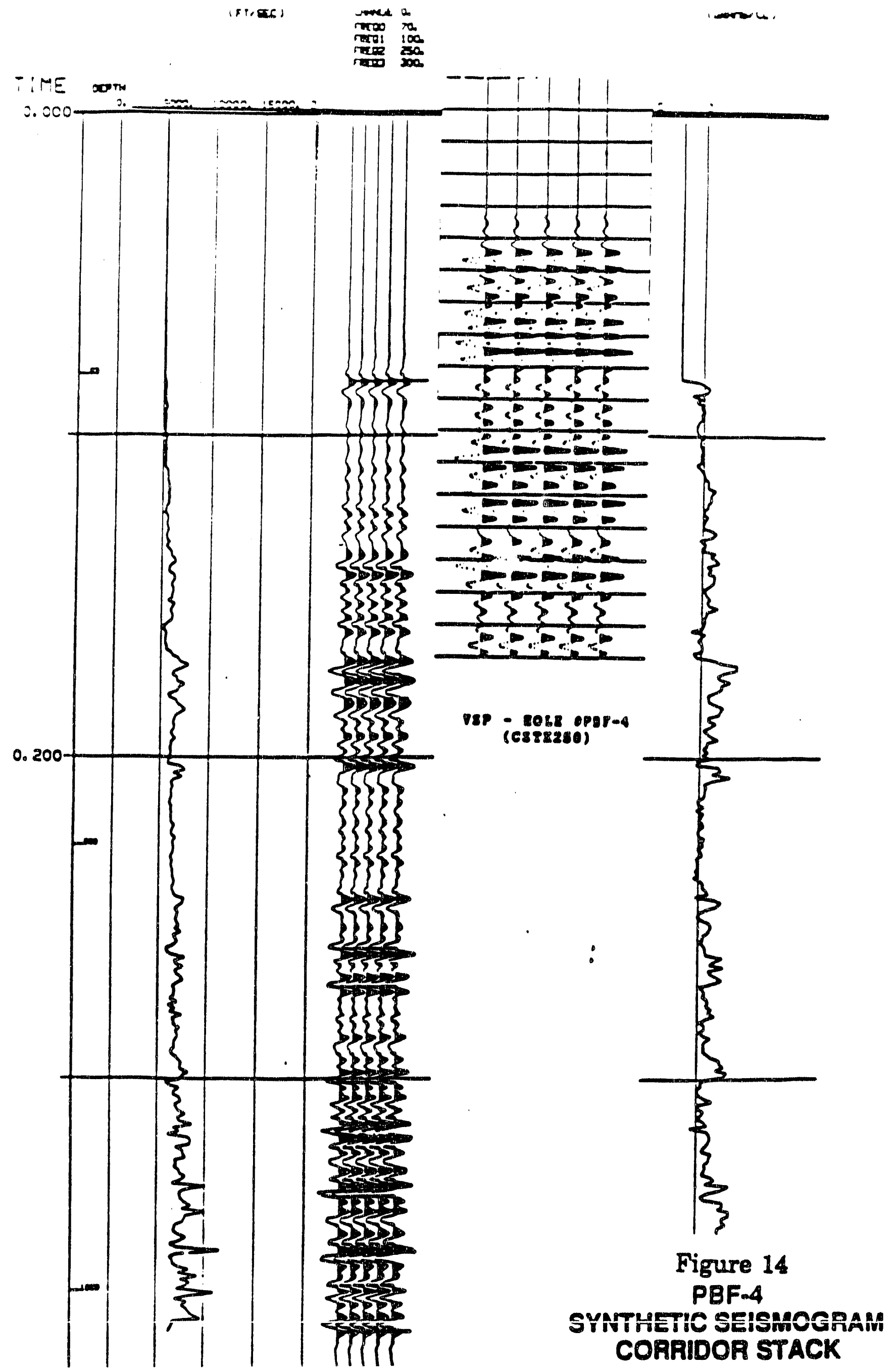




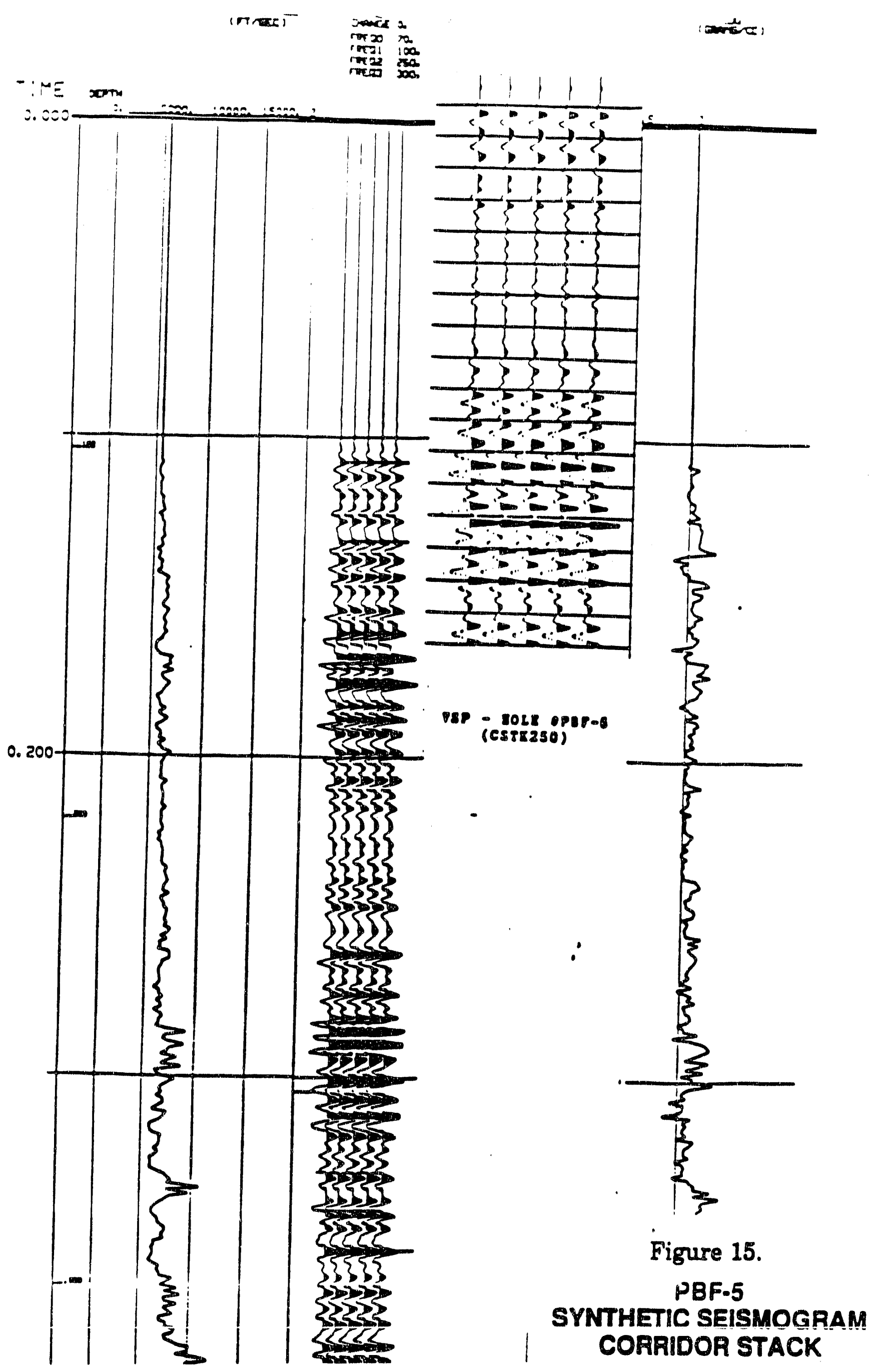




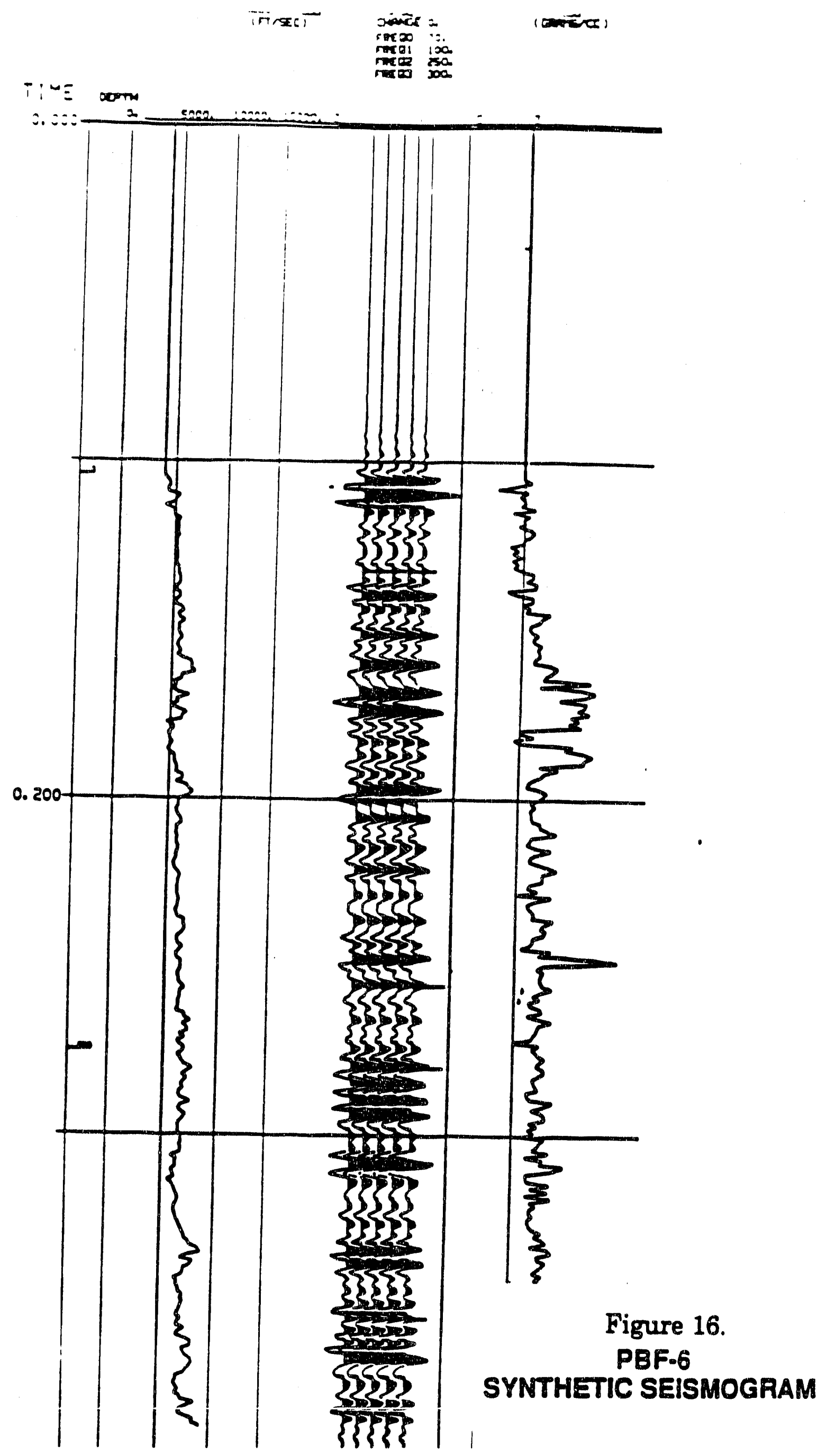






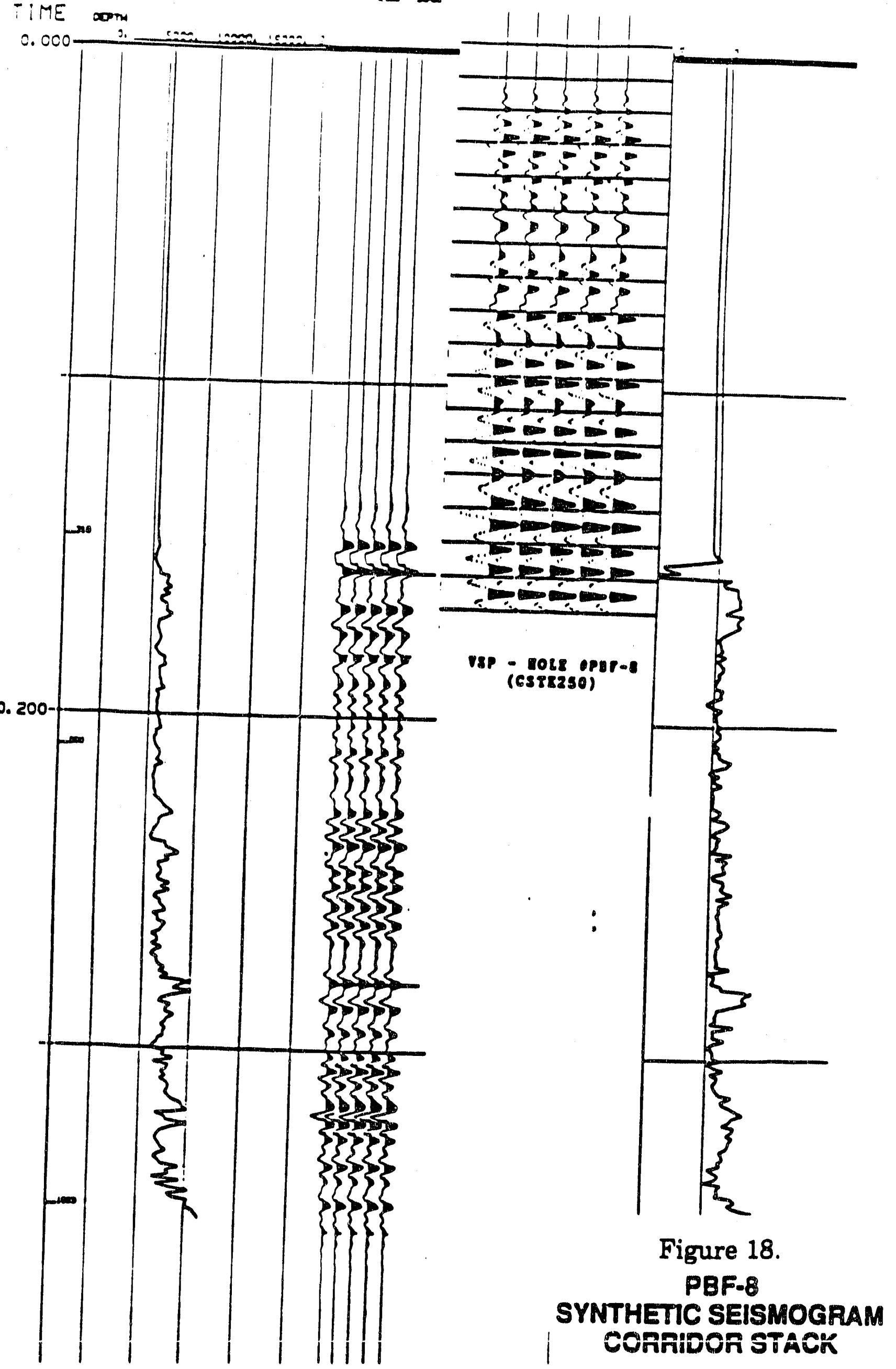




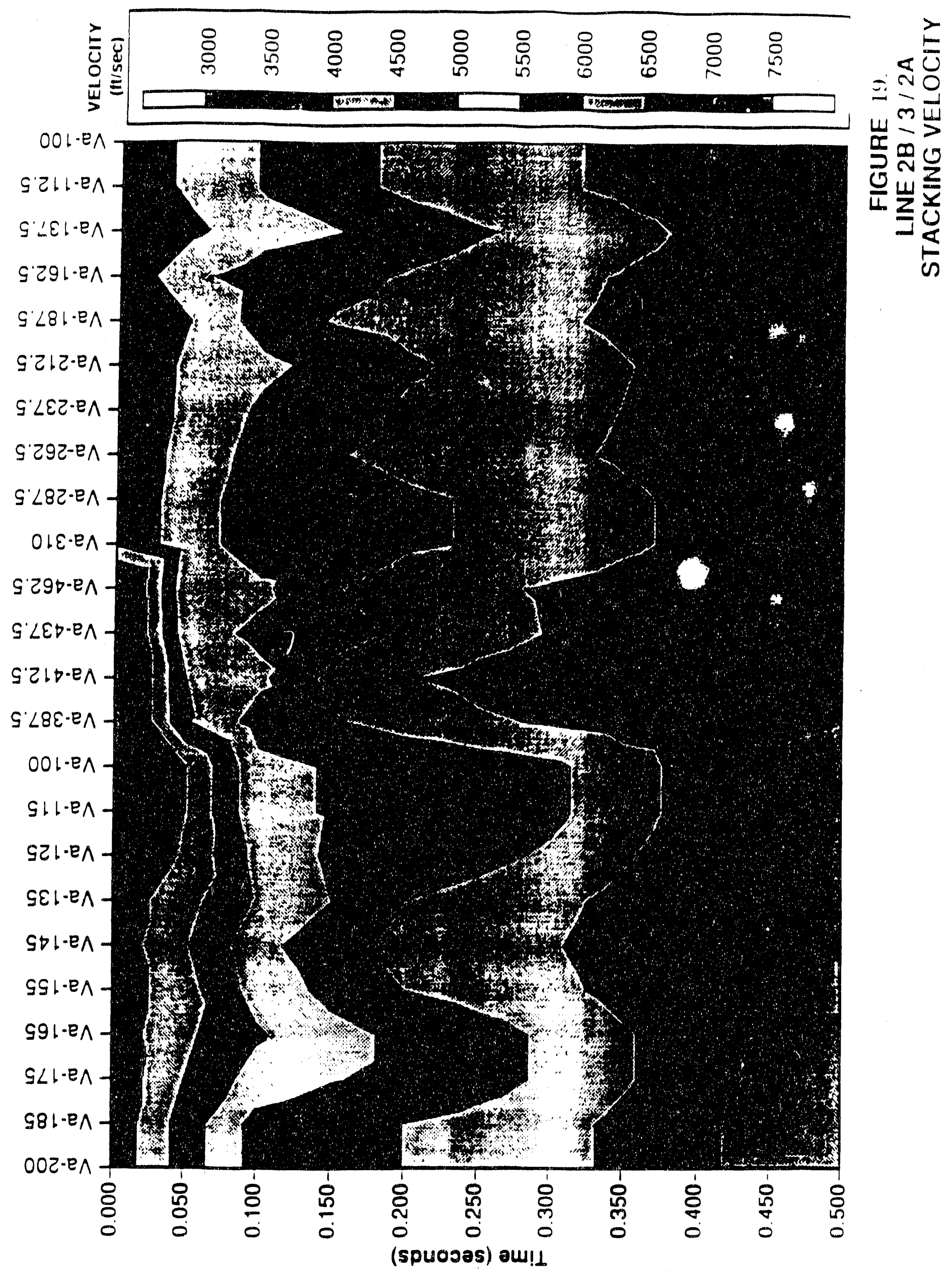




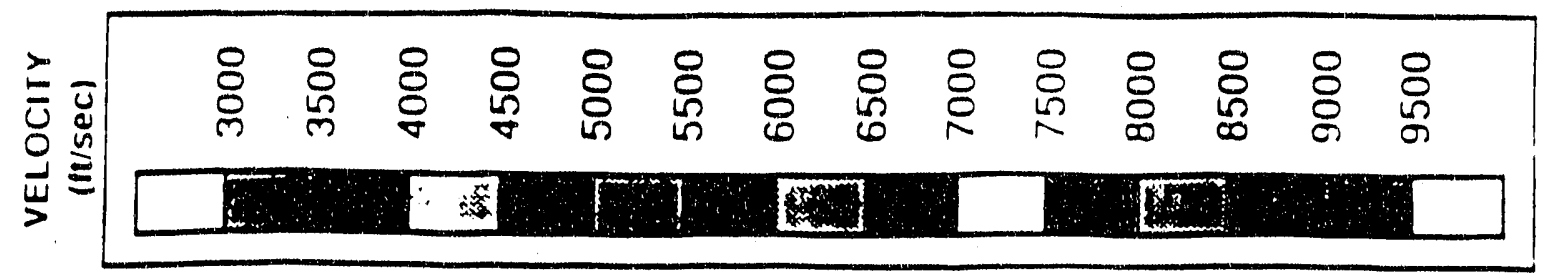

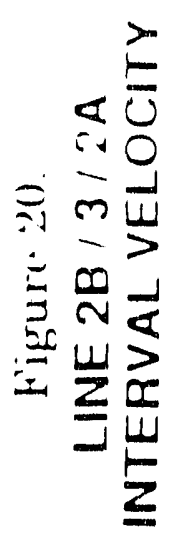

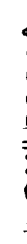

$00 b \cdot ! \Lambda$
$S \cdot 2 b \cdot ! \Lambda \Lambda$
$S \angle E b \cdot ! \Lambda$

$9 \cdot 29 ! \cdot 1 \wedge$

$9 \angle 8+\cdot 1 \Lambda-$

S'Z!Z:!^

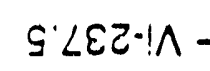

$9 \cdot 292 \cdot 1 \wedge$

$s \angle 82 \cdot 1 \wedge$

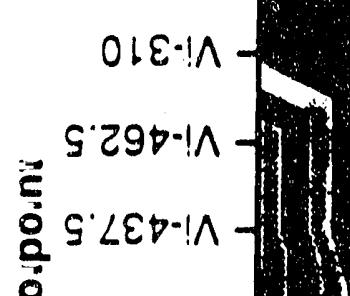

$s \cdot 2 ! t-1 \Lambda$ -

\section{$\mathrm{S}$}

$s<8 \varepsilon-1 \Lambda$

$001-11$

$s \sqcup-1 \Lambda-k^{2}$

Sटเ-!^-

SE $\vdash-1 \Lambda-$

s॰ $!-! \Lambda-$

SSเ-!n-

s9เ-!n-

$S \angle L-1 \Lambda-$

$\varsigma 8\llcorner\cdot ! \Lambda-$

$002 \cdot !$

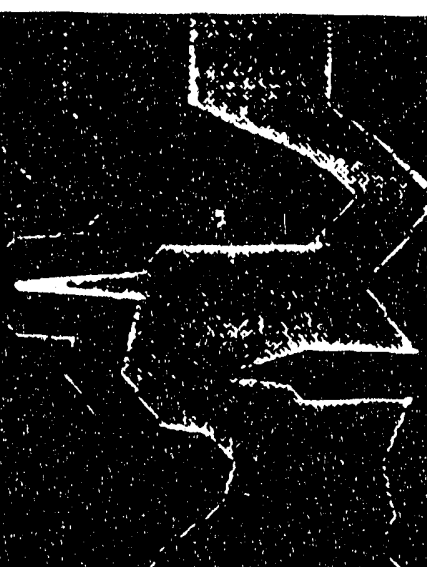

Fon

(1)

$+\infty+2$

(n)

rys

.

( $)$

$+2$

s

$-2$

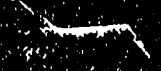

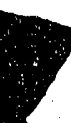

(n)

is 3 s

N - -

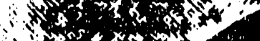

3

(x)

(x)

a d

os $3 x$

(1) $-2 x y$

Is

(3)

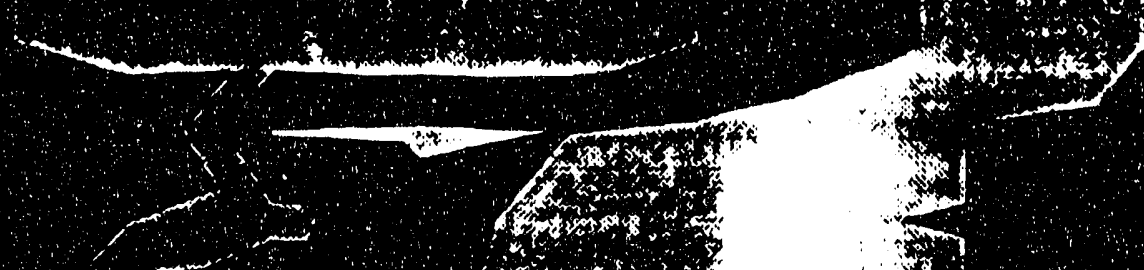

2

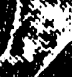

2

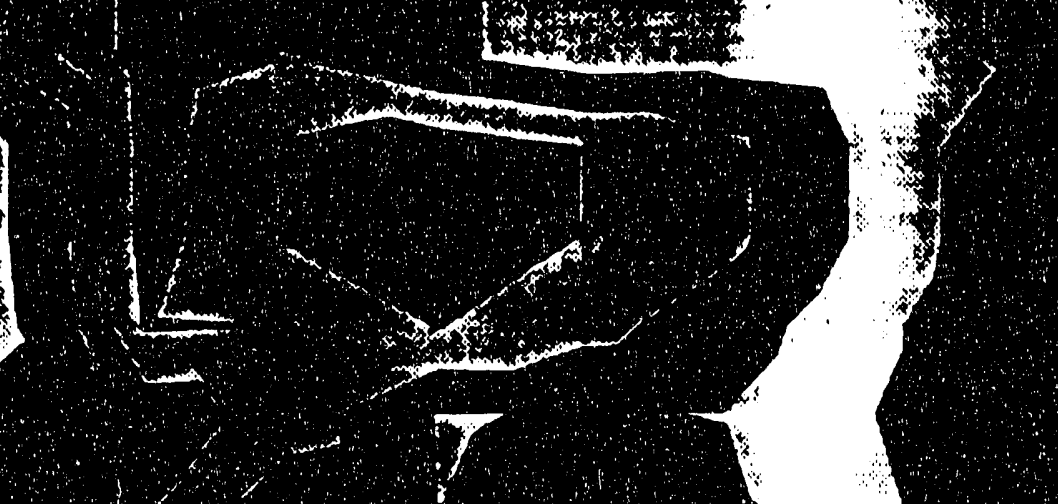

.

m

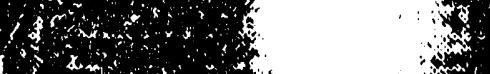

and 
(oos) $\exists W I L$

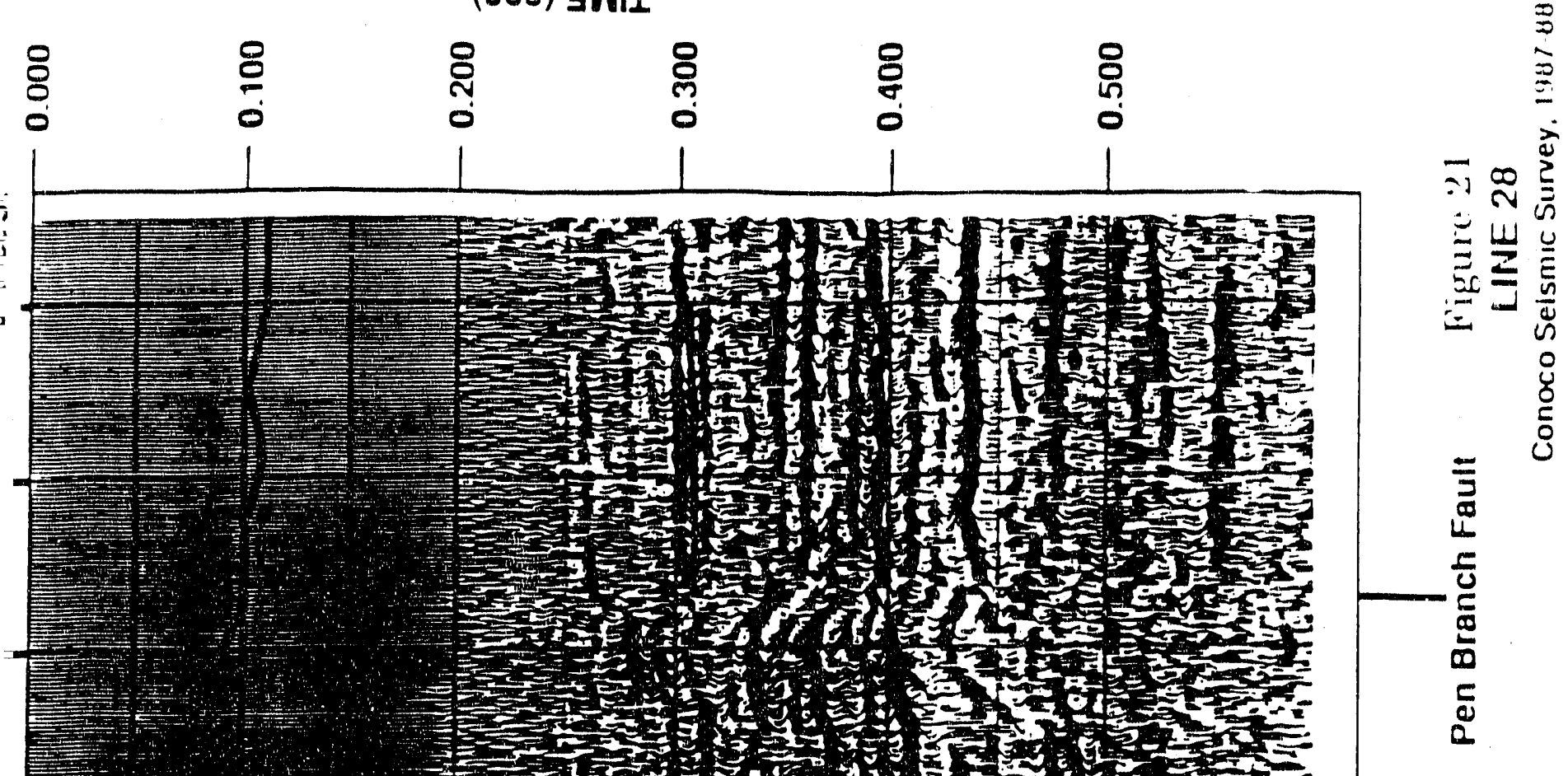




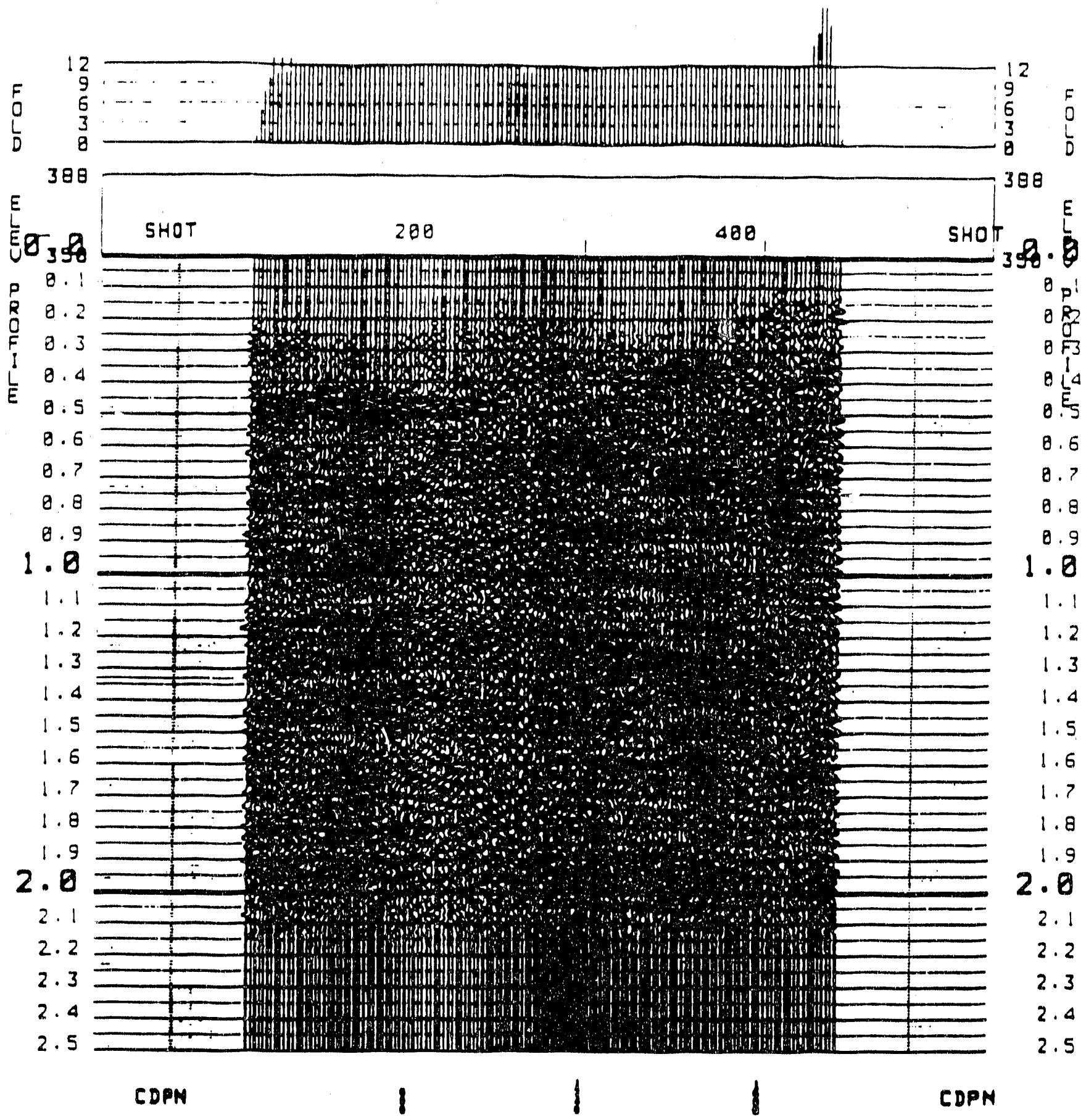




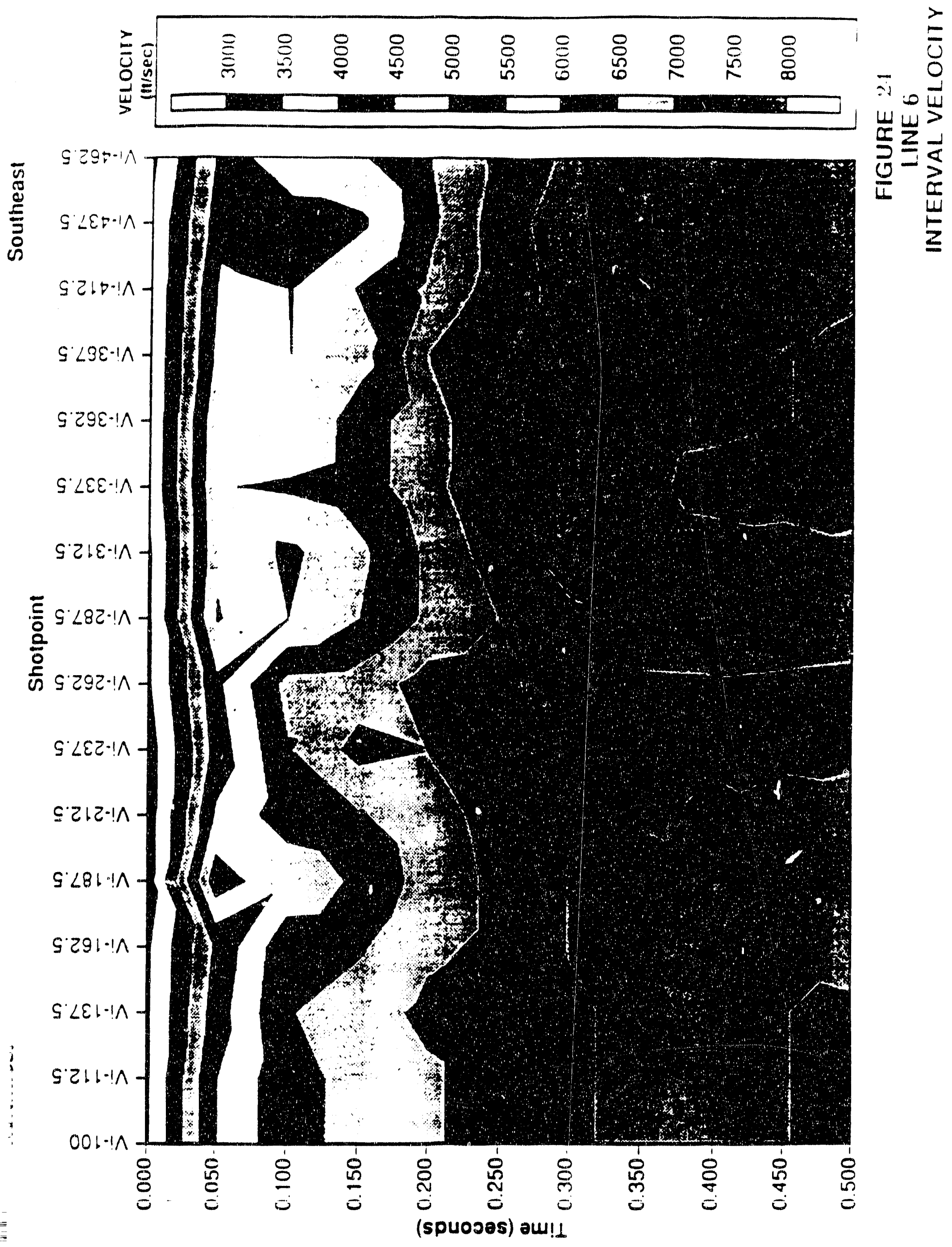




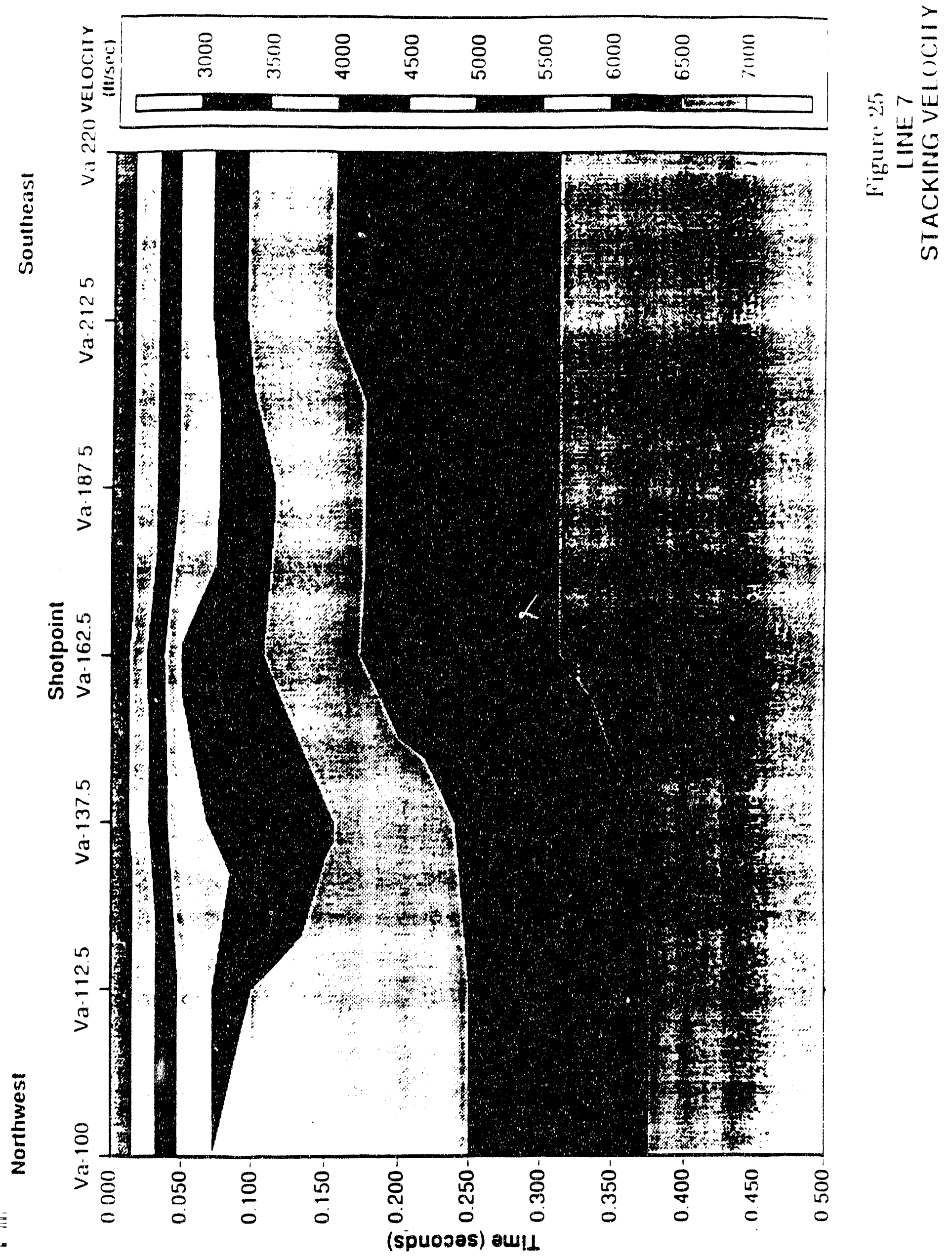




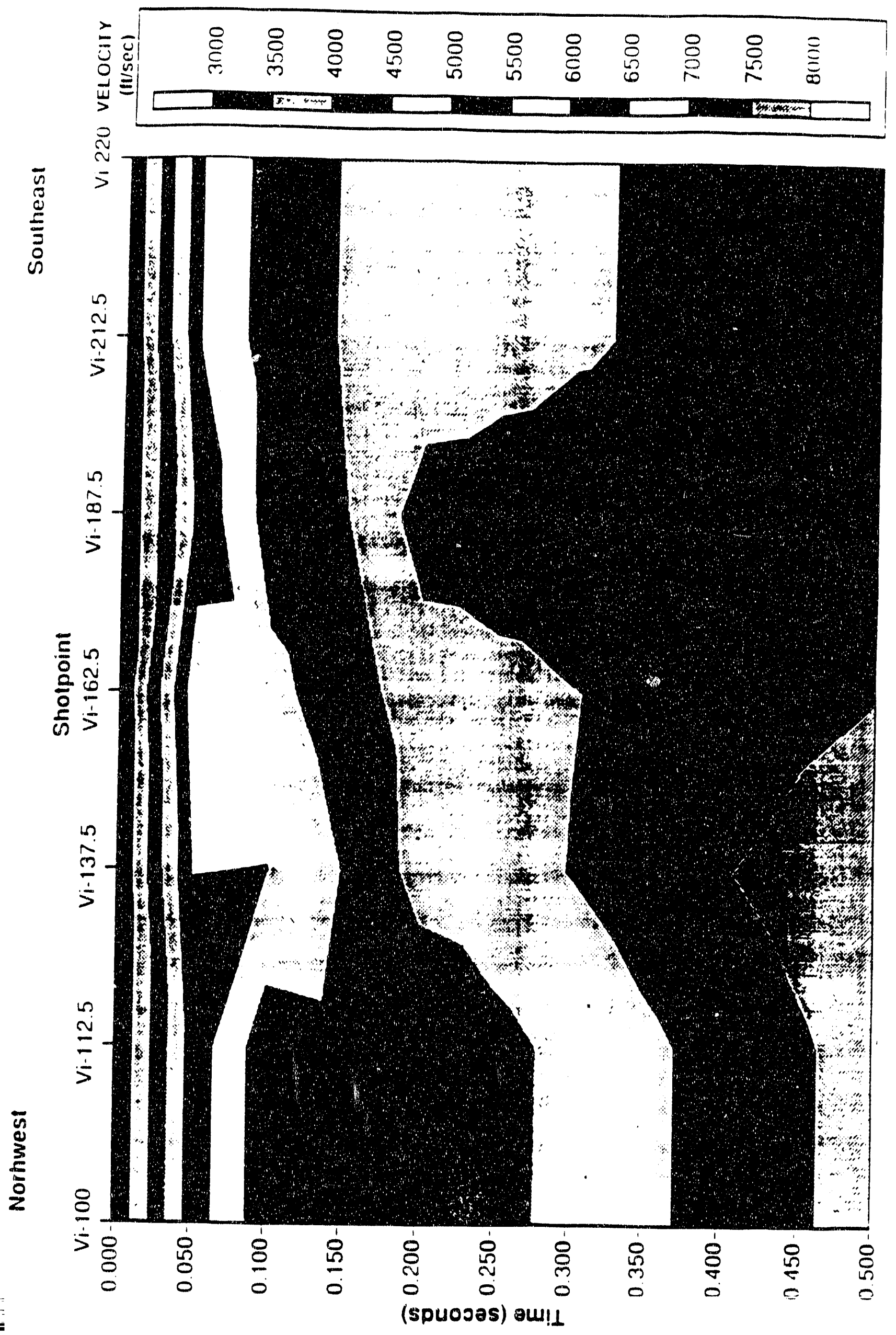

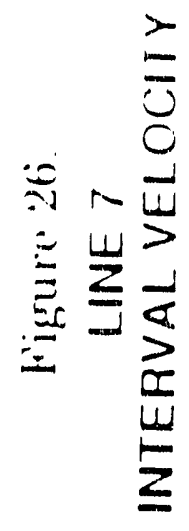








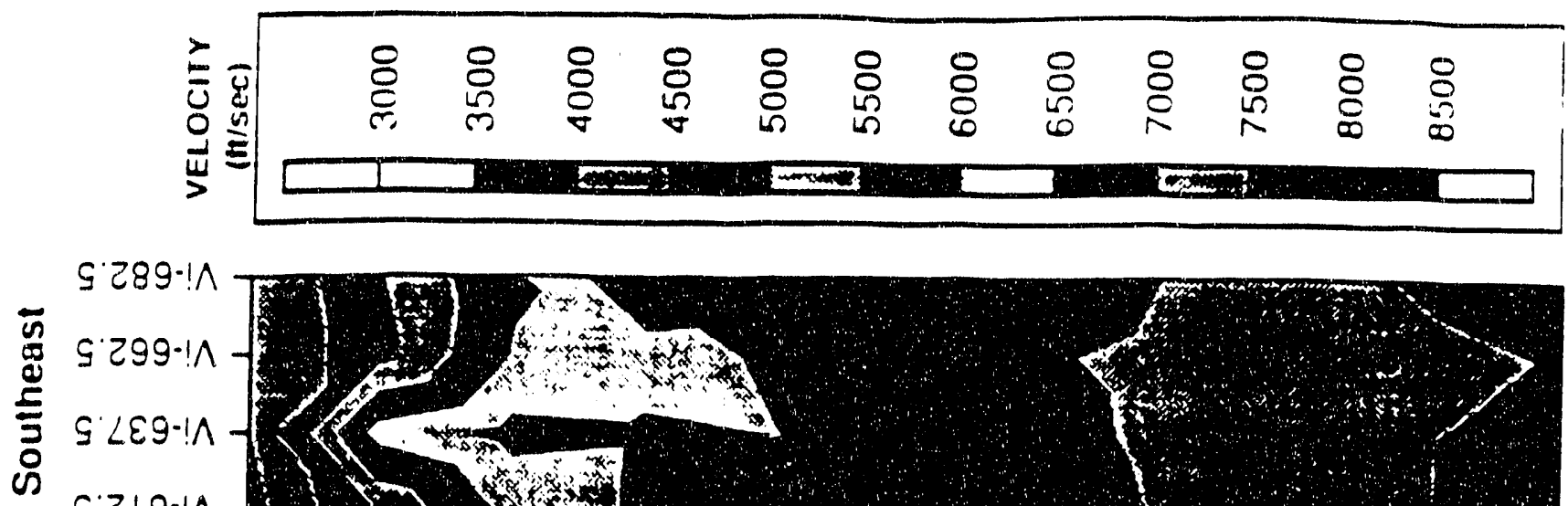

289.1

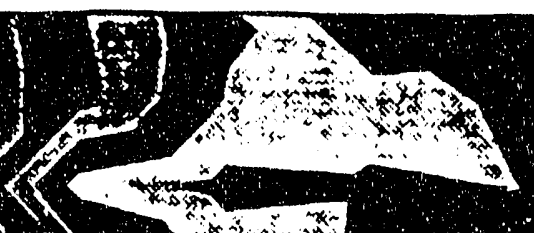









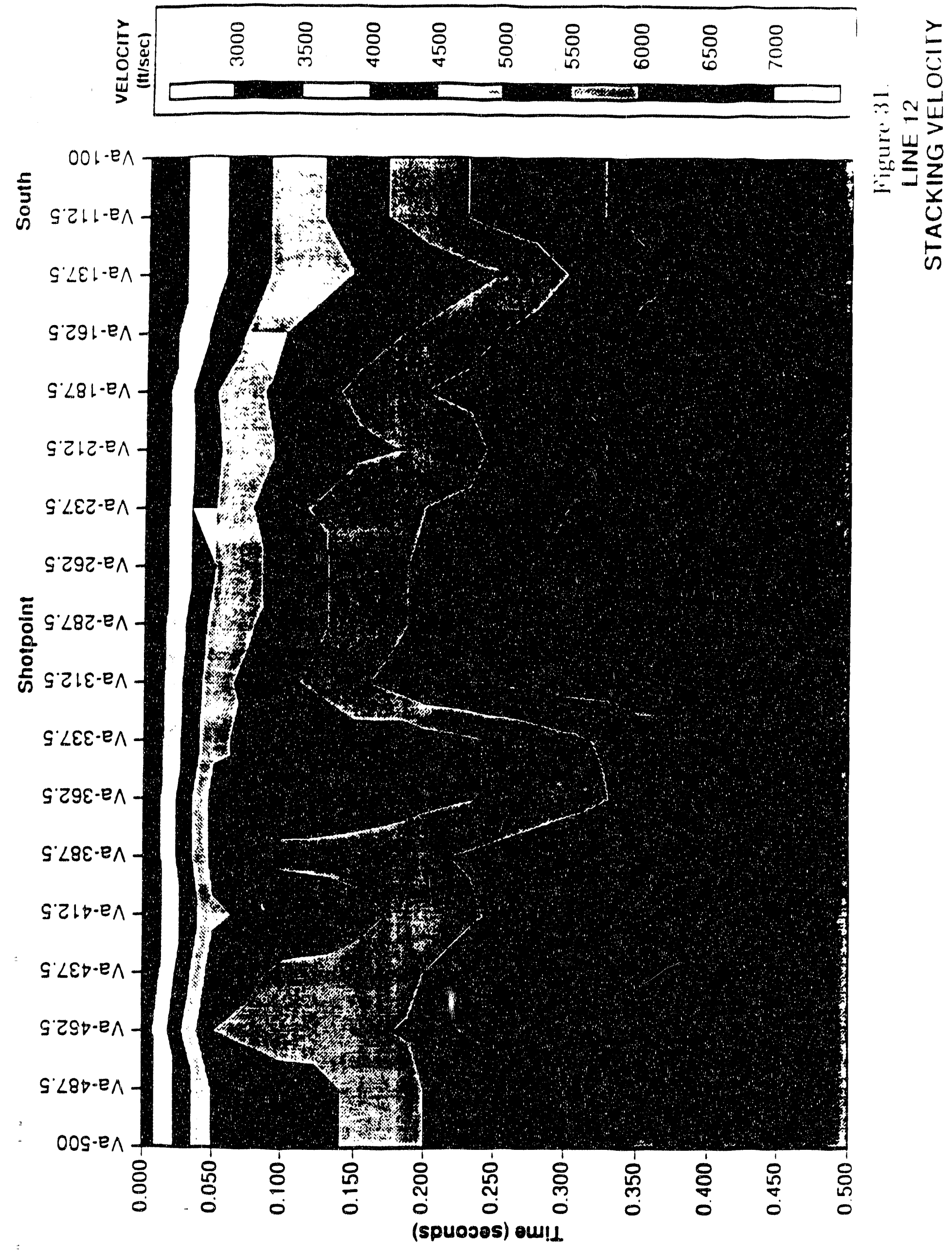




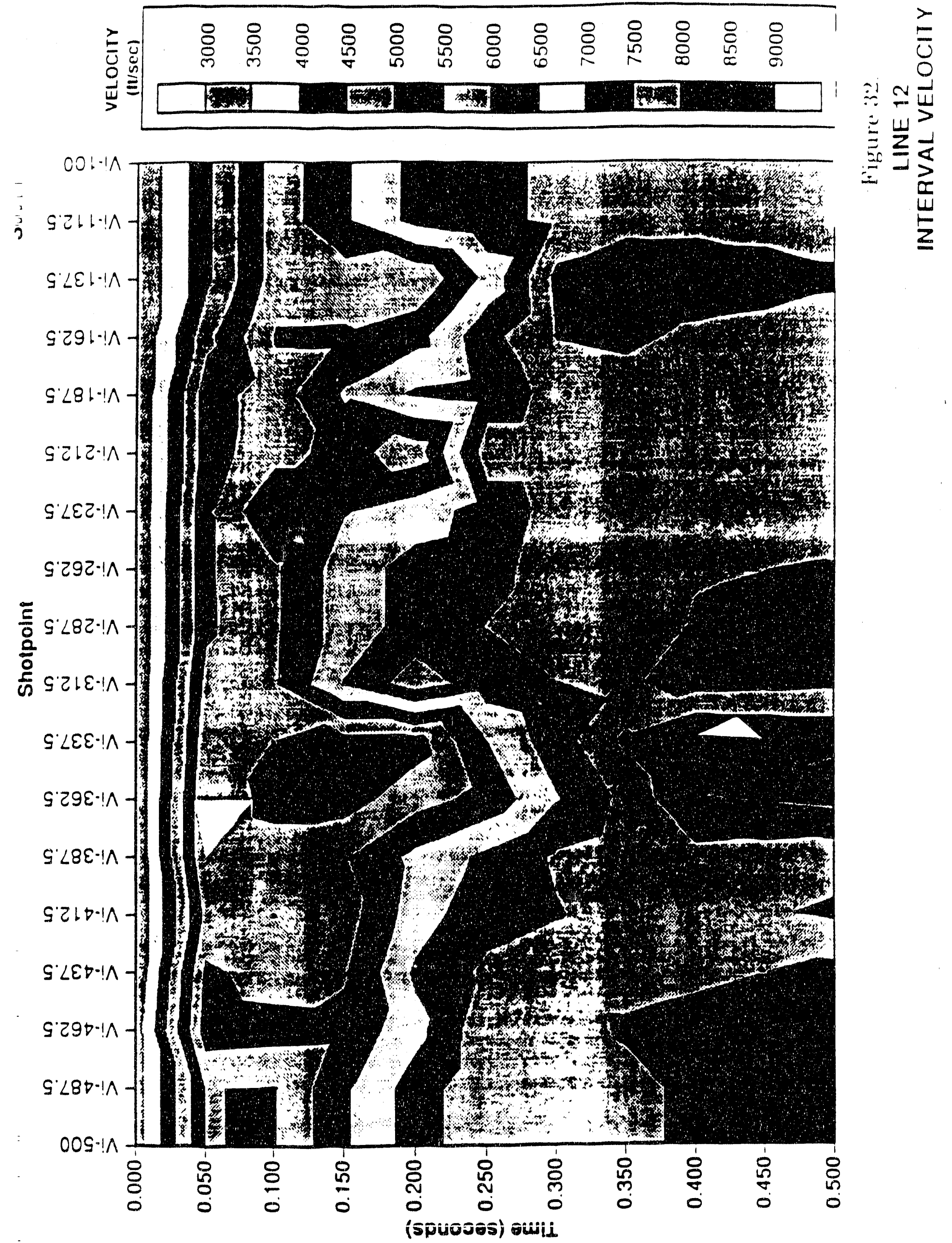


(วas) $\exists W I 1$

$\begin{array}{llllll}0 & 0 & 0 & 0 & 8 & 0 \\ 0 & 0 & 0 & 0 & 0 \\ 0 & 0 & 0 & 0 & 0 & 0\end{array}$

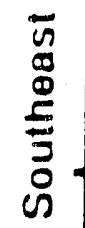

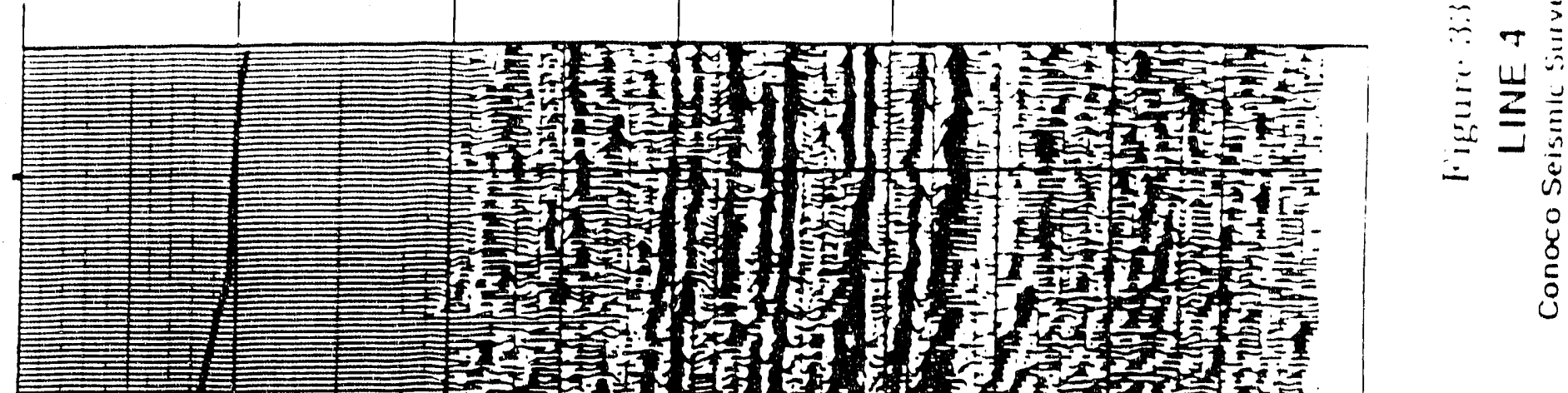

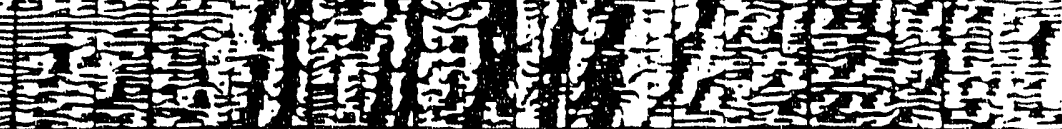

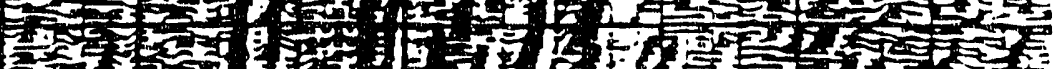

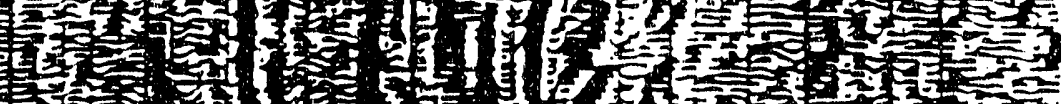

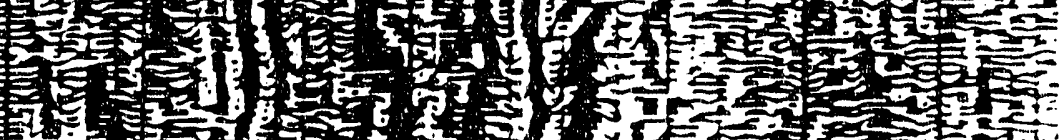
(a)

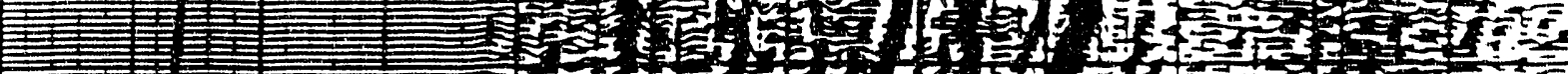

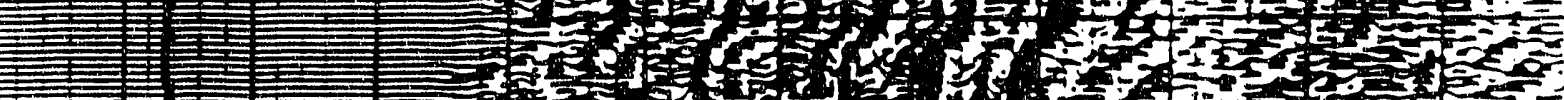
(2) (1)

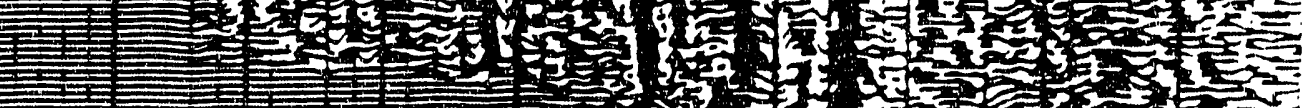
10 1 (2) (1)

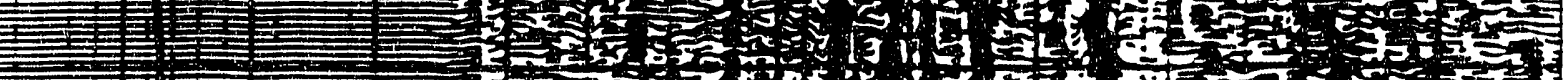
( )

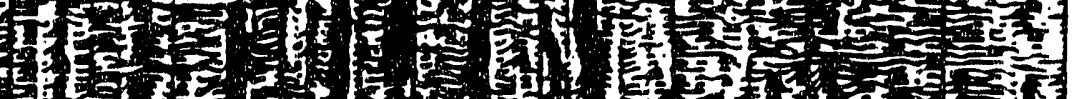

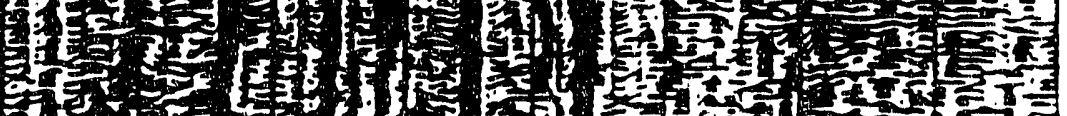

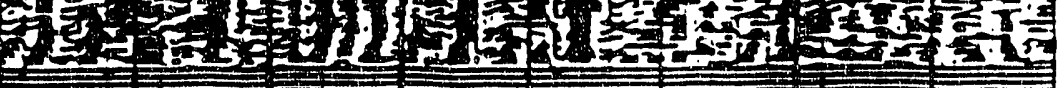

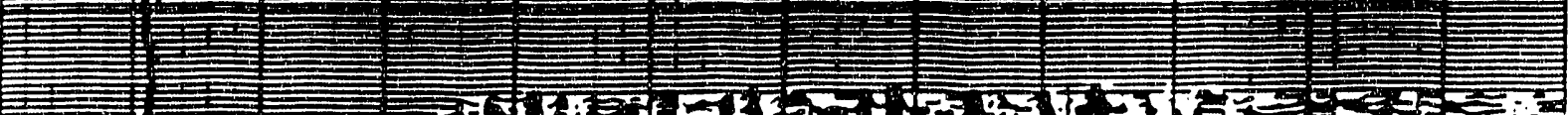
1210

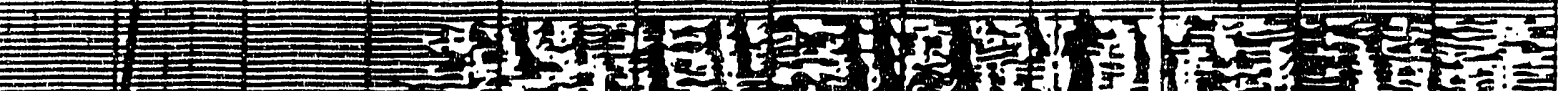

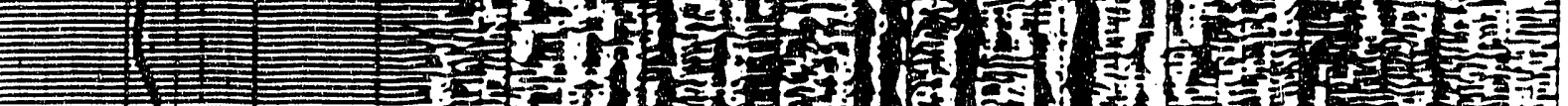

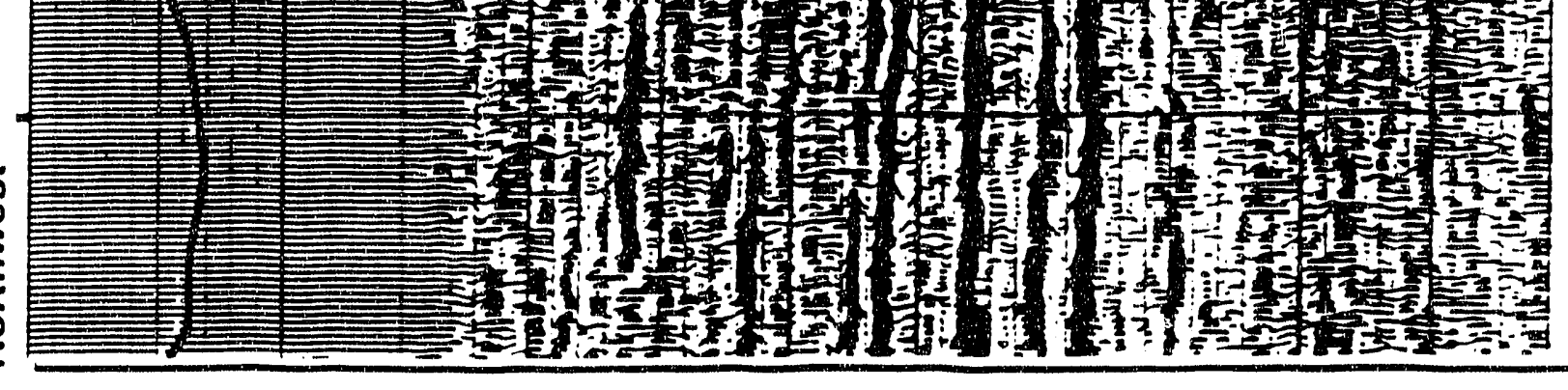




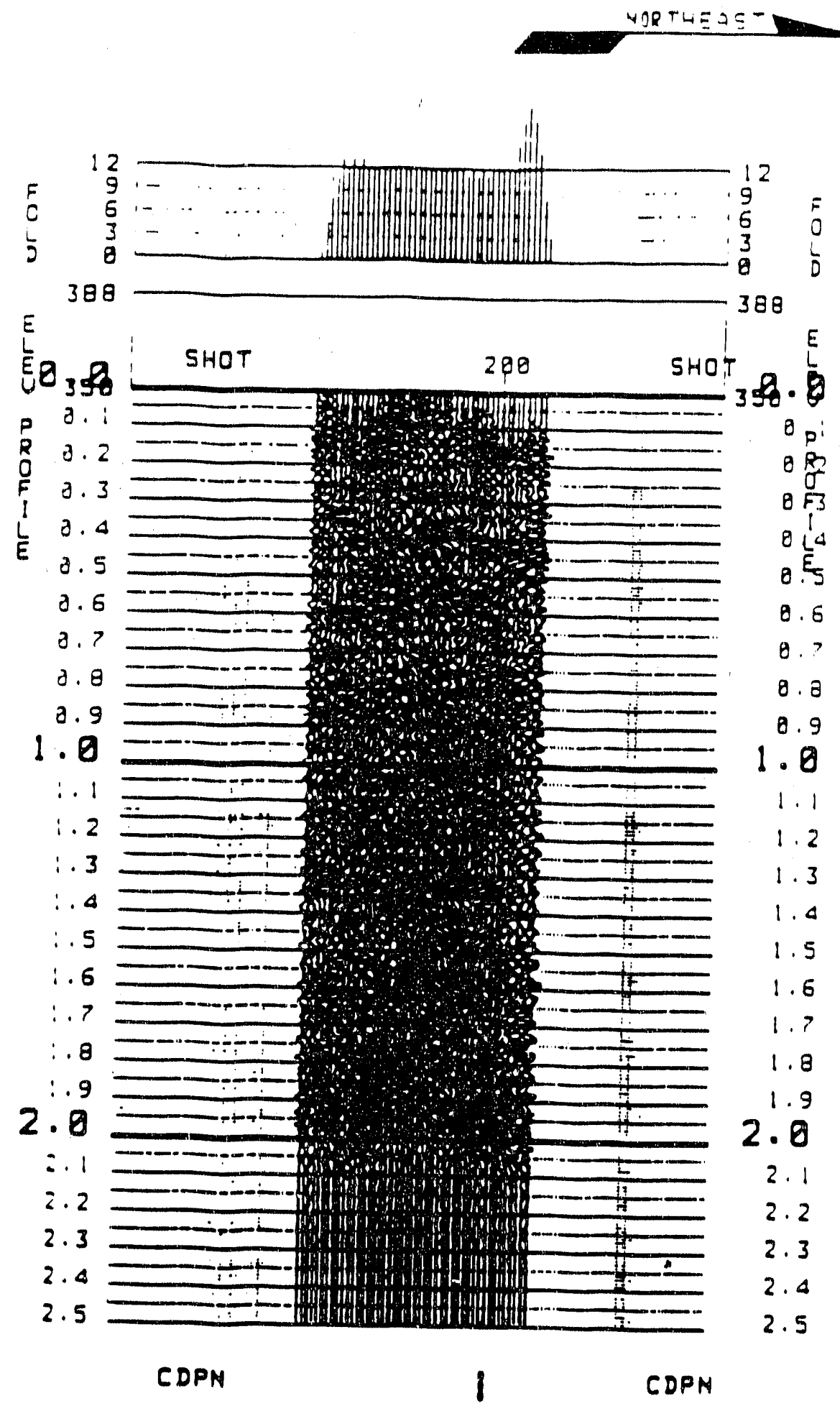

Figure 34. LNNE 13 - REDUCED AND DECIMATED 


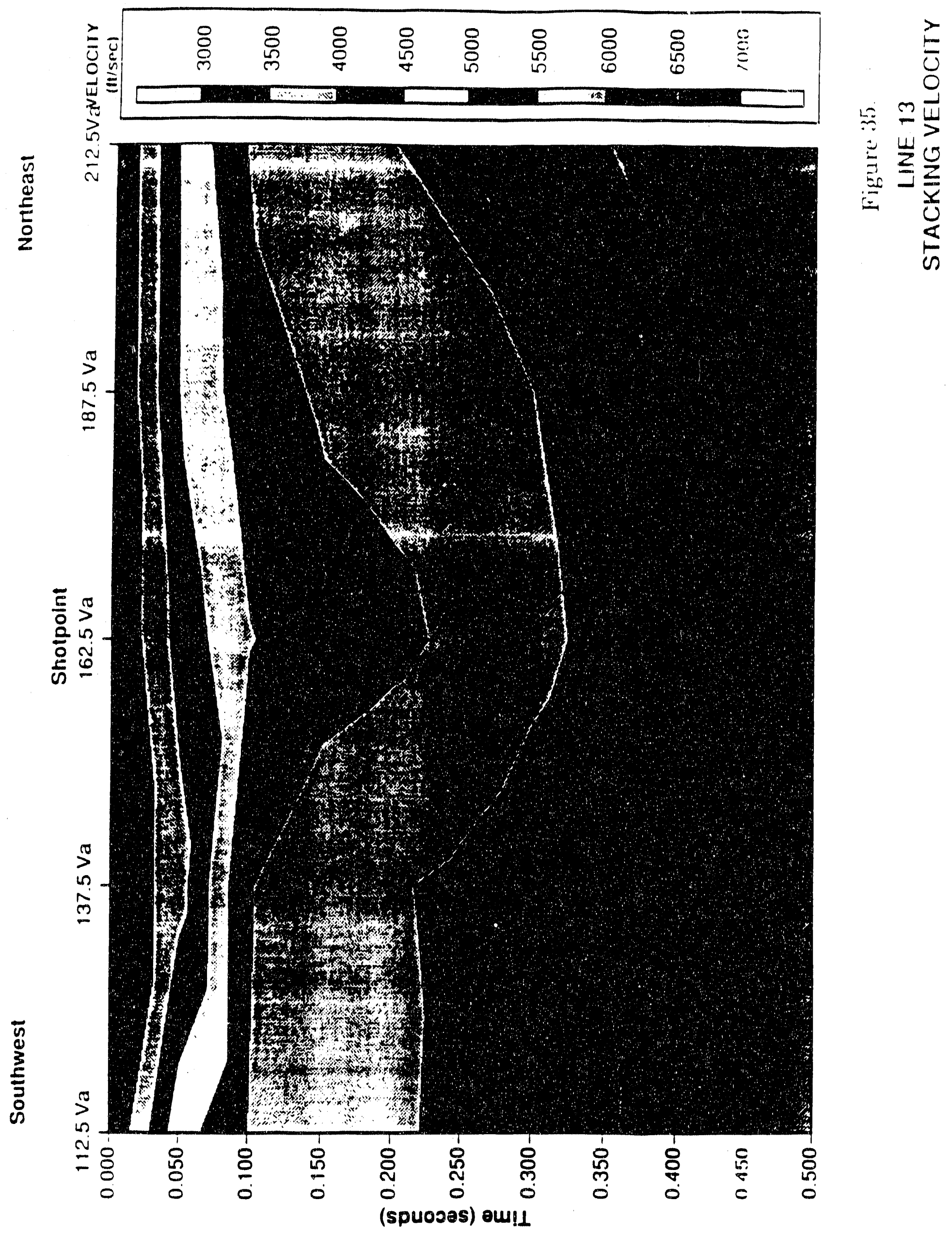







(oəs) $\exists W I \perp$

$\begin{array}{llllll}8 & 0 & 8 & 8 & 0 & 0 \\ 0 & 0 & 0 & 0 & 0 \\ 0 & 0 & 0 & 0 & 0 & 0\end{array}$

$\overline{5}$

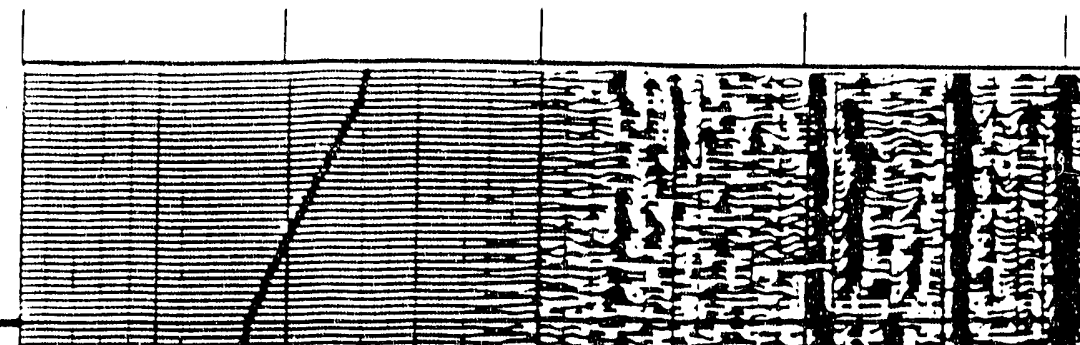



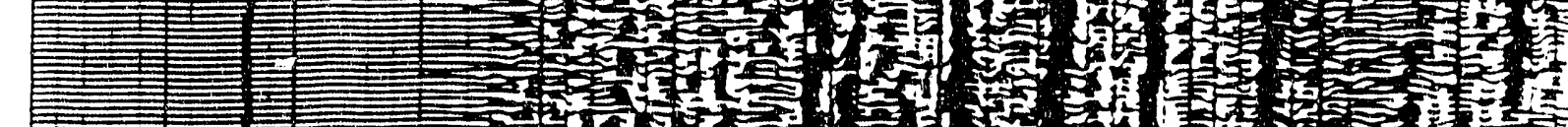
1

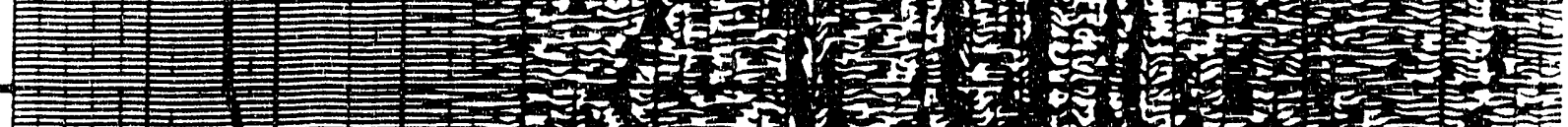

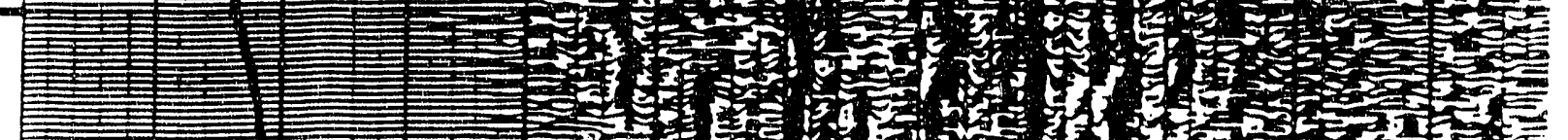

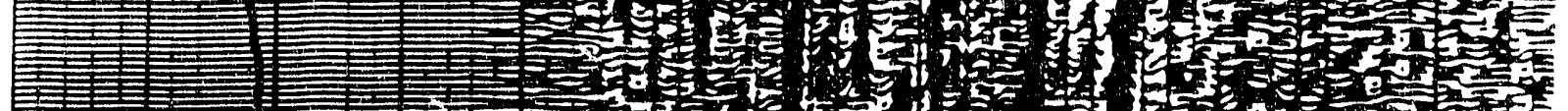
2 (2) (

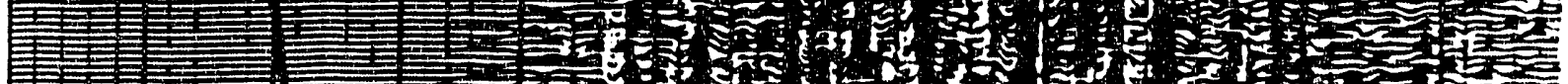
10

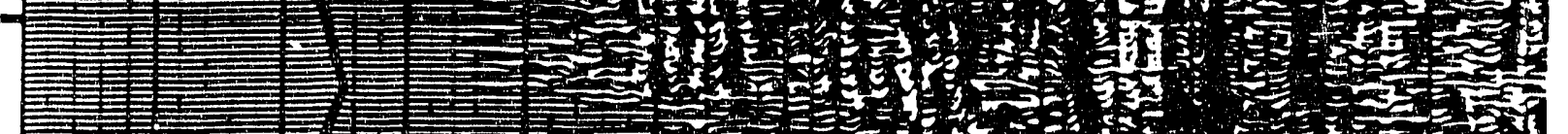

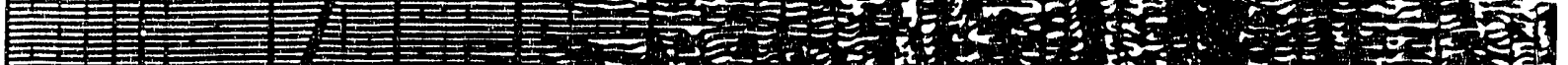

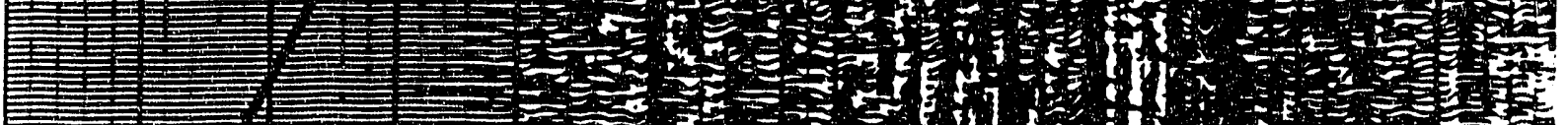
2

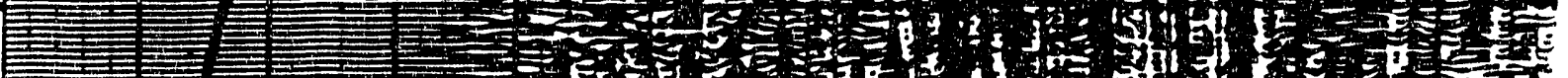
2

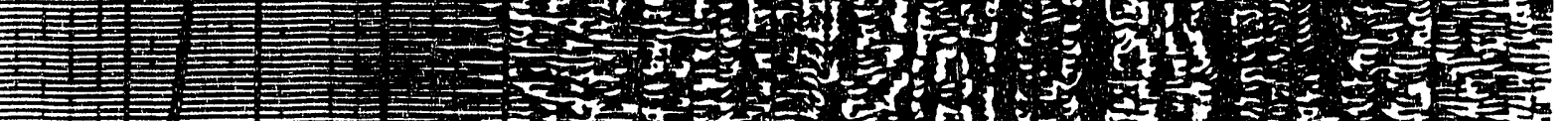
2 (2)

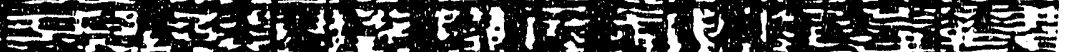
ary (5y)

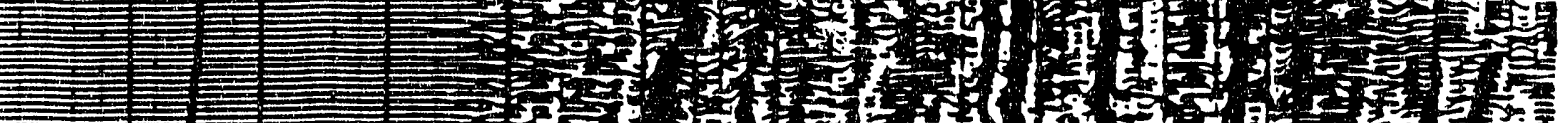

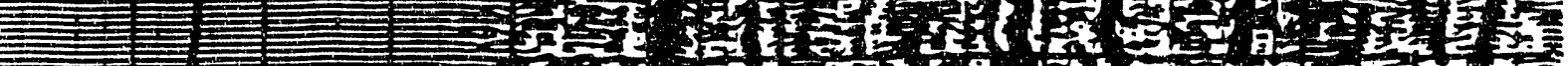

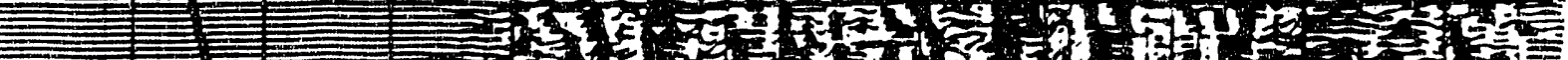

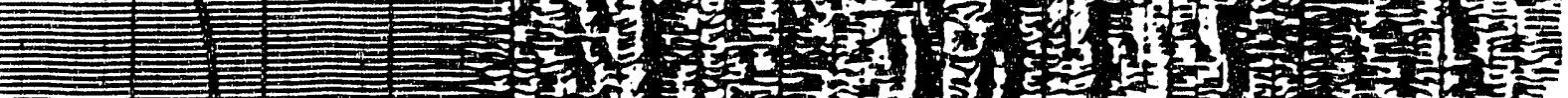

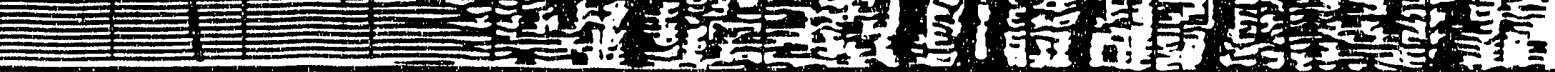




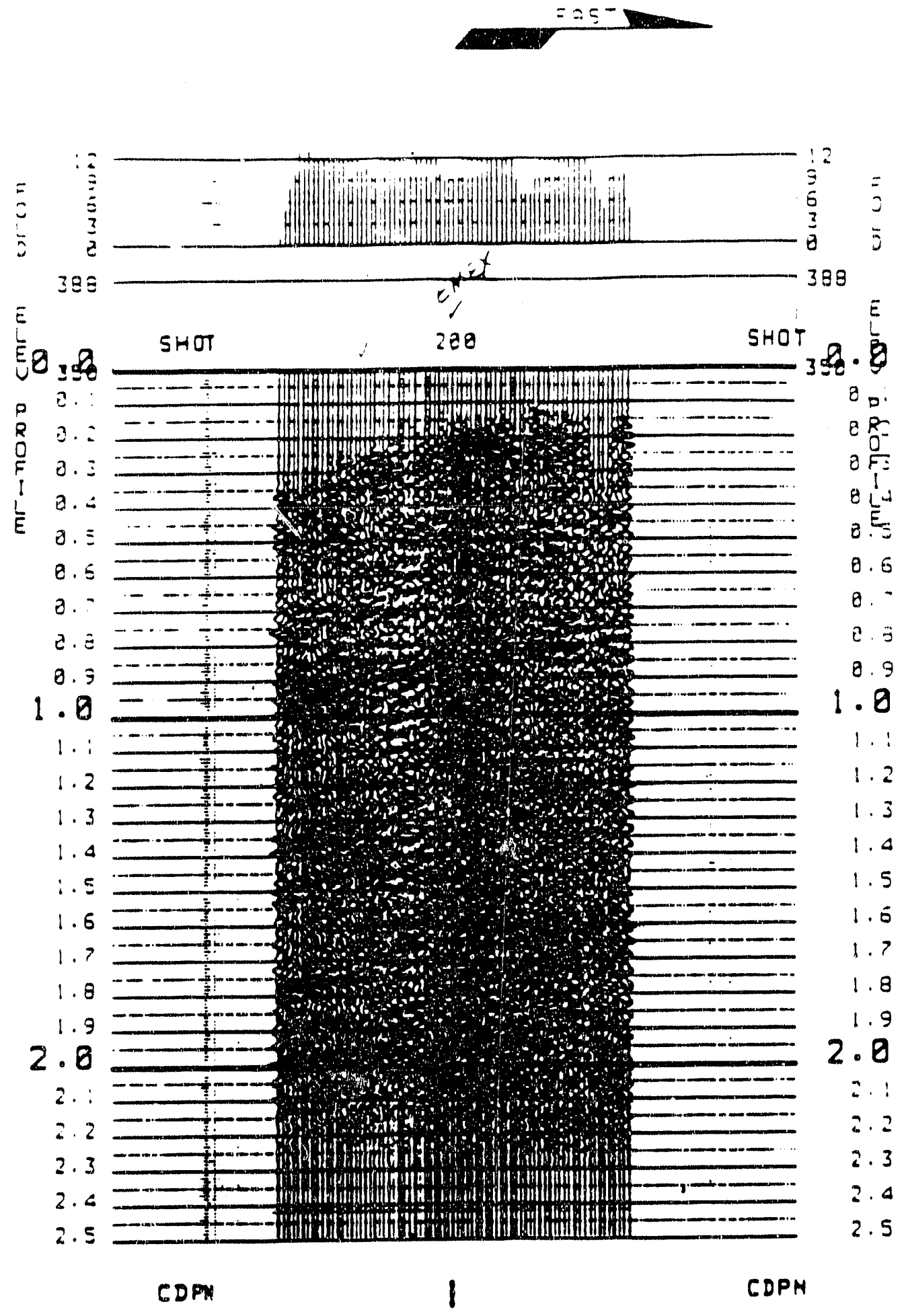

'os', '

Figure 38. LINE 14 - REDUCED AND DECIMATED 


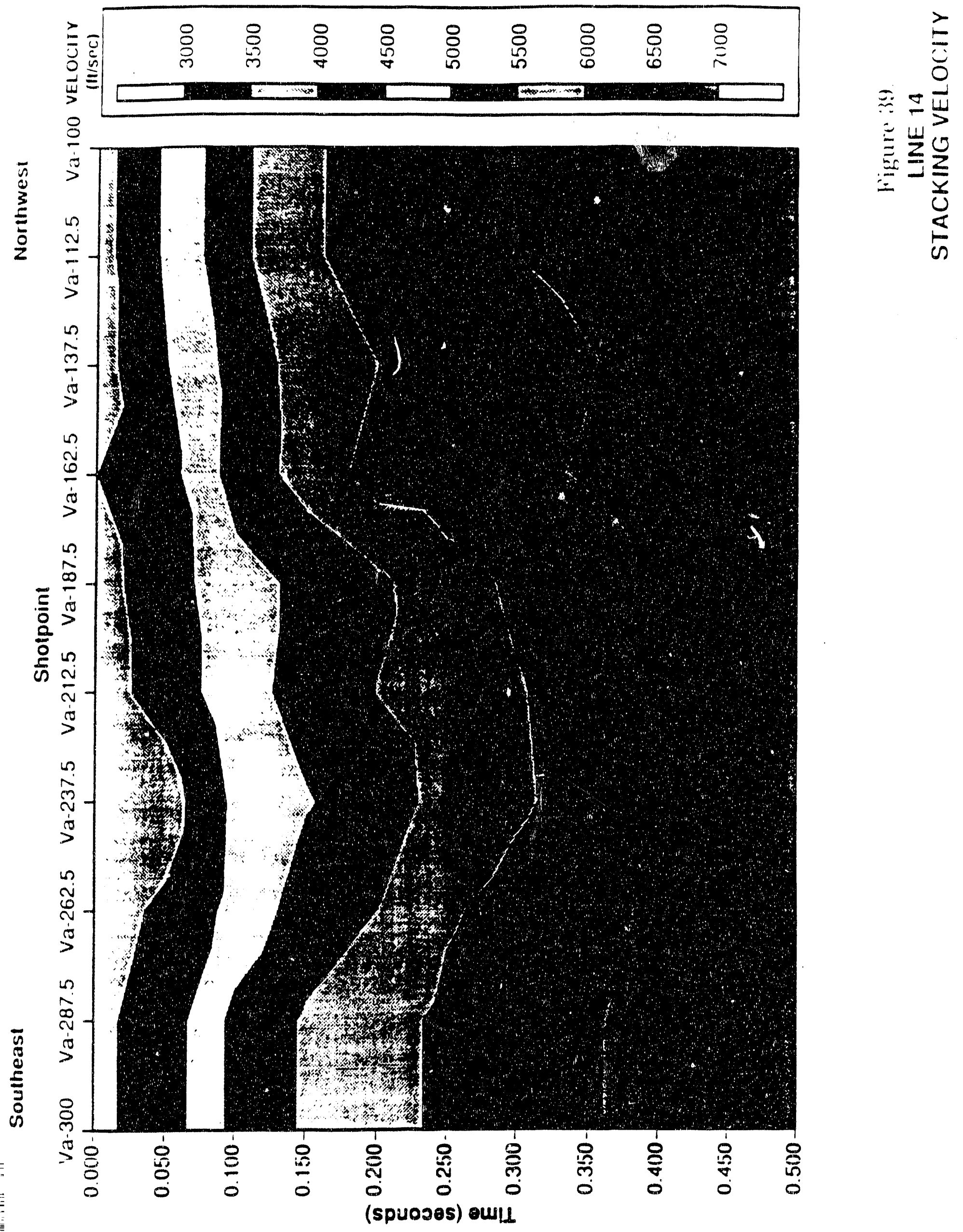









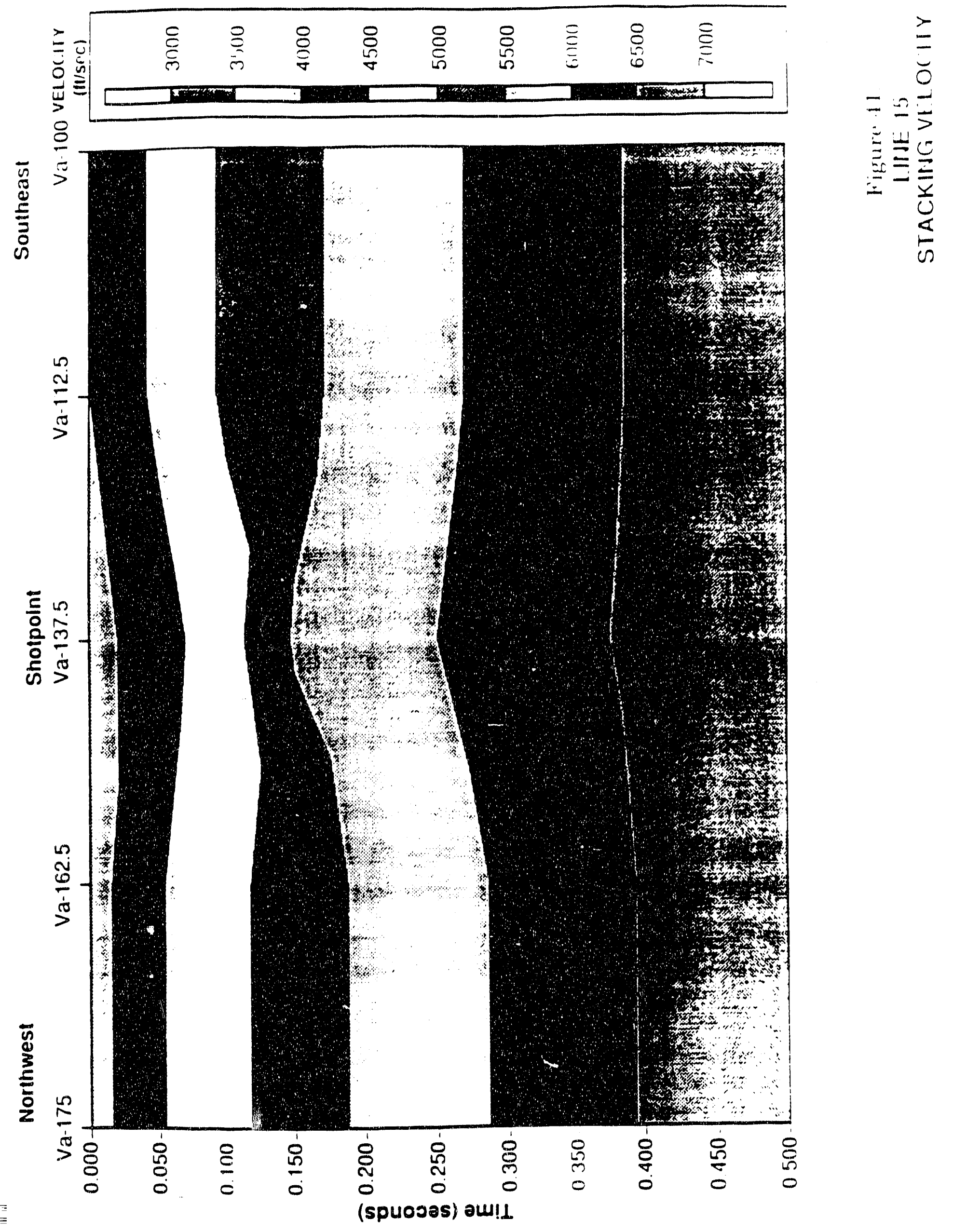




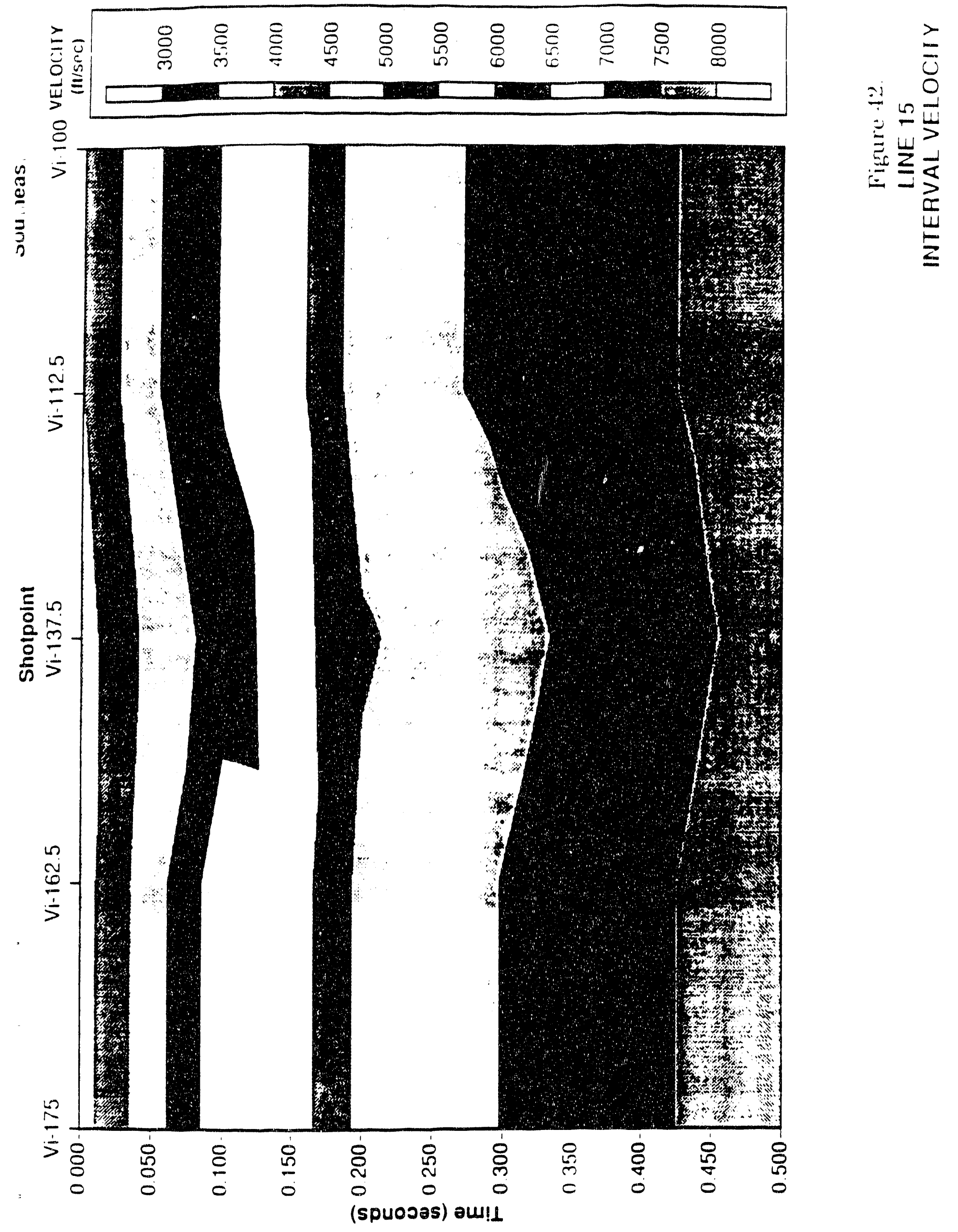




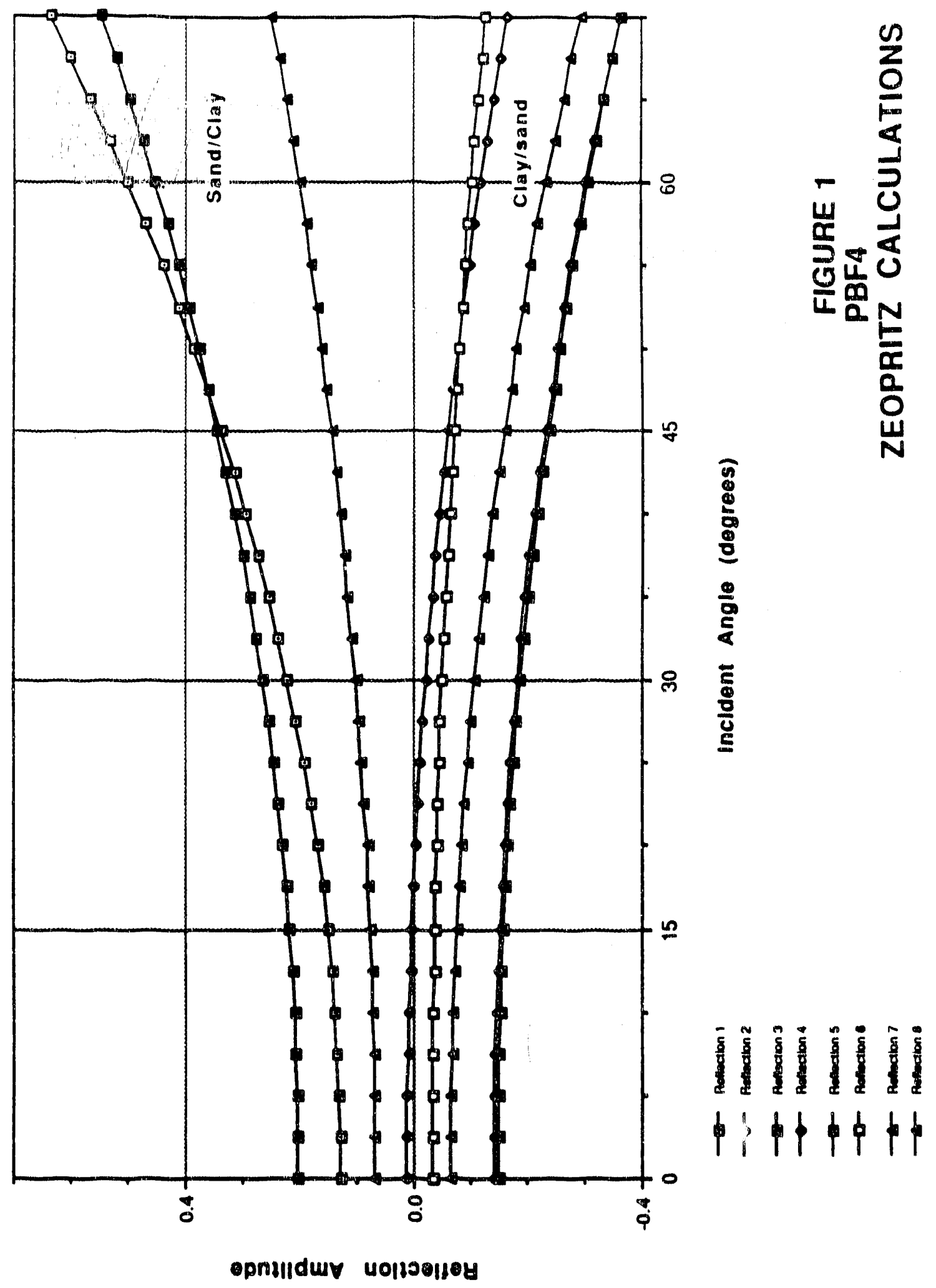




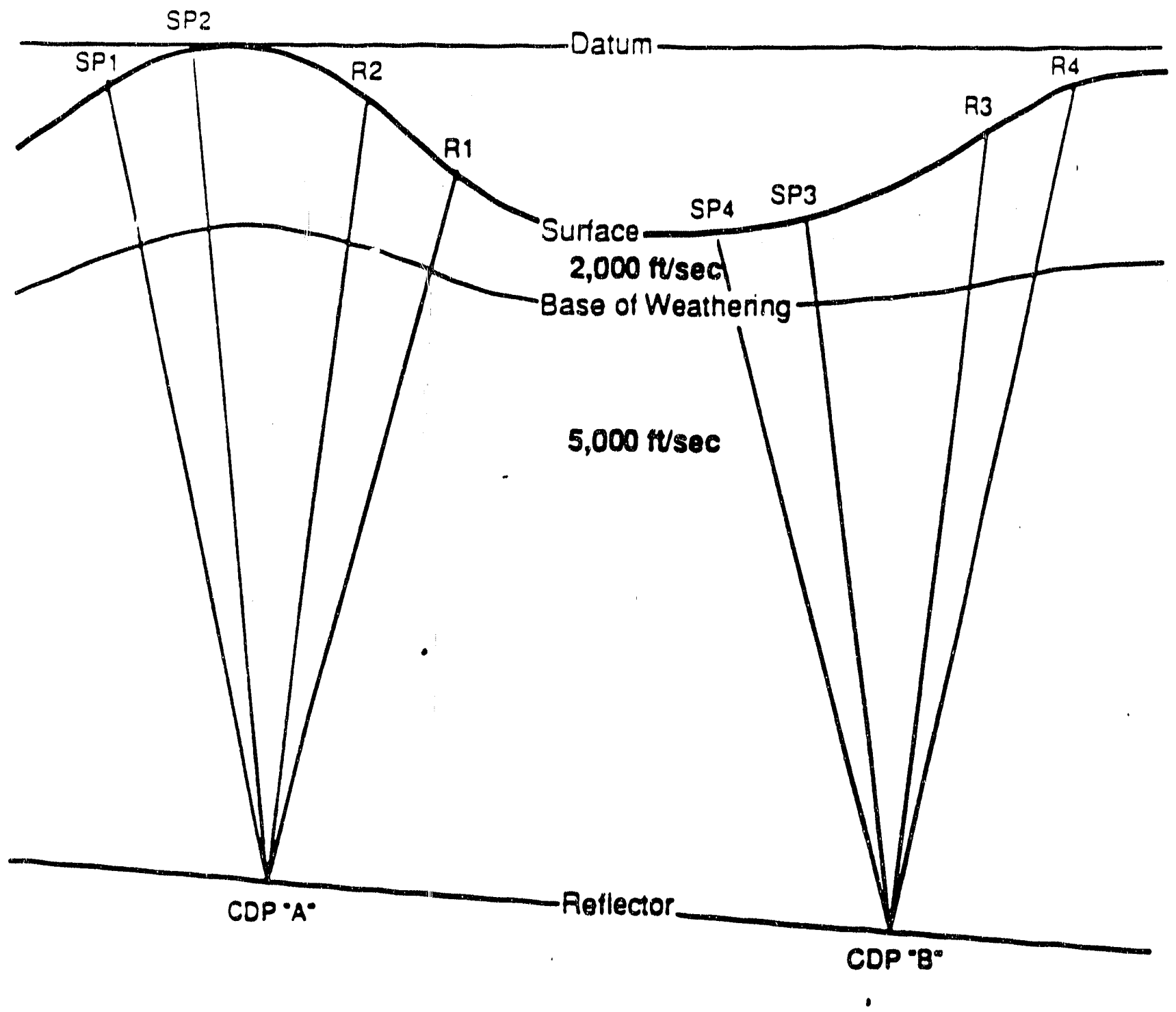

Figure 2. 

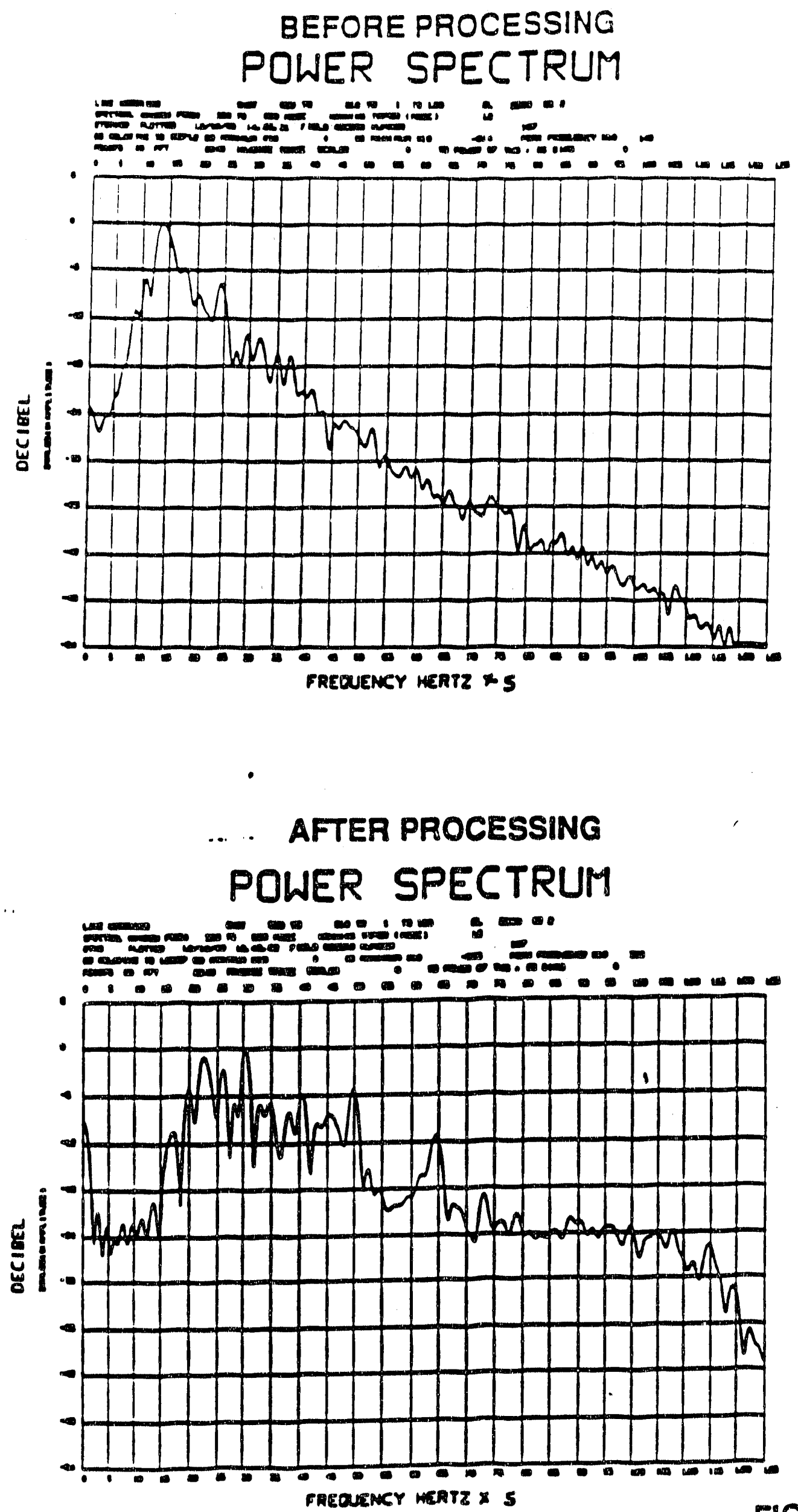

FIGUAE 3 FFEQUENTCY SPECTRA 

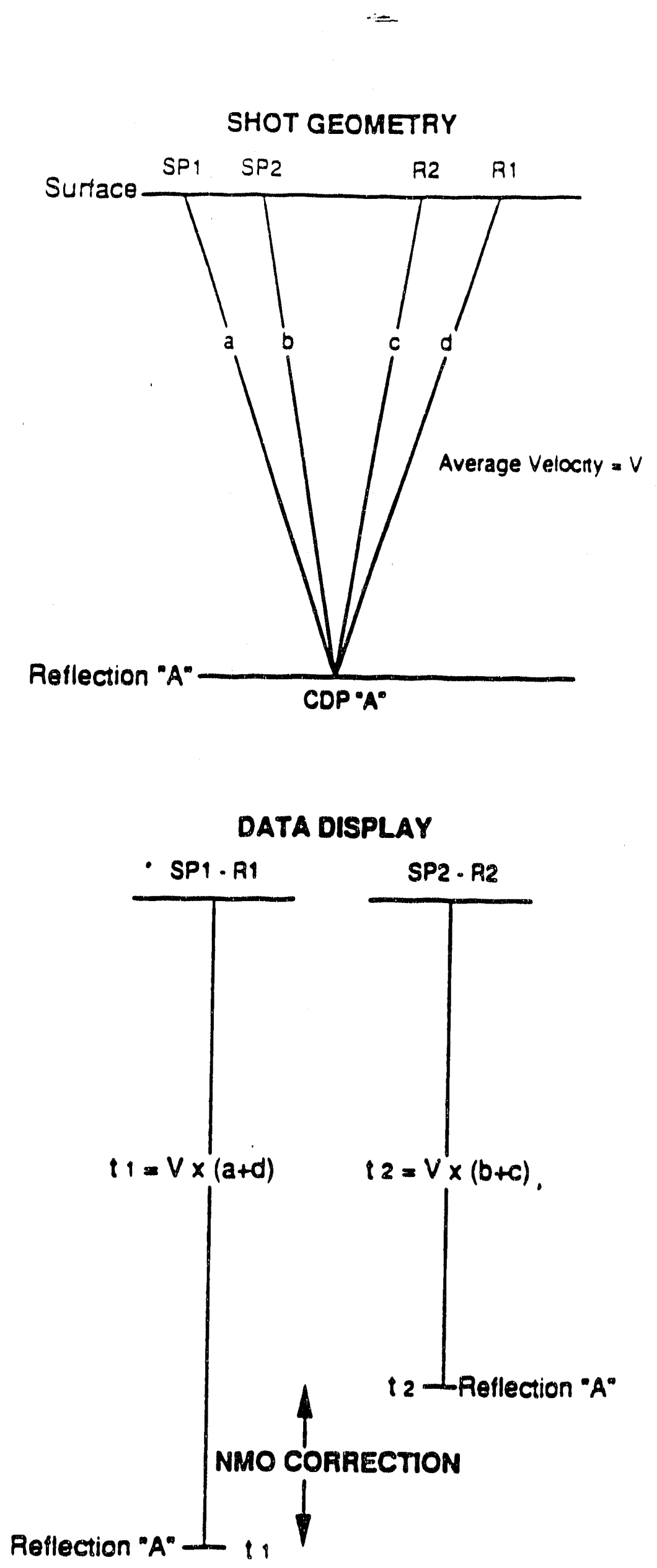

FIGURE 4 


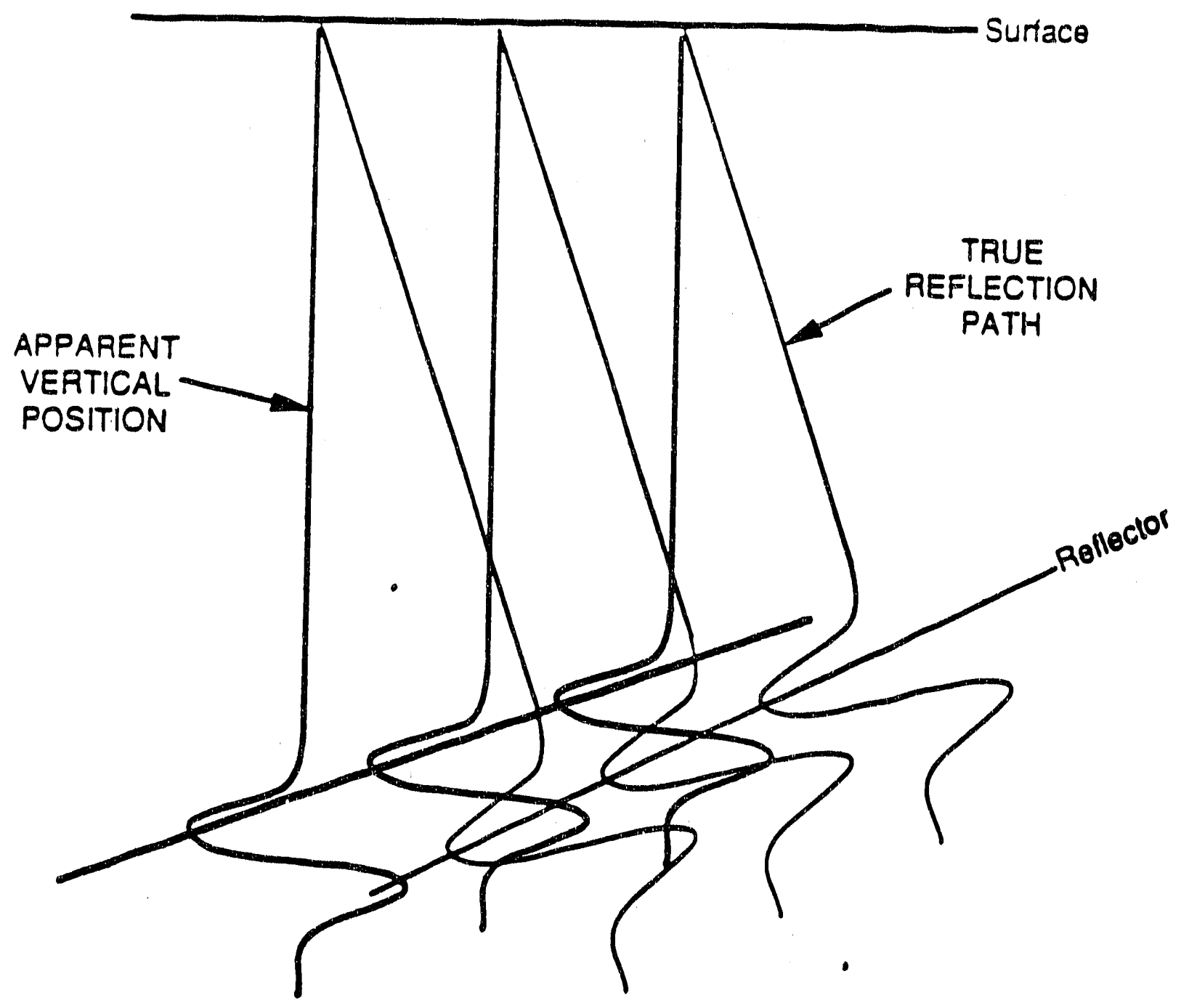

Migration moves data from the apparent vertical position to the inue subsurface becation. 

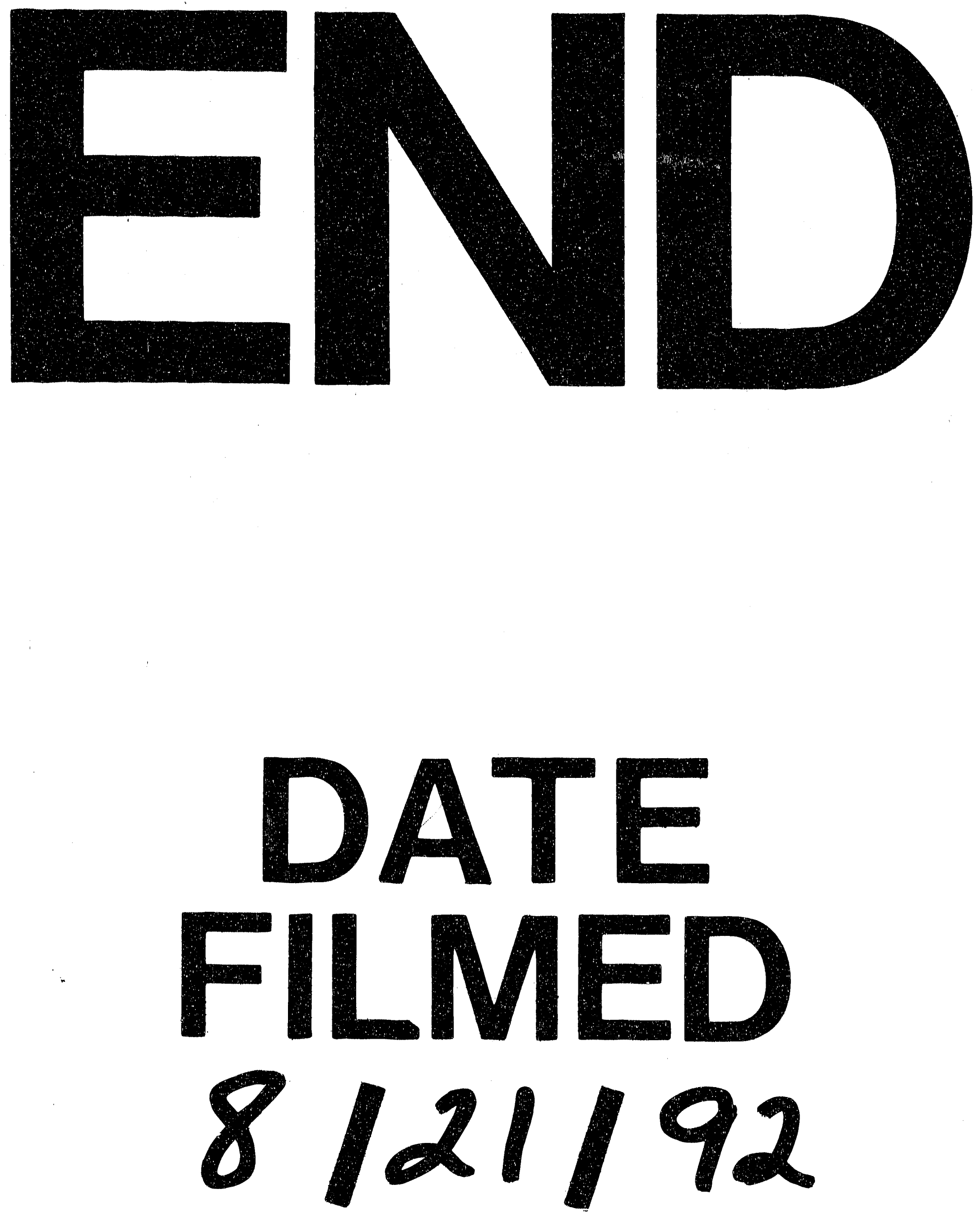


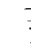

